\title{
ASSESSING ECOLOGICAL IMPACTS OF LAND-APPLIED MUNICIPAL BIOSOLIDS: EFFECTS OF RUN-OFF AND TILE DRAINAGE ON THE AQUATIC ORGANISMS DAPHNIA MAGNA, HYALELLA AZTECA AND LEMNA MINOR
}

by

\section{Sonja Gebert}

Bachelor of Science in Applied Chemistry and Biology, Ryerson University, 2007

\author{
A thesis \\ Presented to Ryerson University \\ in partial fulfillment of the \\ requirements for the degree of \\ Master of Applied Science \\ in the Program of \\ Environmental Applied Science and Management
}

Toronto, Ontario, Canada, 2010

Sonja Gebert, 2010 
I hereby declare that I am the sole author of this thesis.

I authorize Ryerson University to lend this thesis to other institutions or individuals for the purpose of scholarly research.

I further authorize Ryerson University to reproduce this thesis by photocopying or by other means, in total or in part, at the request of other institutions or individuals for the purpose of scholarly research. 


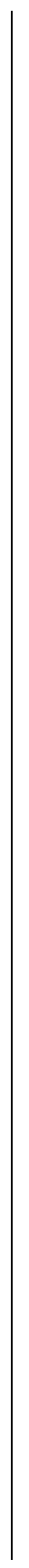


Ryerson University requires the signature of all persons using or photocopying this thesis. Please sign below, and give address and date. 


\begin{abstract}
Assessing ecological impacts of land-applied municipal biosolids: effects of run-off and tile drainage on the aquatic organisms Daphnia magna, Hyalella azteca, and Lemna minor

Sonja Gebert

Master of Applied Science

Environmental Applied Science and Management

July, 2010

Ryerson University
\end{abstract}

The effect of municipal land applied biosolids run-off and tile drainage on aquatic organisms

Daphnia magna, Hyalella azteca and Lemna minor was analyzed through a series of

standardized eco-toxicological tests. Treatments included reference soil, reference soil amended with Guelph Biosolids and reference soil amended with Kitchener biosolids. The assessment was done on biosolids elutriate collected after the simulated rainfall off the ramps on day 1 after the application of biosolids, and day 40 planted versus unplanted soil. Respiration rates, behavioural analysis and survivorship were tested on the two invertebrates, while 7-day Growth Inhibition test was performed on the plant. Although there were some significant differences between the reference soil and soil amended with biosolids elutriate, they were mostly on day 1 and in concentrations that are not likely to happen in nature. The plant Lemna minor showed eutrophication potential in elutriate from Day 1. The results are showing that although there are potential toxic constituents in the municipal biosolids that can adversely affect the aquatic life in the receiving waters, they largely very temporary and for the most part in concentrations that are environmentally irrelevant. To be able to understand the potential of using biosolids on agricultural fields in Ontario, more analytical and eco-toxicological studies should be performed that are relevant to Ontario's laws and topography. 


\section{Acknowledgements}

My research was funded by Ontario Ministry of the Environment, NSERC, Discovery Grant

Program (Dr. Andrew Laursen), the NSERC Strategic Grant Program (Dr. Lynda McCarthy), The Department of Chemistry and Biology, Ryerson University, and the Ryerson University Graduate Award. Acknowledgements go also to the Ontario Ministry of Agriculture, Food, and Rural Affairs, specifically Michael Payne (Ontario Ministry of Agriculture, Food, and Rural Affairs), Natalie Feisthauer and Shelly Bonte-Gelok (Ontario Ministry of the Environment) for continued advice and intellectual support. For technical assistance I would like to thank Karen Terry, which always provided solutions to all the bumps on the journey of masters. I would like to thank the following people for the help with building the troughs, mixing 4 tonnes of soil and for being great friends throughout the masters: Jeremy Lau, Marko Zlatanovic, Konstantin Medvedev, Daniel Kardo, Isabelle Netto, Christopher Bentley, Veronika Patrenko, Eric Da Silva, Vivian Fleet, Alexia Lane and Jason Stolnik.

I would like to express my gratitude to the three supervisors "The Holy Trinity of Ryerson", Dr Andrew Laursen, Dr. Vadim Bostan and Dr.Lynda MCarthy for all their guidance and support, and above all for letting me learn and understand the issues, challenges and importance of environmental science, and through that develop a passion that I will carry through my life and career. I would especially like to thank Dr. Laursen for his patience, understanding and support on all the academic as well as personal challenges I had to overcome during this master.

On the personal note, I would like to thank my boyfriend and best friend Konstantin Medvedev for having endless nerves, love and compassion for me, and for encouraging me all the way. Finally I would also like to offer my greatest appreciation to my mother, Nada Gebert, who has always provided strict but loving support of all my endeavors. 


\section{Table of Contents}

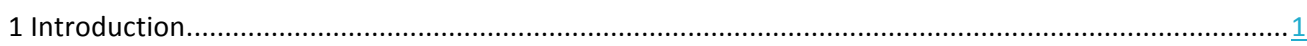

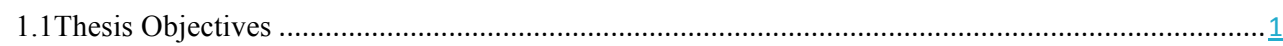

1.2 Historical Use of Animal and Human Waste in Agriculture and Current State of Biosolids in

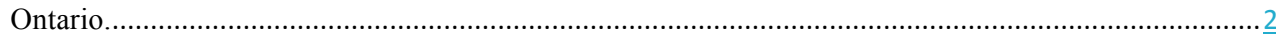

1.3 Potential Concerns in Land-Applying Biosolids ...................................................................



1.5 The Wastewater Treatment Process …………....................................................................

1.5.1 Guelph Wastewater Treatment Plant and Disposal ........................................................... 11

1.5.2 Kitchener Wastewater Treatment Plant and Disposal ....................................................... 11

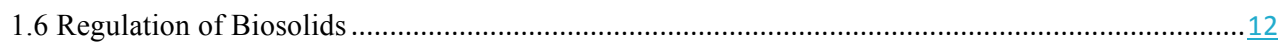

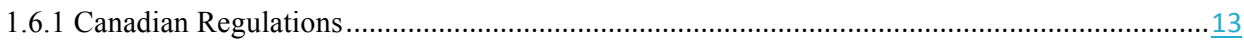

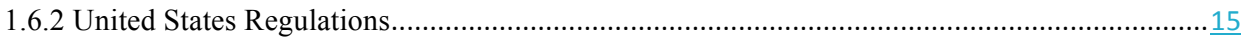

1.6.3 European Union Regulations ........................................................................................ 16

1.7 General Constituents of Municipal Biosolids and Possible Effects on the Environment ..................17

1.7.1 Effect of Biosolids on Soil Microorganisms, Plants, and Soil Properties................................20

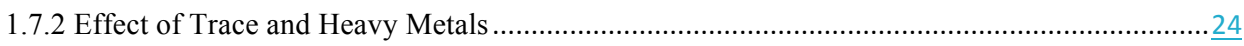

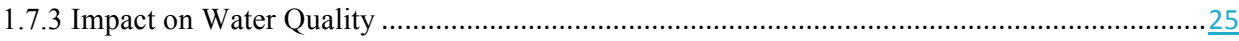

1.7.4 Dilution of Biosolids Run-off and Tile Drainage Entering Receiving Water..........................27

1.7.5 Impact on the Aquatic Biota in the Surrounding Watershed …...........................................29

1.8 Organisms used in Assessing Ecological Impacts of Biosolids in Receiving Waters ..................... 30

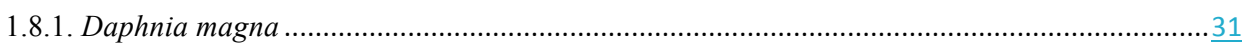

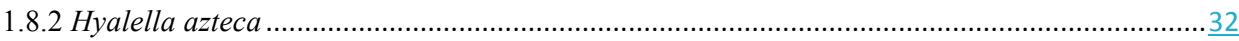

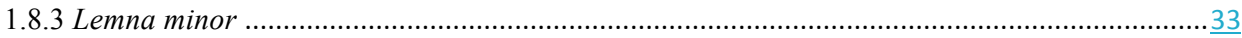

1.9 Rational for Thesis: Need for Ecological Assessment of Land applied Biosolids........................... 33

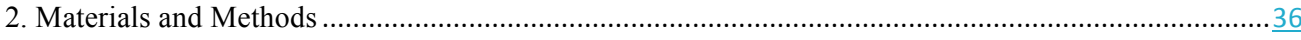

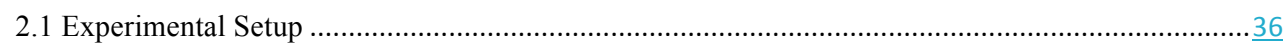

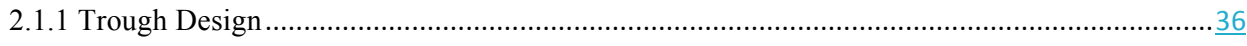

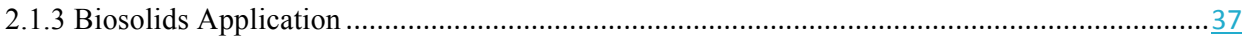

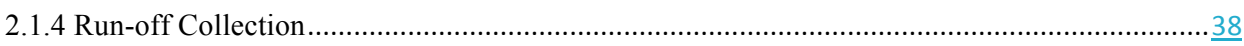

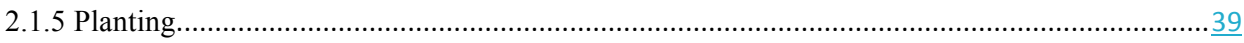

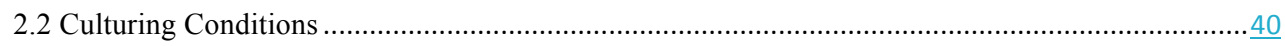


2.2.1 Daphnia magna (Marshall, 2009) .....................................................................................

2.2.2 Hyalella azteca (Marshall, 2009) ………......................................................................... 41

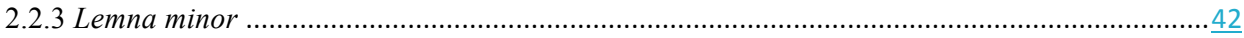

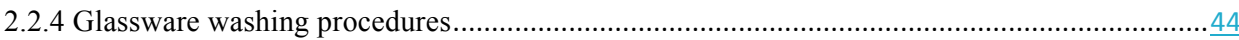

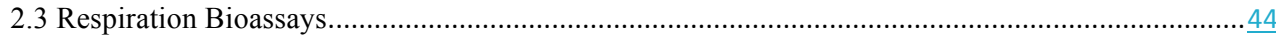

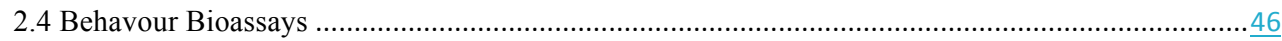

2.4.1 Daphnia magna Motility Behaviour Bioassays.......................................................................46

2.4.2 Daphnia magna $24 \mathrm{hr}$ and 7 day Survivorship and Immobility ........................................... 48

2.4.3 Hyalella azteca Motility Behaviour Bioassasys ................................................................ 48

2.5 Lemna minor Growth Inhibition Tests ………......................................................................

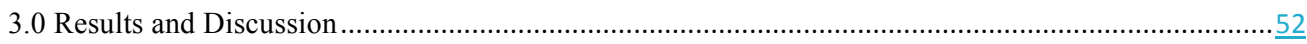

3.1 Respiratory Responses of Macroinvertebrates ….............................................................. 52

3.1.1 Daphnia magna Respiration in Guelph Biosolids Elutriate................................................ 52

3.1.2. Hyalella azteca Respiration in Guelph Biosolids Elutriate .................................................... 59

3.1.3 Daphnia magna Respiration in Kitchener Biosolids Elutriate............................................. 62

3.1.4. Hyalella azteca Respiration in Kitchener Biosolids Elutriate ............................................ 65

3.1.5. Conclusions Regarding the Effects of Biosolids Run-off and Tile Drainage on Respiration Rates in Aquatic Invertebrates.......................................................................................... 68

3.2 Behavioural Responses of Macroinvertebrates......................................................................... 70

3.2.1. Daphnia magna Behaviour in Guelph Biosolids Elutriate ..................................................

3.2.2. Hyalella azteca Behaviour in Guelph Biosolids Elutriate .................................................. 83

3.2.3. Daphnia magna Behaviour in Kitchener Biosolids Elutriate ……..................................... 85

3.2.4. Hyalella azteca Behaviour in Kitchener Biosolids Elutriate .................................................. 91

3.3 Survivorship and Immobility of Daphnia magna in Biosolids Elutriate ....................................... 99

3.3.1 Guelph Biosolids Elutriate …........................................................................................ $\underline{99}$

3.3.2 Survivorship and Immobility in Kitchener Biosolids Elutriate ..........................................104

3.4 . Summary of Behavioural Responses of Macroinvertebrates to Biosolids Elutriate ....................106

3.5. Lemna minor 7 day Growth Inhibition Tests in Kitchener Biosolids Surface Run-off .................107

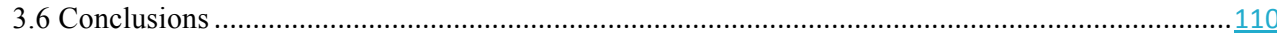

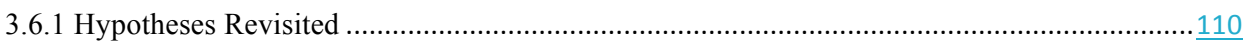

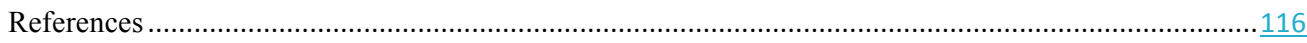

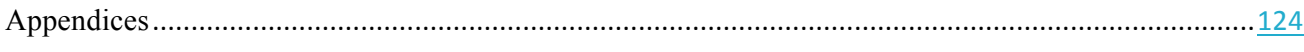


Appendix A. Biosolids Dry to Wet Weight Ration Calculation and Trough Application Quantity ......124

Appendix B. Simulated Rainfall Quantity Calculations

Appendix C. Modified Hoagland's E+ medium for Lemna minor ..................................................126

Appendix D Unisense Oxygen Microelectrode Function (Marshall, 2009) ...........................................127

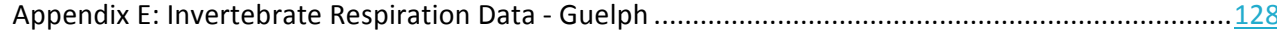

Appendix F. Invertebrate Respiration Data - Kitchener biosolids........................................................ 134

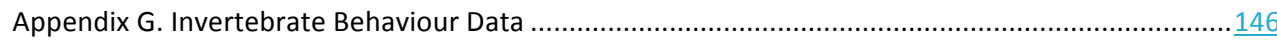

Appendix H. Survivorship and Motility Data for Daphnia magna in Guelph Biosolids Elutriate ..........159

Appendix I. Survivorship and Motility Data for Daphnia magna in Kitchener biosolids Elutriate.........165

Appendix J. Lemna minor Data - Kitchener Surface Run-off $\underline{166}$ 


\section{List of Figures}

Figure 1. Schematic diagram of the experimental design and sequence of bioassays.

Figure 2. Respiration Rates of Daphnia magna exposed to varying dilutions of surface run-off and tile drainage from soil with Guelph biosolids application a) Day 1, all troughs, b)Day 40 unplanted troughs, c) Day 40 planted troughs. Exposure was over hour and a half period, respiration expressed in nanomoles of oxygen consumed per hour per individual. Significant differences $(\mathrm{p} \leq 0.05)$ relative to reference denoted by $*$.

Figure 3. Respiration Rates of Hyalella azteca exposed to varying dilutions of surface run-off and tile drainage from soil with Guelph biosolids application a) Day 1, all troughs, b) Day 40 unplanted troughs, c)Day 40 planted troughs. Exposure was over hour and a half period, respiration expressed in nanomoles of oxygen consumed per hour per individual. Significant differences $(\mathrm{p} \leq 0.05)$ relative to reference denoted by $*$.

Figure 4. Respiration Rates of Daphnia magna exposed to varying dilutions of surface run-off and tile drainage from soil with Kitchener biosolids application a) Day 1, all troughs, b) Day 40 unplanted troughs, c)Day 40 planted troughs. Exposure was over hour and a half period, respiration expressed in nanomoles of oxygen consumed per hour per individual. Significant differences $(\mathrm{p} \leq 0.05)$ relative to reference denoted by $*$.

Figure 5. Respiration Rates of Hyalella azteca exposed to varying dilutions of surface run-off and tile drainage from soil with Kitchener biosolids application a) Day 1, all troughs, b) Day 40 unplanted troughs, c)Day 40 planted troughs. Exposure was over hour and a half period, respiration expressed in nanomoles of oxygen consumed per hour per individual. Significant differences $(\mathrm{p} \leq 0.05)$ relative to reference denoted by *.

Figure 6. Day 1 swimming height of Daphnia magna exposed to varying dilutions of surface run-off (a) tile drainage (b) from soil with Guelph biosolids application. Exposure was over 24 hours period, expressed in average percentage of Daphnia magna swimming through the water column. Error bars showing are standard error. Significant differences (Kruskal-Wallis test) in treatments from the reference are denoted by $*$.

Figure 7. Swimming height of Daphnia magna exposed to varying dilutions of surface run-off (a) tile drainage (b) from soil with Guelph biosolids application in eutriate collected of the unplanted troughs on day 40. Exposure was over 24 hours period, expressed in average percentage of Daphnia magna swimming through the water column. Error bars showing are standard error. Significant differences (Kruskal-Wallis test) in treatments from the reference are denoted by *.

Figure 8. Swimming height of Daphnia magna exposed to varying dilutions of surface run-off (a) tile drainage (b) from soil with Guelph biosolids application in eutriate collected of the 
planted troughs on day 40. Exposure was over 24 hours period, expressed in average percentage of Daphnia magna swimming through the water column. Error bars showing are standard error.

Figure 9. Day 1: swimming style of Daphnia magna exposed to varying dilutions of surface runoff (a) and tile drainage (b) from soil with Guelph biosolids application. Exposure was over 24 hours period, expressed in average percentage of Daphnia magna swimming through the water column. Error bars showing are standard error. Significant differences (Kruskal-Wallis test) in treatments from the reference are denoted by *.

Figure 10. Day 40 un-planted troughs: swimming style of Daphnia magna exposed to varying dilutions of surface run-off (a) and tile drainage (b) from soil with Guelph biosolids application. Exposure was over 24 hours period, expressed in average percentage of Daphnia magna swimming through the water column. Error bars showing are standard error. Significant differences (Kruskal-Wallis test) in treatments from the reference are denoted by *.

Figure 11. Day 40 planted troughs: swimming style of Daphnia magna exposed to varying dilutions of surface run-off (a) and tile drainage (b) from soil with Guelph biosolids application. Exposure was over 24 hours period, expressed in average percentage of Daphnia magna swimming through the water column. Error bars showing are standard error.

Figure 12. Day 1 crawling on the substrate of Hyalella azteca exposed to varying dilutions of surface run-off (a) and tile drainage (b) from soil with Guelph biosolids application. Exposure was over 24 hours period, expressed in average percentage of Hyalella azteca displaying crawling on the substrate behaviour. Error bars showing are standard error.

Figure 13. Day 1 swimming height of Daphnia magna exposed to varying dilutions of surface run-off (a) and tile drainage (b) from soil with Kitchener biosolids application. Exposure was over 24 hours period, expressed in average percentage of Daphnia magna swimming through the water column. Error bars showing are standard error.

Figure 14. Swimming height of Daphnia magna exposed to varying dilutions of surface run-off $(a, c)$ and tile drainage $(b, d)$ from soil with Kitchener biosolids application biosolids elutriate collected on day 40 of the unplanted and planted troughs. Exposure was over 24 hours period, expressed in average percentage of Daphnia magna swimming through the water column. Error bars showing are standard error.

Figure 15. Swimming style of Daphnia magna exposed to varying dilutions of surface run-off (a) and tile drainage (b) from soil with Kitchener biosolids application collected biosolids elutriate on Day 1. Exposure was over 24 hours period, expressed in average percentage of Daphnia magna displaying abnormal swimming behaviour. Error bars showing are standard error.

Figure 16. Swimming style of Daphnia magna exposed to varying dilutions of surface run-off (a, c) and tile drainage $(b, c)$ from soil with Kitchener biosolids application. Biosolids elutriate 
collected on day 40 from unplanted and planted troughs. Exposure was over 24 hours period, expressed in average percentage of Daphnia magna displaying abnormal swimming behaviour. Error bars showing are standard error.

Figure 17: Crawling on the substrate of Hyalella azteca exposed to varying dilutions of surface run-off (a) and tile drainage (b) from soil with Kitchener biosolids application, elutriate collected on day 1. Exposure was over 24 hours period, expressed in average percentage of Hyalella azteca displaying crawling on the substrate behaviour. Error bars showing are standard error. Significant differences (Kruskal-Wallis test) in treatments from the reference are denoted by *.

Figure 18: Crawling on the substrate of Hyalella azteca exposed to varying dilutions of surface run-off and tile drainage from soil with Kitchener biosolids application. Elutriate collected on day 40 off unplanted and planted troughs. Exposure was over 24 hours period, expressed in average percentage of Hyalella azteca displaying crawling on the substrate behaviour. Error bars showing are standard error. Significant differences (Kruskal-Wallis test) in treatments from the reference are denoted by *.

Figure 19. Hyalella azteca exposed to varying dilutions of surface run-off (a) and tile drainage (b)from soil with Kitchener biosolids application, elutriate collected on day 1. Exposure was over 24 hours period, expressed in average percentage of Hyalella azteca displaying normal body length. Error bars showing are standard error. Significant differences (Kruskal-Wallis test) in treatments from the reference are denoted by *.

Figure 20. Hyalella azteca exposed to varying dilutions of surface run-off and tile drainage from soil with Kitchener biosolids application. Biosolids elutriate collected on day 40 from unplanted and planted troughs. Exposure was over 24 hours period, expressed in average percentage of Hyalella azteca displaying normal body length. Error bars showing are standard error.

Figure 21. Average percentage of motile Daphnia magna in surface run-off and tile drainage Biosolids elutriate collected on Day 1 (a), Day 40 from unplanted (b) and planted (b) troughs, from Guelph biosolids application after 24 hours and 7 days. Error bars showing are standard error.

Figure 22. Average percentage of Daphnia magna survived in surface run-off and tile drainage. Biosolids elutriate collected on Day 1(a), Day 40 unplanted (b) and planted (c) troughs, from Guelph biosolids application after 24 hours and 7 days. Error bars showing are standard error. Significant differences $(\mathrm{p} \leq 0.05)$ relative to reference in treatments from the reference are denoted by *.

Figure 23. Neonate production in Guelph biosolids surface run-off, F0 and F1 generations (Bentley, 2010).

Figure 24: Average percentage of Daphnia magna survived in surface run-off and tile drainage (collected on Day 1) from Kitchener biosolids application after 7 days (a). Average percentage of 
motile Daphnia magna in surface run-off and tile drainage collected on Day1 from Kitchener biosolids application after 7 days (b). Error bars showing are standard error.

\section{List of Tables}

Table 1: Example of Nutrient Management Act regulations

Table 2: Effect of sewage sludge and biosolids on physical and chemical properties of soil, microbial activity, and plant yields. 


\section{Introduction}

\subsection{Thesis Objectives}

The objectives of this thesis are to determine the effects of land applied municipal biosolids elutriate (surface run-off and tile drainage) on aquatic life in receiving water, and to contribute to needed risk assessment of biosolids in the environment. Introduction presents a literature review regarding the regulation of biosolids, treatment of sewage sludge and production of biosolids, and the known effects of biosolids on the environment. The remainder of the thesis examines the effect of biosolids run-off on two aquatic macroinvertebrates and one aquatic plant that are common in waters of Southern Ontario. Two sources of biosolids that come from Southern Ontario were evaluated in the study. These biosolids were produced in different communities by different processes, and while this thesis will not claim to provide a blanket assessment of risk for biosolids produced in Ontario, it does provide two case examples for biosolids generated in mid-sized cities, one that produced biosolids by a very common treatment technique, and one that produced biosolids by an emerging treatment technology. In this study, biosolids were applied at the maximum allowable rate for Ontario (application was chosen without assessment of metals and may, actually, represent over-application under Ontario regulatory guidelines), on soil with maximum allowable slope for application, and with simulated rainfall imitating a 100-year storm scenario. These conditions, therefore, represent worst possible case scenarios for run-off to aquatic systems. Different concentrations of the runoff and tile drainage (dilution series with elutriate from reference soil as diluent) were used to test different responses from the two aquatic crustaceans, Daphnia magna and Hyalella azteca, and the plant Lemna minor. Standardized bioassays with these organisms were conducted to 
gain insights into how the organisms are likely to respond to run-off and tile drainage from landapplied biosolids under environmentally-relevant (if extreme case) conditions. The results of this study will provide information to further studies that will be conducted on the biosolids, also it will provide information to people that are interested in how the biosolids are likely to affect the environment, such as managers of the waste water treatment plants, or principal investigators and inspectors that are affiliated with the regulatory agencies. The study will also provide evidence if the laws and policies that are set in Ontario by now, are adequate for protection of aquatic organisms from run-off and tile drainage of soil where biosolids have been applied.

\subsection{Historical Use of Animal and Human Waste in Agriculture and Current State of Biosolids in Ontario}

Agriculture has a number of independent origins dating back $\sim 10,000$ years. In some of these cradles of agriculture, notably Southwest Asia, both plant and animal species were domesticated for human use and consumption. Manure from the animals that were domesticated was used as a soil amendment, and that way soil was supplemented by external nutrients in order to support continual crop production. This practice continued to be used extensively until the $18^{\text {th }}$ century "Agricultural Revolution" that began in England when the demand for more crops grew since the human population was rapidly expanding (Kagan et al, 2004). As societies grew, so did the amount of sewage, and discharge of it into the receiving waters created problems for both human health and ecosystem eutrophication. These problems were starting to be solved by improving the sanitation and introduction of the sewage treatment. In the 1800 s development of waste water treatment plants began in London, Hamburg and Chicago and the idea soon spread to major 
cities (Okun, 1962). In the mid 1800s typoid and cholera epidemics were starting to spread in the Toronto area, and because of this, efficient wastewater treatment system became a necessity. Toronto's first wastewater treatment plant was built in 1910, and was situated at the bottom of Leslie Street (City of Toronto, 2010).

A by-product of waste water treatment is sewage sludge. Since the 1970 s further processing of sewage sludge to reduce pathogen load has been used to produce biosolids, a name given to condensed and treated sewage sludge to emphasize its beneficial and recyclable nature (United States Environmental Protection Agency, 1994b). The use of biosolids as a soil amendment is a natural extension of use of manure as a soil amendment going back to origins of agriculture. Land-application of biosolids as a fertilizer in Canada has been a practice since the 1970s and has greatly increased since the Great Lakes Water Quality Agreement was passed in 1996 (City of Toronto, 2009). The Great Lakes Water Quality Agreement specified that all sewage must go through at least a secondary treatment, requiring additional settling and water clarification which resulted in a considerable increase in solid sludge-waste and in the production of biosolids (City of Toronto, 2009)

Once biosolids are produced in Ontario, depending on their quality and municipal regulations, they are either land applied, incinerated or land filled. Each year, Ontario generates approximately 300,000 dry tonnes of municipal sewage biosolids of which approximately $40 \%$ is land applied, $40 \%$ goes to landfills and 20\% is incinerated (Ontario Ministry of Environment , 2010).

The main wastewater treatment plant for Toronto is Ashbridges Bay and, until recently, most of the biosolids produced in that plant were shipped to and land-filled in Michigan. 
However, Michigan decided to close its border to Toronto's sewage sludge due to odonrs and other complaints in August of 2006 (Bartling, 2008). This has created pressure to find viable alternatives for disposal of biosolids generated in Toronto. Land filling is not a viable option since most landfills around Toronto are already overloaded. Incineration is extremely unpopular and highly criticized because of air pollution emissions (real or perceived). Therefore the City of Toronto came up with the solution called a "Biosolids and Residuals Master Plan" (City of Toronto, 2009). In short, the plan provides direction on the future management of biosolids and water residuals generated by the city's eight water and wastewater treatment plants through the year 2025. This strategic plan includes a 30\% increase in land application of biosolids produced by Toronto.

\subsection{Potential Concerns in Land-Applying Biosolids}

Because sewage sludge is the condensed residual of wastewater that is generated from residences, commercial and industrial sectors, it contains chemicals of concern. Many pollutants do end up in even treated sewage sludge because today's sewage treatment processes are not sophisticated enough to decompose all the pollutants. Therefore the nature by which biosolids are produced means they include not only nutrients, but also metals and toxic trace elements, as well as organic pollutants. Therefore biosolids use in agriculture raises public concerns as they are perceived to pose threats to environmental and public health. The research on sewage sludge and biosolids has emphasized benefits of nutrients and trace elements (Sastre et al, 1996, Banerjee at al, 1997, Qasim et al, 2001, Bozkurt and Yarilgac, 2003, Spier et al 2003, Singh and Agrawal, 2008), but there are concerns about anthropogenic contaminants such as heavy metals, organic pollutants and microbial pathogens. For example, even though there has been a lot of 
research done on metals in sewage sludge, it is still unclear how are they bound, and how mobile once applied to land (Kim et al., 2007; Singh and Agrawal, 2008). Then there is a concern about the persistent organic pollutants such as PCBs and PCDDs which are found in biosolids and which can, indirectly, end up in the human diet (McLachlan et al, 1996; Pedersen et al, 2005), about the amount of pharmaceuticals and personal care products and their potential effect on the plants and organisms in the environment (Wong et al, 1996; Fjallborg and Dave 2003; Sullivan et al, 2007; Topp et al, 2008), and bacteria from biosolids that may compete with the indigenous bacterial community in the soil (Sastre et al, 1996; Banerjee et al, 1997; Spier et al, 2003).

In the last few years media has raised concerns about the safety and land applying biosolids based on risk characterization instead of objective risk assessment. Examples include series of articles in Toronto Star that have raised defensiveness of waste water treatment operators which makes research difficult, as well as raised panic in general population without any objective justifications (Toronto Star, 2008). On the other hand, utility operators, regulatory agencies and most research is focuses primarily on chemical characterization and pathogen assessment of biosolids (e.g. Pedersen et al, 2005; Singh and Agrawal, 2008; Topp et al, 2008).

The missing piece in the debate about the safety of applying biosolids is objective risk assessment based on organism and ecosystem responses to land application. While chemical, physical and pathogen assessment does provide information about the potential nature of risks, it does not provide information on the actual likelihood of ecological impacts. Assessing ecological risk of biosolids land application must includes effects of biosolids on the plants, animals, and microorganisms that live on land and in water receiving run-off from fields where biosolids have been applied. Further, objective risk assessment must include quantifying the impacts biosolids might have on the environment under environmentally-relevant conditions. 
Apart from some chemical characterization of biosolids elutriates (Fjallborg and Dave, 2003; Veldhoen et al., 2006; Sullivan et al, 2007; Topp et al, 2008), very little is known on the way biosolids impact aquatic life in receiving water. Because little is known, it is important to start assessing the impacts that biosolids have on the aquatic life. The general idea of applying biosolids as a soil amendment is great because it provides a means of disposal, and it will contribute to sustainability in agriculture, closing the loop in cycling of nutrients such as phosphorus. However, more knowledge is necessary to be able to resolve environmental and social concerns regarding the safety of land-applying biosolids.

\subsection{Framework for Literature Review}

The remainder of the Introduction is intended to provide a better understanding of the material being discussed, biosolids, so that the nature of potential risks to aquatic organisms can be better understood. This includes a discussion of how biosolids are produced in the wastewater treatment process generally, and more specifically in the plants that supplied the biosolids used in this study. Next, the regulations that relate to land application of the biosolids will be discussed. This will include discussion of regulatory limits on consituents of the biosolids, as well regulations concerning where and when biosolids may be land-applied. This will include a high-level jurisdictional comparison (EU, USA, Canada, Ontario). Then, the known impacts of municipal biosolids on terrestrial organisms, aquatic organisms, and water quality in receiving water will be discussed. Finally, the organisms to be used for assessment of ecological impacts in aquatic systems, and the rationale for their use will be introduced. 


\subsection{The Wastewater Treatment Process}

Wastewater that is gathered from different sectors is collected through the network of pipes and sewers and is transported into wastewater treatment plants. The nature of the wastewater collection system, the processes for wastewater treatment, and the subsequent processes for biosolids treatment have crucial effects on the type, quality and quantity of biosolids generated. The type of wastewater and treatment depends on where the wastewater is collected (wastewater from a rural area will be very different in composition than wastewater from an industrial area), and what kind of technologies are used (United States Environmental Protection Agency, 1999; Oleszkiewicz and Mavinic, 2002). The quality of biosolids can change daily in the same treatment plant depending on what kind of wastewater gets into the plant. For example, if it rains the water will contain a larger amount of pollutants since the sewers will collect street garbage if a municipality has combined storm sewers (Oleszkiewicz and Mavinic, 2002). In addition, the higher the degree of wastewater treatment (e.g. secondary versus tertiary), the higher the volume (but not necessarily the quality) of biosolids generated (United States Environmental Protection Agency, 1999). Higher treatment can also increase the concentration of contaminants in the biosolids, because removal of contaminants from water by addition of chemicals such as lime, ferric chloride or polymers will increase the amount of the contaminants in biosolids together with the precipitated solids (United States Environmental Protection Agency, 1999).

Production of biosolids occurs in two main phases: first the wastewater treatment (after which treated water is then discharged leaving sludge) and second is treatment of sludge that produces biosolids as the end product (United States Environmental Protection Agency, 1999; 
Oleszkiewicz and Mavinic, 2002; Singh and Agrawal, 2008). The usual process of wastewater treatment involves the following treatments in sequence: screening and grit removal, primary wastewater treatment, secondary wastewater treatment and less frequently the tertiary or so called "advanced" wastewater treatment (United States Environmental Protection Agency, 1999; Oleszkiewicz and Mavinic, 2002). Screening is removal of coarse solids that can interfere with mechanical equipment. The collected solids (not to be confused with biosolids) are land filled. In primary wastewater treatment, gravity sedimentation occurs to remove suspended solids. At this point, the sludge produced is $3-4 \%$ solid and that can be increased by thickening or dewatering processes. Secondary wastewater treatment involves biological treatment where microorganisms are used to reduce the biochemical oxygen demand, allowing time and aeration to decrease chemical oxygen demand. After this there can be advanced treatment in which chemicals are used to further reduce pathogens, precipitate unwanted chemicals, stabilize metals and partially remove nitrogen and phosphorus. This is done traditionally by addition of lime, or polymers, iron and aluminum salts and others depending on the treatment plant (USEPA, 1999; Oleszkiewicz and Mavinic, 2002). The precipitate formed from this advanced treatment, combined with solid material from primary and secondary treatment, constitutes biosolids. At this point, the final solid product of wastewater treatment has to meet the regulatory standards to be used for specific applications such as amendment of agricultural land, commercial use such as gardening, or recovery of industrial sites like mine pits (Ontario Ministry of Agriculture, Food and Rural Affairs, 2010b). Most biosolids, after the wastewater treatment plant, go through second phase or biosolids treatment to meet the regulatory standards (Ontario Ministry of Agriculture, Food and Rural Affairs, 2010b). 
The biosolids treatment phase can consist of stabilizing and dewatering the sludge (Ontario Ministry of Agriculture, Food and Rural Affairs, 2010b). Stabilization includes a number of different treatment options depending the quality and quantity of biosolids desired and their final use. These consist of processes that decrease the pathogens, odor, and volatile solids, and immobilize metals. Some of the most commonly used processes are: liming, anaerobic and aerobic digestion and composting. Liming is addition of quicklime or hydrated lime until the $\mathrm{pH}$ is raised to 12 for a minimum of two hours. This process kills most microorganisms and reduces mobility of metals by forming precipitates with low solubility. Anaerobic digestion biologically stabilizes biosolids in a closed vessel at $35^{\circ} \mathrm{C}$, where certain microbes consume organic matter producing carbon dioxide, methane and ammonia and reducing volatile organics. This is the most frequently used digestion process in treatment plants that have a large capacity because of the methane recovery which can be used as an energy source (United States Environmental Protection Agency, 1999; Oleszkiewicz and Mavinic, 2002). Examples of facilities that use this kind of stabilization are Ashbridges Bay in Toronto and the Kitchener wastewater treatment plants. Aerobic digestion is done in an open vessel or a lagoon. Like anaerobic digestion, aerobic digestion reduces volatile (and total) organics and reduces nutrients. Following digestion, biosolids may be composted. Composting is the longest process and can take up to 6 weeks, where addition of other dewatered biosolids or material such as straw or bark is added, and the whole content of biosolids are turned over a few times for aeration (United States Environmental Protection Agency, 1999). Microbes compost the organic material into humus that are excellent for soil conditioning ( $\mathrm{pH}$ 6.5-8), and compost treated biosolids have the strongest water holding capacity. Composting can also be used to raise temperature, killing most pathogens. Dewatering is another biosolids treatment that decreases the volume of water, and therefore increases solid 
concentration (Ontario Ministry of Agriculture, Food and Rural Affairs, 2010b). It is a required step in most cases before the biosolids can be land applied, land filled or incinerated. Different plants use different methods for dewatering, but common methods include use of drying beds or lagoons, vacuum drying beds, high temperature drying or centrifuges (United States Environmental Protection Agency, 1999; Oleszkiewicz and Mavinic, 2002).

Biosolids that are produced using aerobic and anaerobic digestion are used as soil amendment or organic fertilizer on pasture and row crops, forests and industrial and mining recovery sites. These are usually applied as slurry or as solids if they go through the dewatering process. Biosolids that have gone through alkaline stabilization usually are used for land application and landfill cover. The biosolids that have gone through the composting are considered the highest quality for soil conditioning because of high organic content, and are used for horticultural and landscape purposes. Lots of heat and drying produces pellet-like biosolids that can be used as a fertilizer as well (United States Environmental Protection Agency, 1999; Oleszkiewicz and Mavinic, 2002).

These current methods for stabilizing and treating biosolids are directed at reducing volatile organics, reducing labile organic matter, reducing nutrient availability (through denitrification and immobilization of phosphorus) and reducing metals availability through formation of precipitates with low solubility. However, these methods are largely ineffectual in reducing or treating persistent organic contaminants, pharmaceuticals and personal care products, detergent metabolites and many others contaminants found in biosolids that are land applied as a fertilizer (Pedersen et al, 2005; Kinney et al., 2006; Kostich and Lazorchak, 2008; Topp et al., 2008). And although metals availability is initially reduced, biogeochemical cycling of metals can make them available over time. 


\subsubsection{Guelph Wastewater Treatment Plant and Disposal}

The Guelph wastewater treatment plant was built in 1903 and treats sewage from approximately 130,000 residents. Guelph is the fourth fastest growing city in Canada, and the population is expected to increase to 195,000 by 2027 (City of Guelph, 2010). Anticipating this growth and pressure on biosolids disposal, Guelph has developed its own Biosolids Master Plan which provides direction for wastewater treatment infrastructure development, planning and future management of biosolids. Also, since Guelph uses a sophisticated Lystek treatment (Lystek International, 2010.), the master plan includes the commercialization of their biosolids to be sold as a fertilizer. Lystek treatment was developed at the University of Waterloo, and its purpose was to use more advanced processing for biosolids that have gone through anaerobic

digestion, and that way make an end product biosolids exceeding the USEPA's Class A standard (Lystek International, 2010). This means that the concentrations of metals are very low, and the biosolids are virtually free of pathogens. This technology is not very new, it is what is knows as "stabilization" of biosolids. The stabilization is achieved in a big mixer that is filled with biosolids, addition of potassium hydroxide and steam. The biosolids get mixed for hour and a half and are then the final end product that can be stored or used as a fertilizer (Lystek International, 2010). Specific information regarding the amount of biosolids produced and the amount spread on the fields could not be found.

\subsubsection{Kitchener Wastewater Treatment Plant and Disposal}


The Kitchener Wastewater Treatment Plant (WWTP) was built in 1935 and treats sewage from about 200,000 residents, with a capacity of $122,700 \mathrm{~m}^{3}$ of water per day (Region of Waterloo and Earth Tech, 2007). In this plant, the sludge goes through anaerobic digestion. This is a widely used process where anaerobic bacteria convert organic matter into methane (that can be used as an energy source) and carbon dioxide. This process stabilizes the organic matter, and reduces pathogens and odours (United States Environmental Protection Agency, 2006).

Information specifically for the amount of Kitchener biosolids and where they were spread could not be found, but there is information on the Region of Waterloo as a whole. The region land applies most of its biosolids that are produced in the thirteen WWTP. A total of $250,000 \mathrm{~m}^{3}$ is being spread on 1,264 hectares from all thirteen WWTPs in the Waterloo Region (Region of Waterloo and Earth Tech, 2007). Most of the biosolids are applied by subsurface injection, while some is sprayed on plants that are already growing (Andrews, 2003). The Region of Waterloo also has its own Biosolids Master Plan to provide better management of biosolids and residuals for the next twenty years (Region of Waterloo and Earth Tech, 2007).

\subsection{Regulation of Biosolids}

Environmental Protection Agency in the Unites States was a pioneer in proposing and implementing regulations for production and disposal of biosolids in 1974 (UN-HABITAT, 2008). Following the US, most Western European countries adopted similar regulations in the 1970s and early 1980s (UN-HABITAT, 2008). These early initiatives regulated quantities of specific metals, pathogens of concern and some nutrients, although permitted quantities varied among nations. Ontario has passed regulations for the production and use of biosolids, most of 
them closely resembling the EPA's regulations (Environmental Protection Act, O.R. 347). In 2003 after the Walkerton crisis, the Nutrient Management Plan was passed which regulated the management aspect of biosolids in Ontario (Nutrient Management Plan, O.R. 267). Nearly all the jurisdictions with current regulations for biosolids land application specify allowable quantities for some metals and metalloids (arsenic, cadmium, chromium, lead, and mercury etc), pathogens (coliforms and Salmonella) and nutrients (Nitrogen and Phosphorus) of concern.

There have been studies showing that biosolids from all over the world have pollutants such as PPCPs, dioxins and furans, pesticides, pharmaceuticals and personal care products, and others, however for the most part these are not being regulated (McLachlan et al, 1996 in Germany, Hebert, 2004; Pedersen et al, 2005 in US, Topp et al, 2008 in Canada).

\subsubsection{Canadian Regulations}

Division of jurisdiction in Canada is either Federal, Provincial or Municipal; therefore responsibility of environmental protection is controlled by Federal, Provincial and Municipal laws and policies. For the most part biosolids in Canada are regulated through provincial laws. Canada's federal laws do no directly regulate biosolids, but they can be regulated through other laws and regulations. For example, if the WWTP is producing biosolids that are commercialized and can be sold as a fertilizer (as Guelph WWTP plans), the biosolids can be regulated under the Canadian Fertilizers Act, that is enforced through the Canadian Food Inspection Agency, or if the biosolids are found to be adversely affecting fish, they can be regulated under the Fisheries

Act (Lewis, 2006).

\subsubsection{Ontario Regulations}


Currently, biosolids in Ontario are regulated by the Environmental Protection Act, Ontario Regulation 347, and Nutrient Management Plan, Ontario Regulation 267. Two departments that are responsible for implementing and monitoring land application of biosolids in Ontario are the Ontario Ministry of the Environment (MOE) and Ontario Ministry of Agriculture, Food and Rural Affairs (OMAFRA). Every user of biosolids has to get a Certificate of Approval from the Ministry of the Environment. The MOE uses the 'Guidelines for Utilization for Biosolids and Other Wastes on Agricultural Land' that is developed by the Biosolids Utilization Committee, an inter-ministry/external stakeholder advisory committee with representation from municipalities, the agriculture community, the land application industry (e.g. sewage biosolids haulers), the health industry, the scientific community, affected industry associations and non-government organizations, and policy and technical staff of MOE, OMAFRA and the Ontario Ministry of Health and Long-Term Care. This committee works with the provincial government and other associations to discuss, exchange information and educate about the best management practices on how to use biosolids on agricultural land.

Ontario Ministry of Agriculture, Food and Rural Affairs is responsible for implementing and monitoring Ontario Regulation 267/03 which is a General regulation under the Nutrient Management Act. This act addresses the land applied materials that contain nutrients which would include biosolids. This act regulates a large number of management issues, for example the timing of biosolids application (not allowed from December $1^{\text {st }}$ to March $31^{\text {st }}$ ) and required distances from water courses, the water table, wells, etc. (Table 1). The constituents of biosolids are regulated by Environmental Protection Act, Ontario Regulation 347. The guidelines specify what constituents of the biosolids must be measured and set the highest allowable limits, the method for testing various constituents and other restrictions. For example, biosolids have to be 
tested for total Kjeldahl nitrogen, ammonia, nitrates, nitrites, total phosphorus, solids and volatile solids, metals and E. coli. The eleven metals whose concentrations are measured are: arsenic, cadmium, chromium, copper, lead, mercury, molybdenum, nickel, selenium and zinc. Metals are measured as total concentration, not specifying what form the metal is (Jenness, 2001).

Individuals responsible for monitoring application rates, spills, analysis of biosolids, amounts and locations where biosolids are applied are wastewater treatment plant operators and generators and members of the land-application industry. The diffusion of these responsibilities makes it is difficult to obtain information about exactly where biosolids are being applied, when specific parameters are analyzed, and the results of those analyses.

Table 1: Example of Nutrient Management Act regulations

\begin{tabular}{|l|l|l|}
\hline Feature & Distance(m) & Notes \\
\hline Watercourses & $50-200$ & $\begin{array}{l}\text { Depending on slope and soil } \\
\text { permeability }\end{array}$ \\
\hline Water Table & 0.3 & Measured vertically \\
\hline Bedrock & 0.9 & Measured vertically \\
\hline $\begin{array}{l}\text { Drilled wells more than } 15 \mathrm{~m} \\
\text { deep }\end{array}$ & 15 & Measured horizontally \\
\hline $\begin{array}{l}\text { All other wells including dug } \\
\text { wells }\end{array}$ & 90 & Measured horizontally \\
\hline $\begin{array}{l}\text { Individual residences } \\
\text { Residential areas }\end{array}$ & 200 & Measured horizontally \\
\hline
\end{tabular}

\subsubsection{United States Regulations}

The regulation of biosolids in the United States is essentially very similar to Ontario, but is organized and worded a little differently. One major difference is that in the US biosolids are 
regulated though Federal laws, guidelines and policies. Biosolids regulation is guided through "Standards of Use of Disposal of Sewage Sludge", Title 40, Part 503, 1993. This is a part of the Clean Water Act that is implemented and governed through the United States Environmental Protection Agency (United States Environmental Protection Agency, 1994a). Just like in Ontario the regulations for biosolids land application include standards for pollution limits specifying highest allowable concentrations for the metals, nutrients and pathogens. The guidelines and regulations also provide guidance on management practices such as amount to be spread, location, distances from water courses, monitoring, record keeping and other non-constituent matters regarding biosolids (United States Environmental Protection Agency, 1994a). The metals regulated are the same as in Ontario, the concentrations allowed are slightly different. The restrictions on nutrients and pathogens are also the same. The classification system in the US is different than in Ontario. In the US, biosolids can be Class A or B, or "Exceptional Quality" based on their pollutant (metals and nutrients) and pathogen concentrations. The primary difference between the three grades is in the amount of pathogens in the biosolids. Biosolids that meet "exceptional quality" can be commercialized and distributed anywhere. The management side of biosolids is also very similar to Ontario. Application is not permitted on snow covered, flooded or frozen land, cannot be applied within 10m of US surface waters and other similar guidelines.

\subsubsection{European Union Regulations}

Although the percentage varies among countries, the European Union as whole uses $40 \%$ of sewage sludge in form of biosolids on agricultural land (European Commission, 2006). 
Different countries within the European Union have their own regulations from before the formation of the EU, but all treated sewage sludge (biosolids) that are to be applied to agricultural land are regulated by the general EU directive law called "Council Directive of 12 June 1986 on the protection of the environment, and in particular of the soil, when sewage sludge is used in agriculture" (European Commission, 2010), that sets minimum standards for all members of the EU. This directive, like that in the US and most provinces in Canada, regulates metals, nutrients and pathogens. The regulation of organics is left for member states to regulate. However, from the management of biosolids stand point, this directive is not as strong as Ontario's. The legislation does not indicate vertical and horizontal distances from water, and does not specify how the biosolids are to be applied. It has the same usual restrictions such as no biosolids can be applied to frozen or snow covered land, and the application rates much not exceed the specified limit. In general, this legislation is the base-line, and then countries within the EU have their own similar or more stringent regulations. For example although Sweden regulates for the same metals as the rest of the EU, their ceiling limits on most regulated metals are much lower; nickel levels allowed in the European Union is $300-400 \mathrm{mg} / \mathrm{kg}$, while in Sweden the law specifies $50 \mathrm{mg} / \mathrm{kg}$, cadmium in the EU is allowed up to $20-40 \mathrm{mg} / \mathrm{kg}$, while in Sweden $2 \mathrm{mg} / \mathrm{kg}$ is the maximum allowable for land application (Fjallborg and Dave, 2003).

\subsection{General Constituents of Municipal Biosolids and Possible Effects on the Environment}

Biosolids contain a variety of organic pollutants, micro and macro nutrients, nonessential trace metals, organic pollutants and microorganisms (Singh and Agrawal, 2008). As mentioned previously, the composition of biosolids depends on the area from which the 
wastewater is collected and the treatment that wastewater and sludge goes through in production of biosolids. Because biosolids are not uniform in composition, the potential impacts when land applied (beneficial and adverse) may also not be uniform. Some papers emphasize the benefits of using biosolids as a fertilizer, both from a scientific and management perspective (Logan and Harrison, 1995; Metcalf and Eddy, Inc., 2003). Use of biosolids is seen as an alternative to chemically synthesized fertilizers. Biosolids provide soil with organic matter that is metabolized and degraded by microorganisms, which results in accumulation of macro and micro nutrients for the crops to utilize (United States Environmental Protection Agency, 1999). The most emphasized benefits from the scientific point of view are better physical condition of the soil and greater crop yield (Logan and Harrison, 1995). The most important benefit from a management point of view is that land application is the most economical disposal method of dealing with sewage sludge after land filling (Metcalf and Eddy, Inc., 2003). Finally land application of biosolids is seen as closing the chain between food consumers and food producers which is a step towards sustainability (City of Toronto, 2009).

Although biosolids can be used as a fertilizer because it supplies soil with phosphorus, nitrogen, organic matter and micronutrients, it can contain substances that can have an adverse impact on the environment. There are traditional concerns regarding biosolids such as eutrophication, metal accumulation and as a vector for introducing pathogens, and newer concerns such as introduction of persistent toxic organic pollutants, personal care products, pharmaceuticals, and cleaning products into the food-chain through application of biosolids to agricultural soil. Some of the most persistent and toxic chemicals synthesized such as polychlorinated dibenzo-p-dioxins and dibenzofurans (PCDD) are found in biosolids (McLachlan et al, 1996). The sources for higher chlorinated PCDDs in sludge come from textiles 
which become contaminated during production and then when washed, wastewater gets contaminated and PCDDs get concentrated in the sludge because they are hydrophobic (McLachlan et al, 1996). The lower chlorinated PCDDs have other sources such as atmospheric deposition. Major classes of pharmaceuticals found in biosolids and elutriate from biosolids include analgesics, thyroid hormone modulators, neurotransmitter modulators, antiinflammatories, anti-hyperglycemics, lipid modulators, anti-histamines, antibiotics, and gastric antacids (Pedersen et al, 2005; Kostich and Lazorchak, 2008; Topp et al, 2008), not surprisingly as these are the most commonly used pharmaceuticals. One of the biggest challenges is estimating the risk to organisms from human pharmaceutical presence, due to a lack of pharmacological data on non-mammals (Kostich and Lazorchak, 2008). Kinney et al (2008) published a comprehensive survey of organic wastewater contaminants in biosolids that are designated for land application. The samples were from all over the United States. Every biosolids sample analyzed had a minimum of 30 and a maximum of 45 different organic wastewater contaminants analyzed. These contaminants varied from pharmaceuticals such as antihistamines and antidepressants, fragrances, detergent metabolites, fire retardants such as bisphenol A, steroids (mostly plant), disinfectants, plasticizers and preservatives. Some of chemicals found were in very high concentration, for example the fragrance indole was found at a mean concentration of $19,600 \mu \mathrm{g} / \mathrm{kg}$, the detergent metabolite nonyphenol at a mean concentration of $26,100 \mu \mathrm{g} / \mathrm{kg}$, and beta-sitosterol at a mean concentration of $209,000 \mu \mathrm{g} / \mathrm{kg}$. Some of these have a very large $\mathrm{K}_{\text {ow }}$ value indicating that they partition to the organic fraction in particulate matter, and can enter receiving water in particulates from agricultural run-off. Also, the numbers are mean concentrations which would suggest that these organic wastewater pollutants are readily found in many biosolids. 
Potential concerns about environmental presence of organic pollutants in biosolids include adverse physiological effects, increased rates of cancer, reproductive impairment, antibiotic resistance and others (Pedersen et al, 2005; Sullivan et al, 2007; Suresh, 2007; Kim et al, 2007; Kostich and Lazorchak, 2008; Topp et al, 2008). In the following section effects of biosolids (whole or constituent parts) on the environment will be discussed.

\subsubsection{Effect of Biosolids on Soil Microorganisms, Plants, and Soil Properties}

General microbial activity, including respiration and enzymatic, can be used to indicate abundance and health of microbial communities in soil (Sastre et al, 1996; Banerjee et al, 1997; Spier et al, 2003). Parameters such as basal respiration, urease and phosphatase activity, glucosidase, and nitrogen fixation have been analyzed as indicators for microorganism response to biosolids amended soil (Epistein et al, 1976; Sastre et al, 1996; Banerjee et al, 1997; Spier et al, 2003; Kacprzak et al, 2005; Holt et al, 2010).

Sastre et al (2006) measured the activity of beta-glucosidase, phosphatase and urease in soil where municipal, industrial and conventional fertilizers were land applied. Two different types of sewage sludge from two different regions were tested for microbial activity. In one, activities of urease and phosphatase decreased and that was attributed to a high metal content causing microbial inhibition. In the other, urease and phosphatase activity increased indicating nitrogen mineralization, production of nitrates and ammonia and phosphates. Banerjee et al (1997) found that application of sewage sludge increased the amount of nitrogen mineralization. 
Other studies have shown short-term increases in activity of enzymes such as sulphatase, urease and phosphatase activity (Spier et al, 2003; Kacprzak et al, 2005). Holt et al (2010) found that application of municipal biosolids to agricultural soil caused short-term stimulation of nitrogen fixing activity, but that there were no residual effects after three months. Similarly, basal respiration was stimulated in short-term (one-time biosolids application), but had no longer-term impacts on respiration (Holt, 2007). Meta-data analysis of published data on effects of municipal biosolids application on soil microbial activity has found that biosolids applied at or below the regulatory limits have been found to cause short term stimulation of most measures of activity (basal respiration, urease activity, phosphatase activity, and microbial abundance), however there is little evidence of long-term stimulation, nor is there evidence for negative impacts of municipal biosolids on general microbial activity (Laursen et al, in preparation). In other studies waterholding capacity and conductivity of soil increased right after sewage sludge application but then declined over the next several years (Epistien et al, 1976; Spier et al, 2003).

Kacprzak et al. (2005) did a comparative mycological analysis of wastewater and sewage sludge from different wastewater treatment plants. A significant number of Penicillium and Mucroacceae survived treatment in sewage sludge from all plants. Additionally, some fungi of concern survived in biosolids in small quantities, including Sporothirix, Candida and Microosporon. These can be a source of infections in humans, but can also cause ecological imbalance once in the soil (Kacprzcak et al, 2005).

In general there are papers showing a better yield and growth in crops following application of municipal biosolids (Bozkurt and Yarilgac, 2003; Qasim et al, 2001) which would also indirectly show a more productive microbial activity since microbes supply the crops with all the inorganic nutrients. Maize gave an increased germination rate when sludge was applied at 
50 tonnes per hectare. Maximum root and shoot length and leaf area was seen at 20 tonnes per hectare (Qasim et al, 2001). Apple trees amended with sewage sludge at 75 tonnes per hectare showed increased fruit yields, shoot lengths, girth and cumulative yield efficiency (Bozkurt and Yarilgac, 2003).

On the other hand, there are studies showing that microbial activity and soil health can be negatively affected by sewage sludge addition to soil. Metals accumulation, overnutrification, additions of new microbial species, imbalance of carbon to nitrogen ratios and addition of organic pollutants are some major concerns (Spier et al, 2003; Fjallborg et al, 2005; Kim et al, 2007). Zinc and Chromium caused inhibition of root elongation in Brassica chinesis in studies done with Hong-Kong sludge spiked with metals (Wong et al, 1996). Long-term effects of sewage sludge and biosolids application on soil properties is an area that needs attention since it is not well studied or understood. Effects of biosolids and sewage sludge on soil microbial activity, plant performance, and the chemical and physical properties of soil are interwoven; therefore they are all presented together in this section and in Table 2.

It is worth noting that most of the studies cited in Table 2 (with the exception of Qasim et al, 2001) were short-term studies ( $<4$ years). This would indicate that the effects seen were during a relatively short period of time and might be different in later years. This noted, the meta-data analysis conducted by Laursen et al (In prep) includes many long-term experimental data sets and suggests no evidence of long-term impact of biosolids application at regulatory limits, at least for microbial activity. 
Table 2: Effect of sewage sludge and biosolids on physical and chemical properties of soil, microbial activity, and plant yields.

\begin{tabular}{|c|c|c|}
\hline Chemical and Physical properties & Effect & Reference \\
\hline Soil Organic Carbon & Increases & $\begin{array}{l}\text { Sastre et al, (1996), Banerjee at } \\
\text { al, (1997), Spier et al( 2003) }\end{array}$ \\
\hline Nitrogen and Phosphorus & Increase & $\begin{array}{l}\text { Sastre et al, (1996), Banerjee at } \\
\text { al, (1997), Spier et al( 2003) }\end{array}$ \\
\hline Humic Substances & Increase & $\begin{array}{l}\text { Sastre et al, (1996), Spier et al } \\
(2003)\end{array}$ \\
\hline $\begin{array}{l}\text { Contaminants such as Metals and } \\
\text { other Xenobiotics }\end{array}$ & Increase & $\begin{array}{l}\text { McBride (1998). McLachlan et } \\
\text { al (1996) Fjallborg and Dave } \\
\text { (2003), Bozkurt and Yarilgac } \\
\text { (2003), Spier et al (2003). }\end{array}$ \\
\hline $\mathrm{pH}$ & $\begin{array}{l}\text { Increase usually, } \\
\text { decrease due to high } \\
\text { calcium carbonate from } \\
\text { liming of sludge }\end{array}$ & $\begin{array}{l}\text { Epistein (1975), Sastre et } \\
\text { al(1996), Logan and Harrison } \\
(1995)\end{array}$ \\
\hline Water Holding Capacity & Increase (short period) & $\begin{array}{l}\text { Epistein et al (1975), Spier et al } \\
(2003)\end{array}$ \\
\hline Erosion & Decreass (short period) & $\begin{array}{l}\text { Epistein et al (1975), Spier et al } \\
(2003)\end{array}$ \\
\hline \multicolumn{3}{|l|}{ Effect on Microbial Activity } \\
\hline Yeast Populations & Increase & $\begin{array}{l}\text { Sastre et al (1996), Kaprzcak et } \\
\text { al (2005) }\end{array}$ \\
\hline Bacterial Populations & $\begin{array}{l}\text { Can increase, decrease } \\
\text { overall and decrease in } \\
\text { diversity }\end{array}$ & $\begin{array}{l}\text { Sastre et al (1996), Banerjee at } \\
\text { al (1997), Spier et al (2003), } \\
\text { Singh and Agrawal (2008) }\end{array}$ \\
\hline Pathogenic Organisms & Can increase & $\begin{array}{l}\text { Spier et al (2003), Kaprzcak et } \\
\text { al (2005) }\end{array}$ \\
\hline \multicolumn{3}{|l|}{$\begin{array}{l}\text { Effect on Plants of importance in } \\
\text { Agriculture }\end{array}$} \\
\hline Apple trees & $\begin{array}{l}\text { Increased fruit yields } \\
\text { and shoot length. } \\
\text { Increase of some heavy } \\
\text { metals in leaves as } \\
\text { well. }\end{array}$ & Qasim et al (2001) \\
\hline Maize & $\begin{array}{l}\text { Increased germination, } \\
\text { shoot length and leaf } \\
\text { area }\end{array}$ & Bozkurt and Yarilgac (2003) \\
\hline
\end{tabular}




\subsubsection{Effect of Trace and Heavy Metals on Biosolids Amended Soil}

The fate of metals from biosolids and sewage sludge has been a subject of research since the 1970s. Metals have been one of the biggest concerns because they get concentrated in biosolids and sewage sludge and they accumulate in soil over time (Alloway and Jackson, 1991; Kim et al, 2007; Singh and Agrawal 2008). According to many researchers, concentrations of metals such as $\mathrm{Ag}, \mathrm{Hg}, \mathrm{Cd}, \mathrm{Cr}, \mathrm{Cu}, \mathrm{Pb}, \mathrm{Ni}$ and $\mathrm{Zn}$ exceed the average reference soil concentrations from 10 to 100 times depending on how long the biosolids have been applied and the type of sludge (Alloway and Jackson, 1991; Fjallborg et al, 2005; Kim et al, 2007; Singh and Agrawal, 2008). The metal concentration in sewage sludge depends on several factors such as sewage origin, sewage treatment process and sludge treatment processes. Bioavailability of the sludge borne metals to soil is further influenced by soil properties such as $\mathrm{pH}$, redox potential, and the amount and type of organic matter (Singh and Agrawal, 2008). Understanding the behavior of metals, such as speciation in sludge and soil, is necessary to predict important parameters like bioavailability and potential risks they might pose. When Tessier's methodology was used to perform sequential extraction for one municipal biosolid, Cd was mostly found in exchangeable fraction, $\mathrm{Ni}$ in oxidizable phase, $\mathrm{Pb}$ in the acid soluble fraction, and $\mathrm{Cr}$ in residuals (Singh and Agrawal, 2008). The amounts of iron and manganese oxides are very important in soil because they chelate a lot of metals and that way they have absorptive properties (Alloway and Jackson, 1991). Some metals are strongly chelated while others are not; $85 \%$ of Cd and $91 \%$ of $\mathrm{Zn}$ are free metal ions in soil, which makes them mobile and bioavailable (Alloway and Jackson, 1991). Cadmium is a metal of high concern not only because of its small retention time, but also because it is much more toxic than many other bioavailable metals such as zinc, copper 
or nickel (Alloway and Jackson, 1991). Zinc, copper and lead are the most concentrated metals found in sewage sludge and in soil globally (Singh and Agrawal, 2008), where lead is very strongly chelated to ligands and zinc is usually not (Singh and Agrawal, 2008). Because zinc is in high concentrations and is not generally chelated, it is usually presented as a metal of most concern in relation to potential impact on the soil microbial processes and soil fertility because it can inhibit nitrogen fixation, among other processes (Alloway and Jackson, 1991; Fjallborg et al, 2001; Singh and Agrawal, 2008).

Toxicity of metals highly depends on the bioavailability and the form of the metal. Most metals are very strongly complexed with mineral and organic and inorganic components of sludge and are not readily bioavailable, but factors such as lowering of the $\mathrm{pH}$ can make metals available (Alloway and Jackson, 1991).

\subsubsection{Impact on Water Quality}

The impact of land applying biosolids does not end on land with its flora and fauna.

During the spring months when the snow melts, and during the heavy summer rains, agricultural run-off has a potential to expand the adverse impact of biosolids from the fields into receiving water through leaching and erosion (particle transport). Agricultural run-off accounts for a large percentage of non point source pollution (United States Environmental Protection Agency, 2004). Sediments in rivers and lakes tend to be a sink for many hydrophobic contaminants like many metal complexes, persistent organic pollutants, pharmaceuticals and others. Pollution of water by metals from run-off depends on many factors such as if the field is cultivated by crops, climate, type of sediments in the watershed, and type of suspended particulate matter (Alloway and Jackson, 1991; Hakanson and Eckhell, 2005). 
Suspended particulate matter is of great importance in aquatic ecology because it regulates the transport of pollutants, influences water clarity and phytoplankton and bacterioplankton production. This further influences the secondary production; zooplankton such as Daphnia magna, fish or sediment dwellers like Hyalella azteca (Hakanson and Eckhell, 2005). Because particulate matter act as a sponge, many materials get adsorbed to its surface; it transports nutrients, organic materials, heavy metals and radionuclides (Hakanson and Eckhell, 2005). Agricultural run-off and suspended particulate matter (SPM) is often beneficial at lower trophic levels as a carbon source for bacteria and zooplankton or a nutrient source for phytoplankton. However, if SPM carries many pollutants into the water column, it may have an adverse impact on the aquatic organisms. Generally biosolids have been shown to produce less harmful run-off than soils treated with chemical fertilizers due to less erosion and larger water holding capacity, decreasing overall erosion of materials (Joshua et al, 1998; Singh and Agrawal, 2008). As already mentioned, the toxic impact suspended particulate matter can have on receiving water is determined by what kind of pollutants it carries with it. All the chemicals and pathogens mentioned throughout this paper have potential to travel with the particulate matter into the receiving waters. If application of biosolids reduces the delivery of particles through erosion, but those particles carry a heavier burden of toxicants, biosolids could still have a negative impact on aquatic biota.

Topp et al. (2008) spiked biosolids with common pharmaceuticals and personal care products (PPCP) of concern and simulated run-off to see how the chemicals of interest behave in the receiving water. Biosolids were applied in two fashions: sprayed and injected. The samples were collected six times over 266 days. The PCPPs that were used were: ibuprofen, gemifrozil, naproxen, triclosan, carbamazepine, acetaminophen, cotinine, sulfamethoxazole and atenolol. In 
plots where biosolids were sprayed, results showed the highest concentrations of all PCPPs on day one after the simulated rain. It was interesting to notice that iboprufen and acetaminophen rose again in concentrations on day 36. This was attributed to chemicals adsorbing to the soil or biosolids particles and then getting released. Triclosan had a slower rate of decline over time, indicating repeated immobilization and remobilization. Triclosan is of high concern because it was found on several occasions in biosolids at concentrations at which it can impair function of genes that regulate growth and sex hormones in frogs (Veldhoen et al, 2006). Also of interest was that mean concentrations of gemfibrozil remained above the expected limits on day 266 , indicating it was still getting released into the water. The study also concluded that by injecting the biosolids instead of applying to surface, the concentrations of the chemicals were much lower. It was concluded that greatest risks to water are the day after the storm or during ice melts, and that method of application (injection versus spraying) can change the risk of contaminants reaching receiving waters. As will be described, biosolids were incorporated into soil in this thesis research simulating injection rather than spraying.

\subsubsection{Dilution of Biosolids Run-off and Tile Drainage Entering Receiving Water}

Topp et al. (2008) measured direct run-off, and the paper gives a good idea of what chemicals might be found in receiving water where biosolids are land applied. However the values analyzed were absolute concentrations in elutriate, they do not represent the concentrations expected in receiving waters in Ontario where concentrations of contaminants would be diluted upon entry. There is no known literature that represents the dilutions series or approximate concentrations of biosolids constituents in the watersheds of Ontario. An environmentally-relevant dilutions series is difficult to estimate because of the nature of 
biosolids and the complex issue of run-off. Biosolids are highly variable, complex mixtures with different chemical and transport properties that depend on the watershed characteristics such as rainfall, soil grain size, soil composition, land use and many others (Singh and Agrawal, 2008). When biosolids are land applied, different chemical fractions from biosolids will behave differently and there will be different run-off potential as a result. An additional issue is that it is difficult to estimate the volume of run-off relative to the volume of receiving water to approximate a correct dilution.

There are some numbers that can help guide estimation of the dilution of biosolids constituents upon entry into receiving water. Each year 120,000 tonnes of biosolids are applied to 15,000 hectares of Ontario soil (Ontario Ministry of Agriculture Food and Rural Affairs, 2010a). Out of the 120,000 tonnes, 16,000 tonnes are applied to 2,000 hectares on agricultural fields, for an average of 8 tonnes/ha. The rest is applied to recovery mines, tree farms and other land that receives biosolids besides agricultural fields. To be able to estimate the dilution series of biosolids constituents, the locations of where biosolids are applied and watershed profile around that land would have to be known, and as already mentioned in sections regarding the wastewater treatment plants, this information is difficult to obtain since it is individual operators that are responsible for keeping it.

In 2006, Ontario had a total of 3,660,941 hectares in crops (Statistics Canada, 2010). Assuming this represents current crop land in Canada, and biosolids are applied to 2,000 hectares per year, this amounts to $\sim 0.05 \%$ of cropland in Ontario receiving biosolids each year. For estimating dilution of biosolids elutriate from agricultural soil, we can assume that all surface water within a catchment is run-off or drainage from land. In other words, an insignificant amount of water in streams and lakes landed directly on the surface of water, and virtually all 
first landed on soil and either washed off, percolated to tile drainage, or percolated to ground water. If we further assume that biosolids application to Ontario cropland is evenly distributed, then we could estimate that biosolids elutriate is diluted, on average, by a factor of 200 upon entering receiving water in an intensely agricultural watershed. This second assumption is likely false. The Waterloo region, for example, has application of biosolids to 1264 hectares/year or more than $60 \%$ of the total land application of biosolids to agricultural land in Ontario. For 2009, Waterloo region had an estimated 79,000 hectares of cropland (Ontario Ministry of Agriculture Food and Rural Affairs, 2010a). Assuming even distribution of biosolids application within this region, biosolids elutriate would be diluted by a factor of $\sim 60$ upon entering receiving water, on average. In this context, a 100-fold dilution of biosolids elutriate (or 1\%) would have broad environmental relevance, while a ten-fold dilution (or 10\%) might have very localized environmental relevance.

\subsubsection{Impact on the aquatic biota in the surrounding watershed}

Sullivan et al (2007) that found that biosolids can induce CYP1 (Cytochrome P450 which is a group of enzymes responsible for catalyzing many organic substances such as lipids or hormones) and cause DNA damage in fathead minnows (Pimephales promelas). The study was not an agricultural run-off, but used concentrations of biosolids at 0.5 and $2.5 \mathrm{~g} / \mathrm{L}$ dilutions, well above environmentally-relevant concentrations. Chemical analysis of biosolids indicated presence of polybrominated diphenyl ethers, nonylphenos, and a large amount of polycyclic aromatic hydrocarbons (consistent with Kostich and Lazorchak, 2008 and Topp et al, 2008). The CYPlinduction was attributed to the high amount of PAHs in biosolids, which are known to induce DNA damage in other organisms (Sullivan et al, 2007). 
Fjallborg and Dave (2003) assessed toxicity of Sb and $\mathrm{Cu}$ in sewage sludge elutriate to Daphnia magna and Lemna minor. The study also examined how the cultivation of plants changed the toxicity and composition of elutriate. The results indicated that before the cultivation, elutriate was toxic to both Lemna minor and Daphnia magna due to high ammonia and nitrite concentrations, not metals as hypothesized. With cultivation, the elutriate was toxic to neither Lemna minor nor Daphnia magna. Also, after the cultivation with plants elutriates contained less ammonium, nitrite, metals concentrations dropped and the $\mathrm{pH}$ of elutriate remained around neutral. Although this study did not specifically evaluate potential toxicity of an agricultural runoff, it gives good insight into trends that might be expected. While this one study is highly relevant to the research presented in this thesis, in general there are not many adequate studies done on the effect of biosolids run-off on the animals and plants in water receiving run-off and tile drainage. Most of the impacts studied to date have focused on chemical characterization, pathogen detection and quantification, effect on plants (especially important agronomical plants) or effects on the microbial, physical and chemical parameters of soil after the application. Moreover, many of the previous studies focused on single constituents of biosolids rather than a more holistic assessment of biosolids (e.g. impacts of reference biosolids compared with impacts of biosolids spiked with a contaminant).

\subsection{Organisms used in Assessing Ecological Impacts of Biosolids in Receiving Waters}

The organisms used are widely used in eco-toxicological tests, are small and easy to work with, easy to culture in the laboratory, and are important members and niche representatives of aquatic communities in Ontario. 


\subsubsection{Daphnia magna}

Daphnia magna are invertebrate crustaceans that live in freshwater rivers, lakes and ponds across the Northern Hemisphere (Dodson and Hanazato, 1995). They are sensitive to a variety of chemicals at low concentrations, are inexpensive to culture in the laboratory settings and have a short life-cycle (Ren et al, 2007). For this reason they are a good model organism to use as an indicator of toxicity of the water column in the environment. They also have been extensively used for biological monitoring which means that their acute and chronic endpoints are well established and easy to monitor (Dodson and Hanazato, 1995; Paul et al, 1997).

Daphnia magna are important in keeping the water clean as they are filter-feeders and are also a major component in diets of many larger organisms such as fish and amphibians (Dodson and Hanzato, 1995). The parameters to be assessed in this thesis in regards to Daphnia magna are respiration, behaviour and survivorship.

Respiration rates in Daphnia magna measure overall metabolic activity of the organism which is a sensitive and integrative response to contaminant exposure (Geiger and Buikema, 1981). Some studies have conducted the response of Daphnia magna respiration rates to chemical as well as physical stressors, and short-term experiments performed showed more significant results than long-term respiration measurements (Geiger and Buikema, 1981; Fischer et al, 2006).

Behaviour of Daphnia magna is a good indicator of its condition and stress. Daphnia magna has to swim to survive, because by swimming it is able to find food and stay away from predators. It has a very distinct saltatory swimming style, and it is easy to notice once that normal behaviour is disturbed and the organisms is no longer in an equilibrium. Once the 
organism is under physical, chemical or predatory stress it exhibits a range of different swimming patterns (Dodson and Hanazato, 1995). Some of these are inability to propel throughout the water column, sudden “jerky” movements, and spinning (Dodson and Hanazto, 1995).

Survivorship is the third parameter to be tested, and it is also the standard parameter for toxicity testing that can give insight into longer-term exposure stress (Environment Canada, 1997).

\subsubsection{Hyalella azteca}

Hyalella azteca is a fresh-water amphipod that is very widely used for toxicity testing for the same reasons as Daphnia magna. It is small and easy to culture and maintain in laboratory settings. It is widely used especially for sediment toxicity bioassays (Hatch and Burton, 1999). Just like Daphnia magna, Hyalella azteca play an important role in aquatic systems as omnivorous detritivores, and are also a part of the diet for larger animals (Wang et al, 2004). They are wide-spread within the Northern Hemisphere and occupy freshwater lakes, ponds and rivers (Wang et al, 2004). For all these reasons the amphipod is a useful model for toxicity testing. The parameters to be tested in Hyalella azteca are respiration, behaviour and survivorship.

Respiration in Hyalella azteca has been measured as a response to physical and chemical stress, but not as extensively as in Daphnia magna. Oberlin and Blinn (1997) have tested the Hyalella azteca response in respiration to temperature and found that there was a significant increase in oxygen consumption per unit mass as the temperature increased. They have 
concluded that respiration rates should be looked at when performing eco-toxicological tests on this amphipod.

Behaviour of Hyalella azteca is another good parameter to test for environmental stress. Under reference conditions the amphipod crawls on the substrate which is usually the sediment or leaves, and spends the majority of time in the top centimeter of the substrate (Wang et al, 2004). Once the organism is under stress it can exhibit different behaviour such as immobilization, body shortening, not crawling on the substrate, grouping, and burrowing deeper into the sediments (Marshall, 2009). Finally survivorship is a standard response used in toxicity bioassays (Environment Canada, 1997).

\subsubsection{Lemna minor}

Lemna minor are free floating aquatic duckweed plants. This plant is a common floating plant in lakes and ponds. Lemna minor has a short life cycle and is relatively easy to culture in the laboratory. The plants grow mainly by vegetative reproduction: two daughter plants bud off from the adult plant (Environment Canada, 2007). This form of reproduction allows very rapid growth in water, and their growth to be measured. Lemna minor have been extensively used as a model for toxicity testing of urban and industrial effluents, elutriates, and single chemical or product tests (Environment Canada, 2007). The test that was performed with this plant is the 7day growth inhibition test developed by Environment Canada (2007), where total mass of all the Lemna minor is compared among treatments after 7 days.

\subsection{Rational for Thesis: Need for Ecological Assessment of land applied Biosolids}


There are two major reasons why there is a need to assess the land-applied biosolids on the animals and plants in the surrounding watershed. First, since Michigan has closed its borders to Ontario's biosolids, there is pressure to increase the land application of municipal biosolids. Second, since there are very little biological assessments in general, and no relevant biological assessment in Southern Ontario, there is a need to assess the effect of municipal biosolids run-off on the watershed that receives it, particularly in light of Biosolids and Residuals Master Plans for Ontario municipalities. There are other reasons as to why this research is necessary. It is crucially important to encourage the idea of biological monitoring, since biological response data are more holistic, incorporating the potential additive, synergistic, or antagonistic actions of biosolids constituents that cannot be anticipated from chemical analysis. For this reason, biological monitoring is more relevant to the environment than is chemical analysis. Further, biological monitoring can use organisms that are relevant to the geographic area and relevant to the overall health of an ecosystem. Another reason is to provide actual scientific data that assesses risk in an appropriate context. Many citizens are concerned about the whole management of sewage sludge in Ontario municipalities. The public has been bombarded by media risk characterization that plays on emotional response to the use of municipal biosolids, without any scientific and objective risk assessment to justify the concerns raised.

In more general terms, since the population is only likely to increase in the cities in the future, and so is intake of food, something will have to be done with the increase in sewage sludge. The combination of land application and production of energy are two options that seem viable, where land-filling is unsustainable as a long term solution. With the increase of biosolids use there has to be better biological monitoring in place, there has to be a wider consideration of biosolids constituents, and finally there simply has to be more research done in order to be safe, 
to have public support and understanding, and in order to move to a cleaner and more sustainable future. To reiterate the specific objectives of the thesis, the research was conducted to determine the effects of land applied municipal biosolids elutriate (surface run-off and tile drainage) on aquatic life in receiving water using three model aquatic organisms. Further, the research was performed to contribute to needed risk assessment of biosolids in the environment. To that end, the following general hypotheses were tested:

1) Elutriates from biosolids will affect the behaviour, respiration, and survivorship of macoinvertebrates.

2) The effects of biosolids on behaviour, respiration, and survivorship of macroinvertebrates will decrease over time as the biosolids age in soil.

3) Elutriates from biosolids in vegetated soil will have less impact on behaviour, respiration, and survivorship of macroinvertebrates relative to elutriates from unvegetated soil.

4) Elutriates from biosolids will affect the growth of Lemna minor in receiving water. There is potential for both inhibition due to toxic constituents of biosolids as well as stimulation due to nutrient subsidy.

5) Surface run-off from biosolids will have greater impacts on test organisms than tile drainage as more particle-bound contaminants are likely to be delivered in surface run-off. 


\section{Materials and Methods}

\subsection{Experimental setup}

\subsubsection{Trough Design}

Twelve troughs were made to imitate mini agricultural fields. There were twelve troughs made to have replicates of three for each experimental trial (reference unplanted, reference planted, biosolids unplanted, and biosolids planted). The troughs were made out of $1.9 \mathrm{~cm}$ thick plywood. The boxes are made so they are $1 \mathrm{~m}$ in length, $35 \mathrm{~cm}$ wide and $40 \mathrm{~cm}$ deep. The inside of the boxes were lined with a $5 \mathrm{~mL}$ vapour barrier (Film-Gard, $3.05 \mathrm{~m}$ x $7.62 \mathrm{~m}$ Clear polyethylene). 
A $15 \mathrm{~cm}$ diameter black plastic weeping tile was installed in the bottom of each box. This was done to be able to separate surface run-off from tile drainage. Nitex screen $($ mesh size $=0.1 \mathrm{~cm})$ bought from Dynamic Aqua Supply store was put on the bottom end of the boxes so once the rain was imitated the soil would be retained from eroding out of the boxes. All the troughs were laid on a wooden platform that was slanted on a nine degree angle, which is the maximum allowed where biosolids are applied to land (Ontario Ministry of Agriculture Food and Rural Affairs, 2010).

\subsubsection{Reference Soil}

The soil for the troughs used was Environment Canada artificial soil mix (Environment Canada, 2005). This soil by composition is $70 \%$ silica sand, $20 \%$ kaolin clay and $10 \%$ peat moss by mass. The soil was mixed using a cement mixer. Prior to mixing, soil components were sprayed with water to prevent excessive dust. Mixed soil was then used to fill all the troughs that have weeping tiles on the bottom. When first "rain" was simulated in order to see if the troughs were working properly, it was established that there was no water coming out on the weeping tile, regardless of how much water was added to the trough. After this, all the soil was removed, and a mix of gravel and stones were layered around the weeping tiles (total depth of gravel layer $=15 \mathrm{~cm}$, around the weeping tiles), which followed with adding the artificial mixed soil to a depth of $20 \mathrm{~cm}$. This gravel layer allowed water to percolate to the weeping tiles and troughs drained as planned. The soil was saturated with de-chlorinated water up to $80 \%$ moisture and left for one day.

\subsubsection{Biosolids Application}


The two sources of biosolids used were from Guelph and Kitchener Waste Water Treatment Plants. The application rate of applying biosolids was the maximum allowed in Ontario which is 22,000 dry $\mathrm{kg}$ per $10,000 \mathrm{~m}^{2}$ or 22 tonnes ha ${ }^{-1}$ (Ontario Ministry of Environment and Ontario Ministry of Agriculture Food and Rural Affairs, 2004). This was calculated to be $0.88 \mathrm{~kg}$ of dry weight biosolids per trough. Conversion of wet weight to dry was done by drying $100 \mathrm{~mL}$ of biosolids slurry and calculating the percent dry mass. This was done in replicates of 10. The slurry was let dry overnight in the oven at 100 degree Celsius. For Guelph biosolids, the application rates to achieve 22 tonnes $\mathrm{ha}^{-1}$ were calculated to be 8.9 liters of slurry $(8.84 \%$ solids w/v) and for Kitchener it was 13.9 liters of slurry per trough (6.05\% solids w/v). The way the biosolids slurry was applied to the soil was by removing the top $15 \mathrm{~cm}$ of soil, mixing it with the slurry and putting in back into the troughs. In each experiment, biosolids were applied to 6 of the 12 troughs. A volume of de-chlorinated tap water was added to each of the reference troughs, equivalent to the volume added as slurry to biosolids troughs.

The first set of experiments and bioassays were performed with Guelph biosolids, after which all the soil was removed, replaced with new artificial soil and Kitchener biosolids were applied for the second set of experiments.

\subsubsection{Elutriate Collection}

Once the biosolids were applied to the troughs they were left for 5 days for settling and for excess water to drain. After 5 days, rainfall was simulated and this represented "Day 1" collection of run-off. The rain was imitated by using the "multi-annual extreme storm event for South Ontario" which is $49.5 \mathrm{~mm}$ of rain (Environment Canada, 2009), occurring with an average frequency of 100 years. This amount of "rain" required $19 \mathrm{~L}$ for the area of each trough. The 
water used to imitate rain was regular tap water aerated for a minimum of 48 hours to eliminate chlorine. Rain was simulated by taking water in a $7 \mathrm{~L}$ watering can and sprinkling slowly over the troughs. Water was applied to each trough over a period of $45 \mathrm{~min}$. The surface run-off was first collected immediately after the end of the rainfall event. Tile drainage was collected 15$45 \mathrm{~min}$ after the rainfall event. Run-off collected was stored in a refrigerator $\left(4^{\circ} \mathrm{C}\right)$ overnight prior to the start of bioassays (below). An additional $50 \mathrm{~mL}$ sample of run-off from each source (each trough, tile and surface) was collected and frozen $\left(-20^{\circ} \mathrm{C}\right)$ for nutrient analyses. Forty days after the first storm event, a second storm event of equal magnitude was simulated and run-off was collected as above. This was marked as "Day 40".

\subsubsection{Planting}

A week after collecting the first run-off (Day 8), Soya beans (Glycine max) were planted on three troughs with biosolids applied to them and three troughs with reference soil. Six soya beans were planted per trough, at depth twice the length of the seed and $18 \mathrm{~cm}$ apart from each other (Karen Terry, personal communication). The remaining troughs were unplanted. It took 4-7 days for the seeds to germinate, and the ones that did not germinate were replanted. Once planted the seeds were watered every three days to retain the $80 \%$ moisture content. This was measured with the soil moisture probe (Fujan E-Inginst Electron Co). The troughs were watered approximately 4-6mm of de-chlorinated tap water every 3 days. Light and dark cycles of $16 \mathrm{hr}$ of light to $8 \mathrm{hr}$ of dark were maintained using a timer and full-spectrum fluorescent lights (T8 VitaLux bulbs, $121.9 \mathrm{~cm}$ in length, MT-DTC). These bulbs are also recommended by at $\sim 6 \mu \mathrm{E} / \mathrm{m}^{2} / \mathrm{s}(5001 \mathrm{ux})$. 


\subsection{Culturing Conditions}

All bioassays were performed with two invertebrates widely used for fresh water ecotoxicological tests: Daphnia magna and Hyalella azteca, and one free floating angiosperm also widely used for toxicity tests Lemna minor. Culturing of the two invertebrate organisms followed the protocols established by Marshall (2009) at Ryerson University. Marshall's protocols followed closely the culturing protocols from Environment Canada (1996), the United States Environmental Protection Agency (2002) and the Organization for Economic Co-operation and Development (2004).

\subsubsection{Daphnia magna (Marshall, 2009)}

Three cultures of Daphnia magna were kept in the laboratory for use in respiration bioassays as well as the other behavioral bioassays. The cultures were kept in 9 L glass aquaria. Eight liters of natural spring water (Selection Brand, Hillsburg, ON) were added to each tank and aerated for $24 \mathrm{hrs}$ to establish $>80 \%$ oxygen saturation, and these levels of oxygen saturation were maintained with an air bubbler. Water temperature in the aquaria was maintained at room temperature, which was between 18-21 Celsius throughout the culturing and experimental period. Light and dark cycles of $16 \mathrm{hr}$ of light to $8 \mathrm{hr}$ of dark were maintained using a timer and full-spectrum fluorescent bulbs (T8 VitaLux bulbs). According to Environment Canada protocols, light intensity was kept at $\sim 6 \mu \mathrm{E} / \mathrm{m}^{2} / \mathrm{s}$ (500lux) and the cultures were kept on the working benches $45 \mathrm{~cm}$ below the installed lights. Daphnia magna were fed a mixture of Roti- 
Rich Invertebrate Food (Ward's Natural Science, 88V5910) and each tank received 8mL of this food on Monday and Thursday of each week. Debris or decomposing matter was removed with a transfer pipette whenever there was a layer of it visible on the bottoms of the aquaria. A $10 \mathrm{~L}$ plastic container filled with Millipore water was continuously aerated and kept for replenishing culture aquaria, which was done twice a week, on Tuesdays and Fridays. Millipore water was used instead of Spring Water to prevent the concentration of minerals and salts over time due to evaporative loss. Once the Daphnia magna population exceeded more than 200 in each aquarium, neonates were transferred to new aquaria using a transfer pipette. This was done to prevent overcrowding of Daphnia magna which would induce stress to organisms and could induce population crashes.

\subsubsection{Hyalella azteca (Marshall, 2009)}

Two cultures of Hyalella azteca were maintained in the laboratory for use in respiration and behavioural bioassays and evaluations. Cultures were established in two $9 \mathrm{~L}$ glass aquaria. Eight liters of natural spring water (Selection Brand, Hillsburg, ON) was added to each tank and aerated for $24 \mathrm{hrs}$ to establish $>80 \%$ oxygen saturation, and these levels of oxygen saturation were maintained with an air bubbler. $24 \mathrm{hrs}$ prior to putting Hyalella azteca into the tanks, 2 sterile cotton gauzes pieces $\left(1 \mathrm{~cm}^{2}\right)$ were laid on the bottom of each aquarium to act as substrate for the invertebrates. Every two weeks the gauze pieces were replaced with new ones due to organisms shredding the cotton as well as to the build up of organic debris. Water temperature in the aquaria was maintained at room temperature (between 18-21 Celsius) throughout the culturing and experimental period. Lighting conditions (photoperiod, intensity, and bulbs used) were as for Daphnia magna. Hyalella azteca were fed a mixture of Roti-Rich Invertebrate Food 
(Ward's Natural Science, 88V5910) and each tank received $11 \mathrm{~mL}$ of this food on Monday and Thursday of each week. Debris or decomposing matter was removed with a transfer pipette whenever there was a layer of it visible on the bottom of the aquaria. A $10 \mathrm{~L}$ plastic container filled with Millipore water was continuously aerated and kept for replenishing culture aquaria, which was done twice a week, on Tuesdays and Fridays. Neonate Hyalella azteca were transferred into new aquaria whenever visible during the tank maintenance periods twice a week.

\subsubsection{Lemna minor}

Culturing procedures were developed based on protocols established by Environment Canada (2007). Two cultures were maintained in the lab for seven-day growth inhibition tests. The cultures were maintained in two separate 9L aquaria. The growth medium used was a modified Hoagland's E+ medium (Environment Canada, 2007). Light and dark cycles of 16hr of light to $8 \mathrm{hr}$ of dark were maintained using a timer and full-spectrum fluorescent lights (T8 VitaLux bulbs). According to the Environment Canada protocols, light intensity was kept at $\sim 9$ $\mu \mathrm{E} / \mathrm{m}^{2} / \mathrm{s}$ (700lux) and the cultures were kept on the working benches $35 \mathrm{~cm}$ below the installed lights. The $\mathrm{pH}$ of the growth medium was between 4.4 and 4.8 .

However, culturing Lemna minor by following the Environment Canada (2007) protocol proved difficult because the culture failed to double every 2.5 to 3 days, and this is a requirement of the protocol for a culture to be used for the experiments. Because Lemna minor cultures were not growing properly it was concluded that Hoaglands medium was not the best medium to use as a growth medium for the Lemna minor. Two other media were tried for culturing Lemna minor, regular peat moss and a freshwater plant nutrient mix "Yamato Green". Thirty mg of Peat Moss was put into a crucible, and autoclaved. After this it was aseptically transferred into 
aquaria full of natural spring water. Once most of the moss has settled to the bottom, which would take 24 hours, 50 Lemna minor plants were aseptically transferred to each aquarium. Every four to five weeks, Lemna minor were transferred to a new aquarium with fresh medium. This medium resulted in greater success than Hoagland's for maintaining cultures. However, it was assumed that because peat moss is not always uniform in texture and composition, nutrient concentration would vary from batch to batch. Further, for the culturing of, and experiments with, Lemna minor the doubling time of the plant has to be 2.5 days or less (Environment Canada, 2007). While growth was better in this peat moss medium, the doubling time of $\geq 2.5$ days was rarely realized.

Another method of culturing Lemna minor was by using a freshwater plant nutrient mix c "Yamato Green" (Yamato Green Products Aquarium Supply), typically used for fresh water aquarium plants. It is recommended on the label of the bottle to provide a $2 \mathrm{~mL}$ of this nutrient to every litre of culturing water every week. The addition of $14 \mathrm{~mL}$ of "Yamato Green" was added aseptically to the two culturing aquaria. Culturing of Lemna minor using this source of nutrients was also partially successful, however the replication time was not 2.5 days or less and plants commonly turned yellow after 3 to 5 weeks.

The healthiest Lemna minor cultures grew in the "mixed cultures tank" where Daphnia magna, some snails and Hyalella azteca co-existed in the same aquarium. This aquarium consistently had healthy Lemna minor, with appropriate doubling times, long roots and green leaves. While it is recognized that pure cultures are appropriate for ecotoxicity experiments, the need for healthy, growing plants necessitated use of mixed cultures for maintaining Lemna. 


\subsubsection{Glassware washing procedures}

In order to make sure that all the traces of chemicals were removed prior to culturing and experimental use, all the glassware, aquaria and falcon tubes were washed using the standard procedures from Environment Canada (1996). This included washing all glassware with acetone three times, then rinsing with tap water. After this the glassware was soaked in Extran soap solution for fifteen minutes, and then scrubbed. The soap was then rinsed with tap water and washed in $10 \% \mathrm{v} / \mathrm{v}$ hydrochloric acid. After this, the glassware was rinsed with distilled water and inverted to dry on paper towels. It was also stored inverted in the glassware cupboards prior to use.

\subsection{Respiration Bioassays}

The effect of different dilutions of run-off from biosolids-amended soil on respiration rates of Daphnia magna and Hyalella azteca were tested for both Guelph and Kitchener biosolids, surface run-off and tile drainage on Day 1, and on Day 40 (planted and unplanted soil). Bioassay vessels used in these experiments were $3.5 \mathrm{~mL}$ vials with conical lids which displaced water when closing (ensuring no headspace) and prevented gas exchange with the surrounding environment. Lids were polypropylene and the rate at which oxygen could diffuse through the lid was negligible relative to oxygen consumption rates by respiration. The run-off dilution series had been centrifuged (as above), decanted into a cleaned Ehrlenmeyer flask, bubbled to ensure initial oxygen concentration was near $100 \%$ saturation, and added to the test vials. During the experiment with Daphnia magna, five 5-day old daphnids were put into each vial containing run- 
off. During the experiments with Hyalella azteca, two random adult non-pregnant amphipods were put into each $3.5 \mathrm{~mL}$ vial with run-off. In each experiment, a control of natural spring water with no organisms was used to provide a baseline for normal respiration behavior. Bioassays were performed using six replicates for each treatment, including the control. During incubation, positions of all the vials were randomized to ensure control for variation such as temperature or other abiotic conditions that may be present in the area of testing. Also the vials were all covered with a cardboard box to prevent light from coming into the vials. This was done because the culturing tanks had a small amount of algae that could be transferred with the organisms to the vials and produce oxygen, confounding oxygen consumption results.

Dissolved oxygen content in the vials was recorded by a Clark-type oxygen microelectrode and picoammeter (Unisense, Denmark). This electrode had a membrane diameter of $25 \mu \mathrm{m}$ and could measure dissolved oxygen concentrations with high precision while minimizing oxygen consumption by the electrode. The electrode was calibrated using water at $100 \%$ oxygen saturation and $0 \%$ saturation (tap water bubbled with air and with $\mathrm{N}_{2}$ ).

Picoammeter readings from each vial were recorded at $0 \mathrm{~min}, 30 \mathrm{~min}, 60 \mathrm{~min}$ and $90 \mathrm{~min}$. Oxygen consumption was determined to be linear over this time interval in preliminary studies. The respiration rates for each replicate vial were found by determining the slope of oxygen concentration versus time. Respiration rates were compared among treatments using a One-Way ANOVA and Two-Way ANOVA (comparison between surface run-off and tile drainage, with post-hoc Tukey's HSD test for pairwise comparisons among treatments. All statistical analyses were performed using Systat version 11 (Systat Software, Inc., Chicago, IL). 


\subsection{Behavour Bioassays}

\subsubsection{Daphnia magna Motility Behaviour Bioassays}

Swimming behaviour bioassays using Daphnia magna exposed to varying concentrations of biosolids run-off were performed by visual observations. Fifty milliliter Falcon tubes were used as test chambers. Dilution series were made (1\%, 10\% and 100\% for Guelph biosolids and $0.5 \%, 1 \%, 5 \%, 10 \%$, and $100 \%$ for Kitchener biosolids) using run-off from reference soil as a diluent. Following the creation of dilution series, water for bioassays was centrifuged for 10 minutes at $3000 \mathrm{rpm}$. This was done because, in preliminary experiments, the clay from run-off was being ingested by Daphnia magna and they became immobile on the bottom of the Falcon tubes.

After centrifugation, Falcon tubes were let sit for one hour, uncapped to let any exchange of gasses to happen. Five 24-hour old neonates were placed into each Falcon tube and observed at times $0,2 \mathrm{hrs}, 4 \mathrm{hrs}, 6 \mathrm{hrs}$ and next day at $24 \mathrm{hrs}$. At each time, visual observations of each Daphnia magna were made for a duration of 1 minute. The behavioural endpoints observed were: swimming height, swimming style and immobility. The behavioural patterns which were observed were based on past bioassays conducted by Gill Marshall (2009). Marshall based her behavioural patterns on bioassays conducted by Dodson and Hanazato (1995), Schmidt et al. (2005), and Szulkin et al. (2006). The three most useful behavioural endpoints identified by Marshall for indicating stress were swimming heights, swimming style and immobility. The differences in these three behaviours were easy to observe visually, and clear distinction could be made between stressed and unstressed individuals, which are important because the observations could be done objectively. 
Swimming height of Daphnia magna is a good indicator of their behaviour because under normal reference conditions the daphnids swim throughout the water column to graze and filterfeed on algae and other patches of food. They are also able to swim rapidly up or down in the water column in order to avoid a predator such as a fish. During the observations, if daphnids were swimming above the first four centimeters from the bottom of the Falcon tubes, they were considered to be able to swim through the water column. If they could not swim above the first four centimeters from the bottom, the daphnid was considered not to be able to swim through the water column.

Swimming style is a second important indicator of healthy behaviour in Daphnia magna. Daphnia magna under normal reference conditions have a very distinct saltatory swimming pattern. They move smoothly through the water, with their bodies upright. However, once the organisms are under stress they quickly start exhibiting other types of swimming style that are easily discerned. For example, they may start spinning rapidly, or swimming may become excessively jerky and they may exhibit looping behaviours. Any of these behaviours were considered as Daphnia magna not showing normal swimming style.

Immobility is another important indicator of behaviour in Daphnia magna. In order to live the organism has to move, find food, stay away from predators and reproduce. Once Daphnia magna cannot swim, and lie immobile on the bottom, they become vulnerable. Immobility is not an adaptive behaviour for Daphnia magna, and can indicate serious physical or chemical stress. Immobile daphnids may still have a visible heart beat or small movement of antennae and are usually lying on their side or inverted. 


\subsubsection{Statistical Analysis of Daphnia magna behaviour}

Changes in individual behaviours over time were evaluated by determining the percent of the organisms which displayed altered behaviour in each replicate. At each time interval, a nonparametric Kruskal-Wallis test was then performed to determine if the different treatments had an effect on the individual movement parameters. Where there was a significant treatment effect, Mann-Whitney U-tests were used for post-hoc paired comparisons of each treatment against reference. All statistical analyses were performed using Systat version 11 (Systat Software, Inc., Chicago, IL).

\subsubsection{Daphnia magna $24 \mathrm{hr}$ and 7 day Survivorship and Immobility}

The next day at $24 \mathrm{hr}$ observation, daphnids were also examined for mortality and immobility. This was indicated as survivorship after $24 \mathrm{hrs}$. These daphnids were then fed with Roti-Rich, 1 drop per falcon tube 2 times a week and left besides the culturing tanks. After 7 days daphnids were again examined for mortality and immobility and this was indicated as 7-day survivorship.

\subsubsection{Hyalella azteca Motility Behaviour Bioassasys}

The procedure that was used for behavioural bioassays with Daphnia magna, where the run-off was centrifuged did not work for Hyalella azteca because they burrowed and became immobilized in the clay very quickly. Because of this, the run-off was centrifuged at $3000 \mathrm{rpm}$ 
for $10 \mathrm{~min}$ and supernatant was decanted into clean $50 \mathrm{~mL}$ beakers. A piece of sterile cotton gauze $\left(4 \mathrm{~cm}^{2}\right)$ was laid on the bottom of the beakers. The gauze prior to use was soaked for 24 hours in natural spring water. Five adult, non pregnant, Hyalella azteca were placed into each beaker. Visual observations were recorded at times $0,2 \mathrm{hrs}, 4 \mathrm{hrs}, 6 \mathrm{hrs}$ and $24 \mathrm{hrs}$. The observations were made by watching each Hyalella azteca for one minute. The behaviours observed and recorded were substrate crawling, body length and immobility. These behaviours were selected based on work by Gill Marshall (2009) which identified these as the three behavioural responses most useful (sensitive and easy to discern) for identifying chemical stress in Hyalella azteca. Marshall based her behavioural patterns on bioassays conducted by Hatch and Burton (1999) and Wang et al., (2004).

Substrate crawling is an important behaviour because under normal reference conditions Hyalella azteca spends a majority of time crawling on the surface of the substrate, foraging, looking for patches of organic debris and other food sources (Wang et al., 2004). Once the organism is under stress, it stops crawling on the substrate therefore it is a sensitive parameter to sub-lethal stress.

Under normal reference conditions Hyalella azteca has an elongated, though slightly curved, body. It crawls on the substrate and swims with its body elongated. Shortening of the body, caused by curling that minimizes exposure of the ventral surface, has been observed as a common sub-lethal stress response (Wang et al., 2004). It is an easily visible and sensitive parameter. 
All motile organisms have to move in order to find food, stay away from predators and reproduce. Immobility is an indicator of stress to the organism. Just like in Daphnia magna, immobility is a useful and easily discerned parameter to test for stress.

\subsubsection{Statistical Analysis of Hyalella azteca behaviour}

Changes in individual behaviours over time were evaluated by determining the percent of the organisms which displayed altered behaviour in each replicate. A non-parametric KruskalWallis test was then performed to determine if the different treatments had an effect on the individual movement parameters when compared to reference treatments over the 24-hour experimental period. Where there was a significant treatment effect, Mann-Whitney U-tests were used for post-hoc paired comparisons of each treatment against reference. All statistical analyses were performed using Systat version 11 (Systat Software, Inc., Chicago, IL).

\subsection{Lemna minor Growth Inhibition Tests}

The test performed on Lemna minor was a 7-day growth inhibition test that was developed by Environment Canada (2007). Ten, 3-fronded Lemna minor plants were aseptically placed into each of six $40 \mathrm{~mL}$ sterile, acid-washed beakers for each run-off test concentration. Beakers were placed under a light bank and grown for one week under the same light intensity and photoperiod used for culturing. Placement of the beakers under the light bank were randomized to control for temperature, light and other abiotic gradients that might be present in the testing area. After a week, the plants were carefully taken out of the beakers and transferred into clean ceramic crucibles. The plants were dried at $60^{\circ} \mathrm{C}$ for $12 \mathrm{hrs}$ and their mass was 
measured. The masses were compared among treatments using a One-Way ANOVA, with a post-hoc Tukey's HSD test for pair-wise comparisons among treatments (Systat version 11, Systat Software, Inc, Chicago, IL).

A schematic diagram that summarized the experimental methods, design and the sequence of the bioassays is shown in figure 1 below.

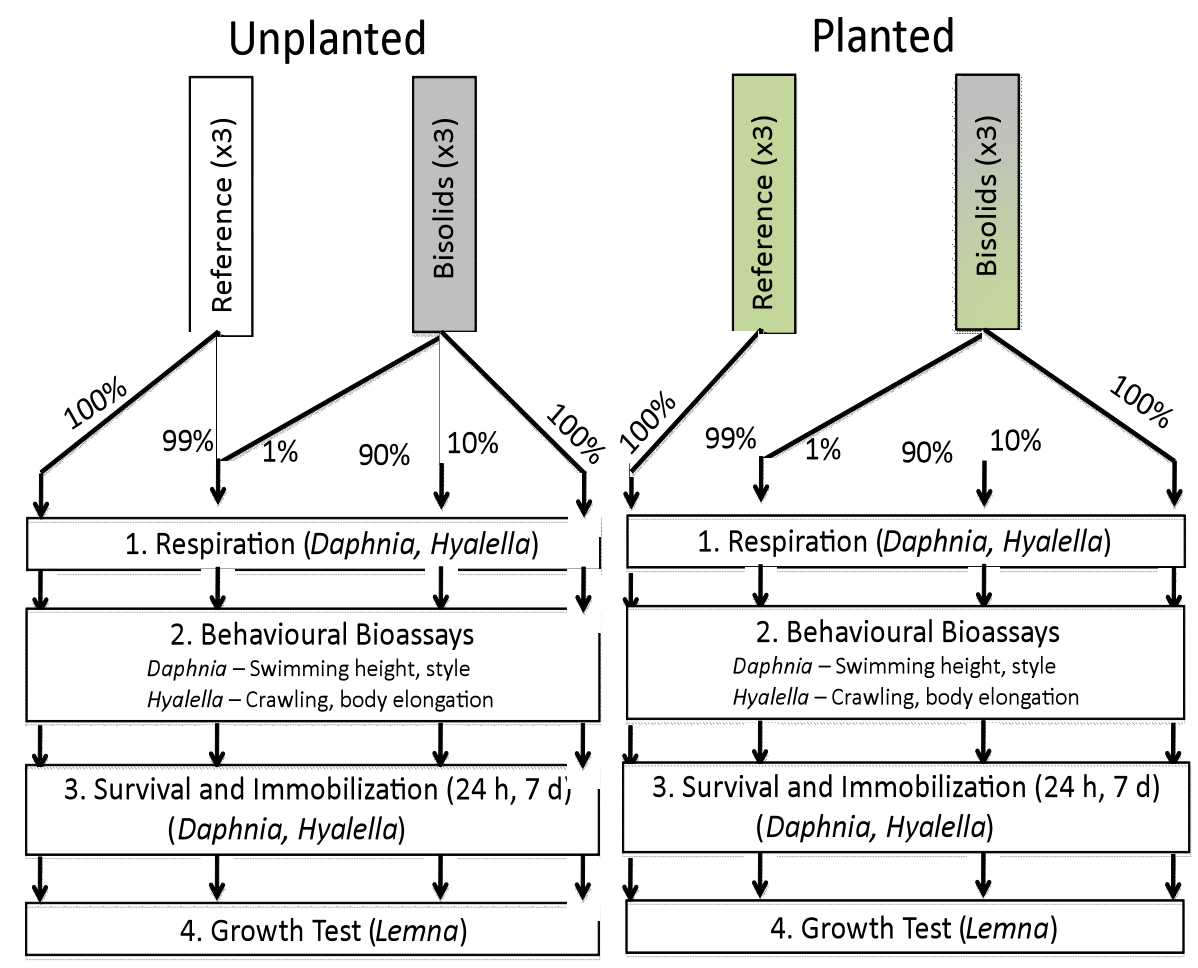

Figure 1: Schematic diagram of experimental methods and sequence of bioassays. 


\subsection{Results and Discussion}

\subsection{Respiratory Responses of Macroinvertebrates}

\subsubsection{Daphnia magna Respiration in Guelph Biosolids Elutriate}

On Day 1, there was a significant overall difference in respiration rates between $100 \%$ biosolids surface run-off and the rest of the biosolids treatments (Figure 2a, $\mathrm{p}=0.0424$ ), and also there was a significant difference between the respiration rates in the surface run-off and the tile drainage $(p<0.001)$. This result is indicating a few things. First, the significant difference between $100 \%$ surface run-off and the rest of the treatments is showing that there is enough toxicity in the $100 \%$ biosolids elutriate on day 1 to decrease overall respiration in Daphnia magna in the first hour and a half that they are in the elutriate. This is an important fact because biosolids elutriate was shown to have an immediate effect on the respiration rates of Daphnia magna, however at this concentration the effect is not environmentally relevant. It is highly unlikely that the concentrations of biosolids run-off are to exceed $1 \%$ in real life scenario in a natural receiving body of water. The concentrations that the biosolids are most likely going to be found in South Ontario are between $0.1 \%$ and $1 \%$. The concentrations might increase more than one percent in cases of small, stagnant ponds very near the agricultural fields receiving biosolids application.

It is important to notice that Figure $2 \mathrm{a}$ is showing the worst possible case scenario that can happen. The run-off and drainage were collected a day after the biosolids were applied at the highest allowable rate to the highest allowable slope, with rainfall simulating the rain storm that happens with an average frequency of once every hundred years in Southern Ontario. Given these conditions, the only results that had a significant difference from the reference were the 
$100 \%$ run-off and $100 \%$ tile drainage with no effect on respiration of Daphnia magna at concentrations of $10 \%$ or less.

The second point that came from these results is the consistent pattern of respiratory inhibition at $100 \%$ biosolids in surface run-off and tile drainage. This suggests that whatever is causing toxic effect is able to penetrate through the soil to the tiles and that the toxicity is high enough to decrease the overall metabolism of the organism. Since the biosolids are a soup of chemicals and possible toxicants it is most likely not just one chemical. However, considering that the effect is very immediate $(1.5 \mathrm{hrs})$, and the decrease in respiration is seen both in surface $100 \%$ run-off as well as tile $100 \%$ run-off, whatever is affecting the respiration is unlikely hydrophobic (i.e. does not partition to organic matter in sediment, ameliorating toxicity in tile drainage) and acts immediately as a toxicant. It is possible that large amount of ammonia $\left(\mathrm{NH}_{4}\right)$, and possibly some chlorine in the elutriate is affecting the Daphnia magna and decreasing its overall metabolism and respiration rates. The reason why it is possible to be high amounts or ammonium and chloride is those are found in large amounts in sewage and biosolids large amounts of ammonia are typically found in sewage sludge and biosolids (Fjallborg and Dave 2009, Mendoza et al, 2006).

Fjallborg and Dave (2003), while assessing the toxicity of antimony and copper from sewage sludge on Daphnia magna and Lemna minor, found that when the sludge-earth mix was not cultivated by plants, elutriate had enough ammonia that it significantly reduced overall metabolism and mobility of Daphnia magna. Only 10-20\% of Daphnia magna were mobile after 48 hours in the sewage sludge elutriate due to ammonia levels being between $50 \mathrm{mg} / \mathrm{L}$ and 300mg/L (Fjallborg and Dave, 2003). This is a logical and probable explanation in a significant decrease in respiration rates in Daphnia magna but not confirmed as no nutrient analysis was 
performed at this experimental stage. If it was ammonium impacting the respiration of a Daphnia magna it is important to understand that although the experiments were trying to replicate what happens in nature, the experiments were still performed in vitro and the containers used for respiration only contained the elutriate. In nature, ammonium gets "taken up" by plants or oxidized through the usual nitrogen cycle. Therefore, if the effect that is seen on respiration (and only at $100 \%$ elutriate) comes from a large amount of ammonium, the effect would not be seen to this extent in nature.

Chloride is also typically very concentrated in sewage sludge, is hydrophilic and would penetrate to the tiles, and also has immediate toxicity on metabolism (Terasaki et al, 2008). Significant amounts of chloride and chlorinated by-products can be present in sewage sludge. After processing, chloride and chlorinated residues could be as high as 0.1 to $0.3 \%$ of dry sewage sludge (Khan et al, 1987). This is not a surprise considering how many chlorinated products are being used today for all kinds of purposes. For example, disinfection of water, from pesticides, pharmaceuticals and personal care products (dish soaps, halogenated parabens ) and many other products that are chlorinated (Terasaki et al, 2008). Acute toxicity of chlorine in Daphnia magna would decrease respiration rates within 15 minutes, cause immobility and is lethal at doses between 2 and $62 \mathrm{mg} / \mathrm{L}$ depending on the form of chloride (Terasaki et al, 2008). The suggestion that chloride and ammonium have an effect on respiration rates in Daphnia magna in day one $100 \%$ surface and tile biosolids is based only on the literature review and most probable causes; it is not supported by actual chemical analysis.

Respiration rates in various invertebrates have been measured traditionally as a response to toxicity levels in eco-toxicology. Examples are experiments done by Geiger and Buikema (1981) who have concluded that respiration rates in Daphnia magna are a good indicator of 
overall metabolism of an organism, and that this response is a very sensitive response to chemical exposure. Theoretically when there is a low or moderate level of a toxicant present, there may be an increase in respiration because the organism is trying to metabolize the toxicant. This is an example of a hormetic effect. Hormesis was first described by Hugo Schultz in 1888, who demonstrated that low concentrations of toxicants could stimulate growth of yeasts at low concentrations, while inhibiting growth at higher concentrations. While there is debate about the importance of hormetic dose-response relationships (e.g. Calabrese, 2005; Axelrod et al., 2004), Calabrese (2005) has demonstrated by examination of toxicology literature that the phenomenon is widespread across many organisms and many behavioural and physiological endpoints, and Calabrese made a strong case that hormetic effects are likely the norm for dose/concentration response relationships. Kefford et al (2008), while acknowledging hormetic effects are likely typical in eco-toxicology, argue against their inclusion in Ecological Risk Assessment and derived Water Quality Guidelines, primarily because data are limited (i.e. studies often do not include the low concentrations eliciting hormetic responses) and because extrapolation from dose-response models requires many assumptions about behaviour of natural populations. Similarly, hormetic responses reported in this thesis should not be taken to suggest beneficial effects of biosolids run-off in a Risk Assessment framework (i.e. a small amount of biosolids run-off is good for Daphnia magna), but rather to indicate no evidence of impairment.

Overall, at Day 40 in elutriate collected from unplanted troughs (Figure 2b), there was no significant difference between among treatments $(\mathrm{p}=0.069)$. However, within the tile drainage replicates, there was a significant difference in respiration between $10 \%$ tile drainage and $100 \%$ tile drainage. This appeared to arise from a small (but not statistically significant) increase in respiration at $10 \%$ biosolids, relative to reference, combined with a decrease (again, not 
statistically significant) in respiration at $100 \%$ relative to reference. The increase in respiration rate in $10 \%$ tile biosolids drainage suggests a hormetic effect which is described above. These results are indicating that although the overall toxicity has significantly decreased after the biosolids have been there for 40 days, there are still significant variations among the treatments and some residual toxicity may contribute to the pattern of lower respiration (though not statistically significant) at $100 \%$ biosolids in both the run-off and tile drainage.

In elutriate collected on Day 40 from planted troughs (Figure 2c), there was no significant difference among the treatments $(\mathrm{p}=0.091)$ or between surface run-off and tile drainage $(p=0.699)$. These results suggest that when troughs are planted not only does toxicity of elutriate decrease, but the variation among different biosolids concentrations decreases. Plants may prevent toxicants from penetrating through the soil by immobilizing them and may reduce surface erosion of soil containing toxicants (Fjallborg and Dave, 2003). This study that tested the difference in toxicity between the elutriate from planted and unplanted buckets found that there was insignificant toxicity observed in Lemna minor plants and Daphnia magna organisms in elutriate from planted buckets, where there was significant toxicity observed in the plant and the organism in elutriate from unplanted buckets. This is suggesting the important role of plants in limiting transport of materials into receiving water, which is recognized and codified by legislation regulating biosolids application in Ontario. In Ontario, depending on the soil type and permeability the biosolids can be applied 50- 200 meters from the watercourses (Nutrient Management Act, Ontario Regulation 267/03). Also in 44(1) part of the Nutrient Management Act, it is written that "No person shall apply nutrients to a field that contains or is adjacent to surface water unless there is a vegetated buffer zone in the field that is adjacent to the surface 
water and that lies between the surface water and where the nutrients are applied". This means that the Ontario watersheds where biosolids are applied should be properly protected. 


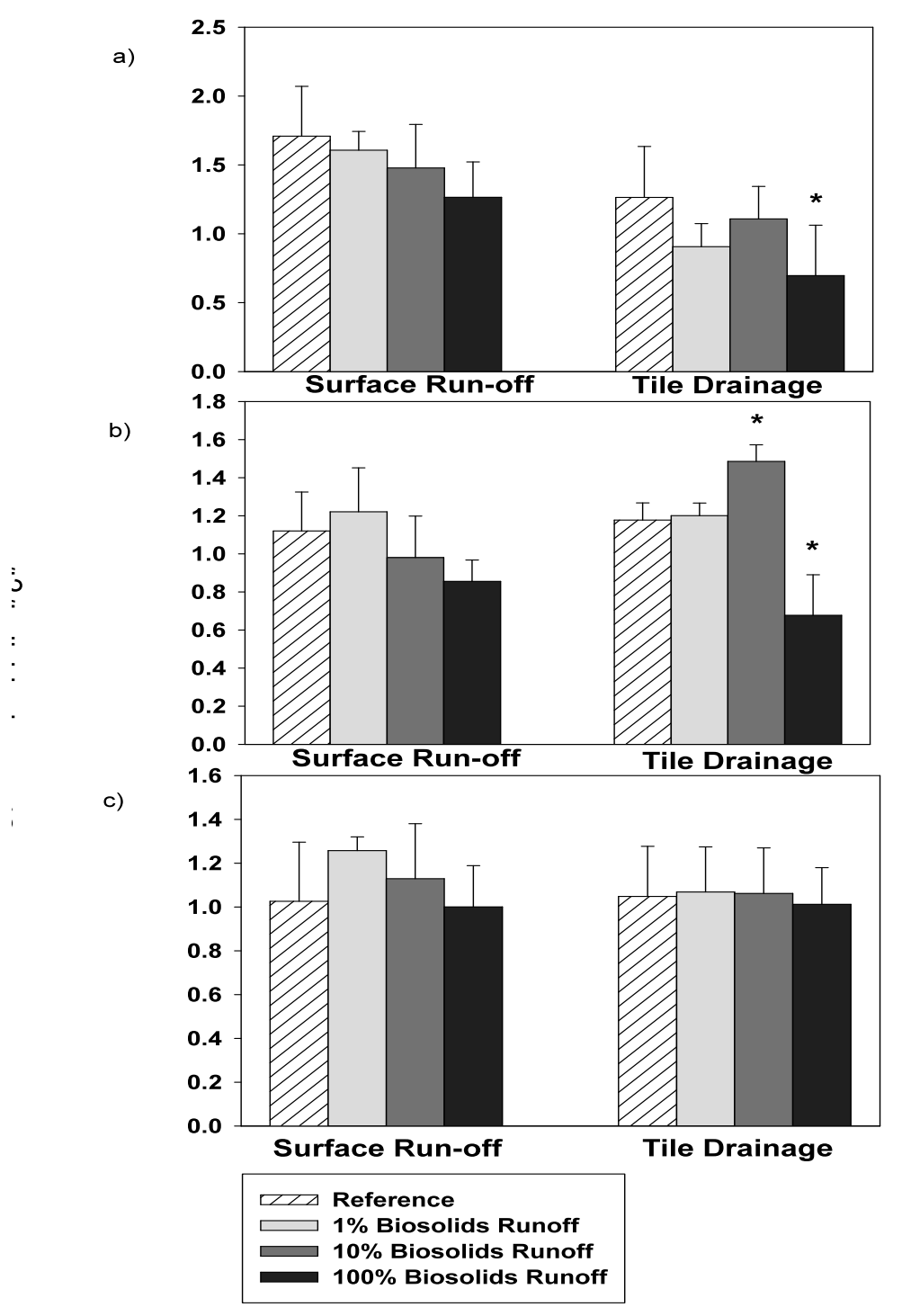

Figure 2. Respiration Rates of Daphnia magna exposed to varying dilutions of surface run-off and tile drainage from soil with Guelph biosolids application a)Day 1, all troughs, b)Day 40 unplanted troughs, c)Day 40 planted troughs. Exposure was over hour and a half period, respiration expressed in nanomoles of oxygen consumed per hour per individual. Values are mean \pm standard deviation. Significant differences $(p \leq 0.05)$ relative to reference denoted by $*$. 


\subsubsection{Hyalella azteca Respiration in Guelph Biosolids Elutriate}

The effects of biosolids elutriate on respiration rates in Hyallela azteca were similar to those for Daphnia magna. At day 1, when any toxic effects of biosolids would be expected to be highest, the respiration rate decreased at a 100\% biosolids run-off and tile drainage (Figure $3 \mathrm{a}, \mathrm{p}$ $=0.002$ ). The reasons for this effect on Hyalella azteca respiration (i.e. the probable toxicants that explain the effect) are probably the same as for Daphnia magna explained above. Similarly, the environmental relevance of the results is the same as for Daphnia magna; the run-off and tile drainage collected on day 1 is the worst case scenario based on loading, field slope, and rainfall intensity that could be expected in the environment, and even then, the effect is seen only in the concentrations that are not environmentally relevant (100\% biosolids elutriate). Forty days after biosolids application to unplanted soil, there was again a significant difference among biosolids run-off treatments $(\mathrm{p}=0.001)$ driven by differences between reference and $100 \%$ biosolids elutriate (Figure 3b). Respiration in treatments receiving $100 \%$ biosolids run-off and tile drainage was significantly increased, in contrast to results for Hyalella azteca on day 1 and for Daphnia magna on day 1 and day 40. It is difficult to suggest what might cause the stimulation in Hyalella azteca respiration at day 40 since excess of nutrients are expected to get washed away with the first "rain storm" (Draggan, 2009). Toxicants causing the respiratory inhibition observed on day 1 at $100 \%$ biosolids elutriate might be degraded, transformed, or washed away by day 40, unmasking a stimulatory effect on respiration due to increased organic carbon subsidy for $100 \%$ biosolids. The important conclusion from these results are that run-off and tile drainage from soil with biosolids application caused no impairment of respiration, at any concentration, by day 40. Any potential stimulatory or hormetic effect is not environmentally relevant, as the concentration that resulted in stimulation will unlikely occur in an agricultural ecosystem. 
Forty days after application of biosolids to planted soil, there was a significant effect of biosolids elutriate concentration $(\mathrm{p}=0.0402)$ caused by the $100 \%$ biosolids surface run-off. Again, respiration rates of Hyalella azteca were significantly increased compared to the reference (Figure 3c). Generally, respiration rates among treatments were more similar using run-off and tile drainage collected from planted versus unplanted troughs on day 40 . The plants may moderate release of biosolids constituents due to uptake, transformation, or reduced soil erosion, reducing any impacts of run-off and tile drainage on respiration of Hyalella azteca, as was also suggested by Daphnia magna results. It is also worth noticing that although the elutriate is exactly the same, Daphnia magna showed no significant difference in the elutriate from planted troughs collected on day 40 . This might suggest that Hyalella azteca is stimulated by the run-off and drainage. This is suggested because it appears that they are released from the toxic impact due to weathering from the biosolids, and therefore they can actually better exploit the organic carbon subsidy coming from the biosolids more effectively than can Daphnia magna. 
a)

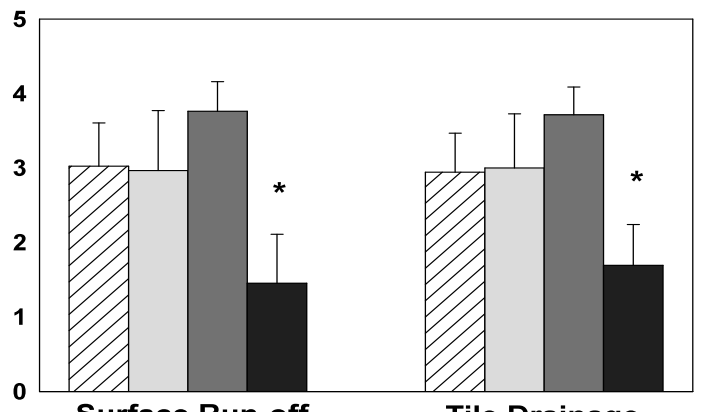

b)

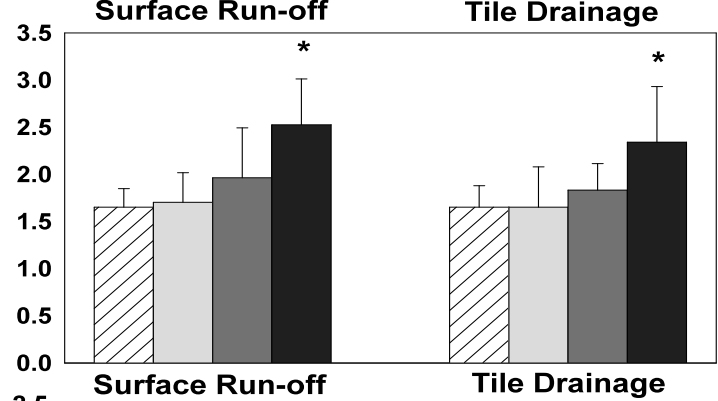

c)

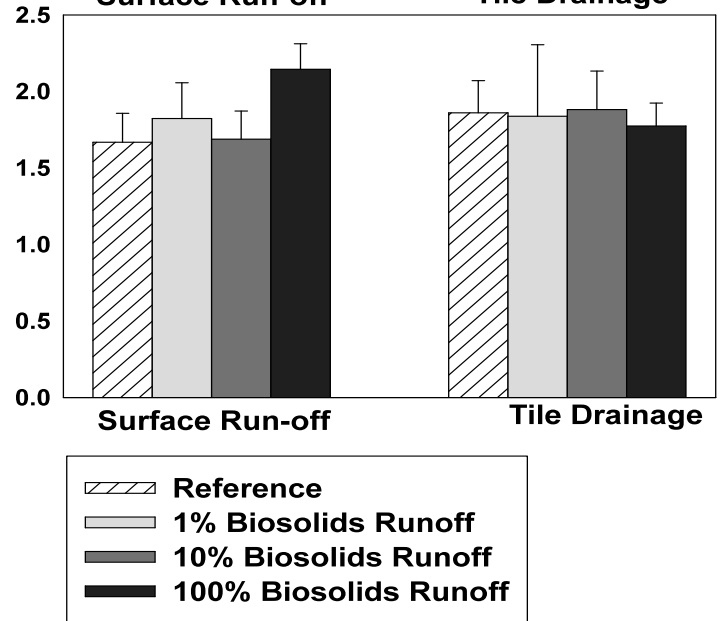

Figure 3. Respiration rates of Hyalella azteca exposed to varying dilutions of surface run-off and tile drainage from soil with Guelph biosolids application a)Day 1, all troughs, b)Day 40 unplanted troughs, c)Day 40 planted troughs. Exposure was over hour and a half period, respiration expressed in nanomoles of oxygen consumed per hour per individual. Values are mean \pm standard deviation. Significant differences $(\mathrm{p} \leq 0.05)$ relative to reference denoted by $*$. 


\subsubsection{Daphnia magna Respiration in Kitchener Biosolids Elutriate}

Respiration rates in Daphnia magna during the experiments with Kitchener biosolids runoff was measured the same way as during Guelph biosolids elutriate experiments. The two new concentrations were added in order to make the study more environmentally relevant as concentrations larger than $10 \%$ biosolids elutriate are highly unlikely to be found in the environment.

On day 1 following application of biosolids, there was a significant difference in respiration rates between the blank (mineral water reference) and other treatments (Figure $4 \mathrm{a}, \mathrm{p}=$ 0.001), but no differences among the remaining treatments (reference and biosolids elutriates), and there was no significant difference between surface run-off and tile drainage $(p=0.240)$. Respiration rates of Daphnia magna vary considerably depending on their age and the environmental conditions of their water. Because of this it is difficult to find a good standard for their respiration, however overall respiration rates in run-off water or tile drainage (any treatment and percentage of biosolids elutriate) were slightly higher than those measured in mineral water here (blanks) or in previous studies (Marshall, 2009, Martins et al, 2007b). This difference in respiration between the blank and the reference could be explained by the fact that when the first elutriate is collected (both for Guelph and Kitchener set of experiments) it was noticed that large amounts of clay and particulate matter in general, were washed off the troughs, especially from the surface. Although the samples were centrifuged (to prevent Daphnia magna from ingesting a lot of clay and just settling on the bottom), clay and other particles were still seen under the microscope and were in the water column of the supernatant. Because organic and inorganic matter is adsorbed to the clay particles, it can act as a food source for Daphnia magna which are 
filter feeders. Comparing to reference (run-off or tile drainage from soil) with the blank (mineral water), Daphnia magna in reference water may be filtering the water more, and expending energy to digest clay particles, therefore increasing their respiration rates. Further, when comparing day 1 with day 40 from unplanted (Figure $4 \mathrm{~b}$ ) and planted troughs (Figure 4c), it can be noted that the overall respiration (from all treatments) in elutriate collected on day 1 (1.702 nanomoles $\mathrm{O}_{2} / \mathrm{hr} /$ Individual) is higher than respiration from unplanted troughs on day 40 (1.138 nanomoles $\left.\mathrm{O}_{2} / \mathrm{hr} / \mathrm{Individual}\right)$ and planted troughs on day 40 (1.127 nanomoles $\left.\mathrm{O}_{2} / \mathrm{hr} / \mathrm{Individual}\right)$. Although it was expected that the largest difference in the amount of particulate matter, in particular clay, will be clearly evident between the planted and unplanted troughs due to plants' role in preventing soil erosion, it was clear when elutriate was collected, that the largest amount of particulate matter and clay washes off from newly constituted Environment Canada artificial soil then from older soil that has been rinsed by more "rainfall" events.

There were no significant differences in respiration rates among any of the treatments in unplanted soil on day 40 (Figure $4 \mathrm{~b}, \mathrm{p}=0.195$ ), and there is no significant difference between surface run-off and tile drainage $(p=0.782)$. Similarly, in planted soil elutriate (Figure $4 c)$, there were no significant differences among treatments $(\mathrm{p}=0.394)$ or between surface run-off and tile drainage $(\mathrm{p}=0.278)$. These results indicating that Kitchener biosolids elutriate had no positive or negative impact on the respiration rates of Daphnia magna, even under a worst-case scenario. 


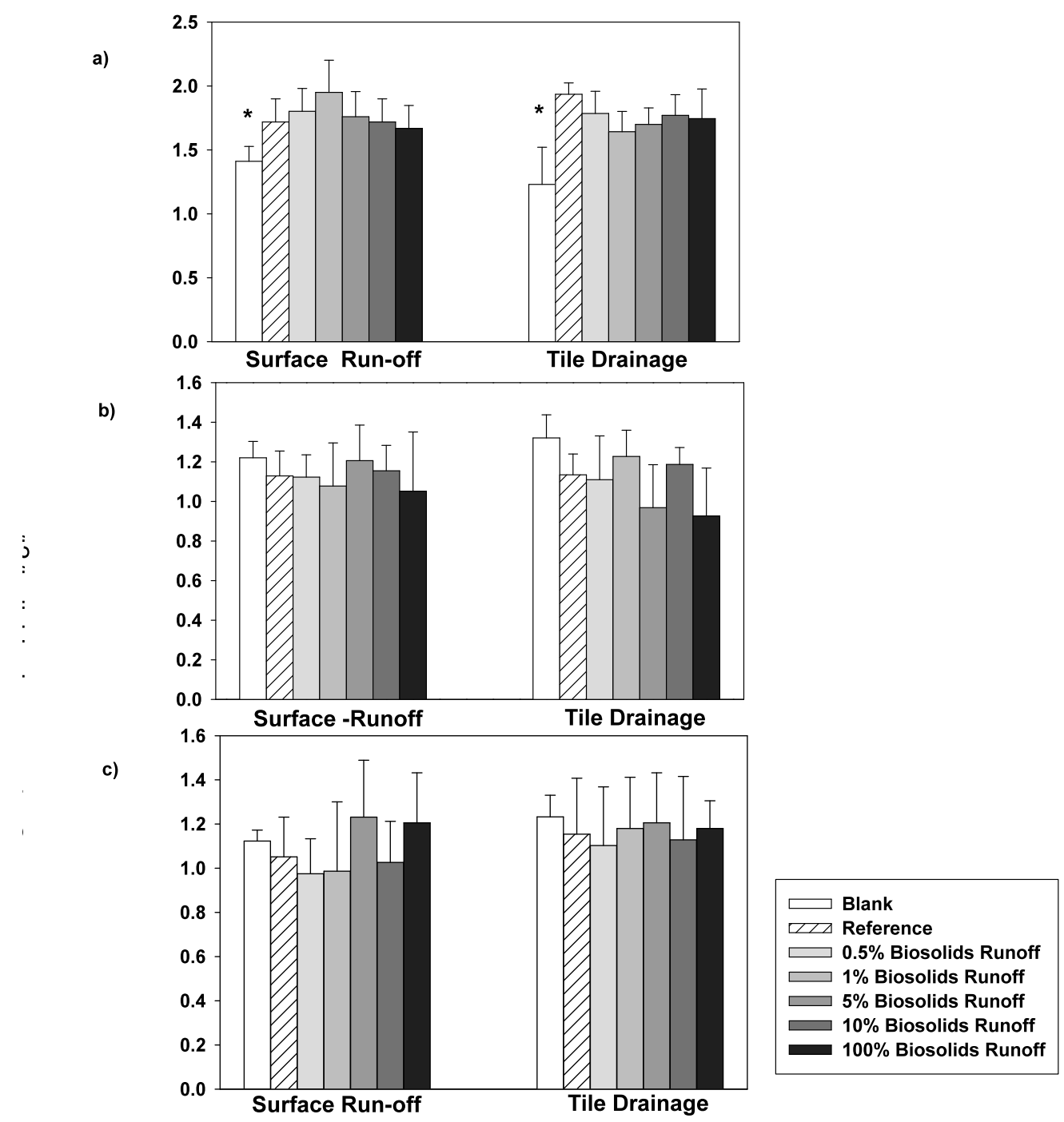

Figure 4. Respiration Rates of Daphnia magna exposed to varying dilutions of surface run-off and tile drainage from soil with Kitchener biosolids application a)Day 1, all troughs, b)Day 40 unplanted troughs, c)Day 40 planted troughs. Exposure was over hour and a half period, respiration expressed in nanomoles of oxygen consumed per hour per individual. Values are mean \pm standard deviation. Significant differences $(\mathrm{p} \leq 0.05)$ relative to reference denoted by $*$. 


\subsubsection{Hyalella azteca Respiration in Kitchener Biosolids Elutriate}

As was observed in Daphnia magna experiments, respiration rates of Hyalella azteca were significantly different in mineral water blanks than in the rest of the treatments receiving run-off or tile drainage (Figure $5 \mathrm{a}, \mathrm{p}=0.003$ ). However, there were no significant differences between reference soil elutriate and elutriate from soil with biosolids applied. There was also no significant difference in respirations rates comparing surface run-off and tile drainage $(\mathrm{p}=$ 0.573). Just like in Daphnia magna, Hyalella azteca's respiration rates are higher in the elutriate than the reported values in mineral water for the invertebrate (Brunec-Turk, 1998). Hyalella azteca is an invertebrate that is also a filter feeder that eats whatever organic matter could be found in the debris in the sediments. For this reason, although the samples of elutriate are centrifuged, they still contained clay and particulate matter that is adsorbed to the clay. Clay grain is so fine that most of them do settle on the bottom once centrifuged. However they do not settle completely and there is still a significant portion of it in the water column. Therefore the increase in respiration rates in day 1 could be attributed to Hyalella azteca having more to feed on than in the blank which is mineral water, therefore increasing overall respiration rates. Also, the average respiration rates in Hyalella azteca in elutriate collected on day 1 (2.803 nanomolesO $\mathrm{O}_{2} / \mathrm{hr} /$ Individual ) is higher than the average respiration rate in elutriate collected from unplanted troughs on day 40 (2.027 nanomoles $\left.\mathrm{O}_{2} / \mathrm{hr} / \mathrm{Individual}\right)$, which is higher than the same in the elutriate collected of the planted troughs on day 40 (1.928 nanomoles $\mathrm{O}_{2} / \mathrm{hr} /$ Individual). Again, the change from day 1 to day 40 may be explained by the fact that there is more clay and other particulate matter washing off the troughs on day 1 than on day 40 when newly constituted soil has been more thoroughly washed. Therefore, the subsidy of particulate matter, and possibly the ingestion rate, decreased from day 1 to day 40 . 
By day 40 , respiration showed no significant difference among treatments (including mineral water blanks) (Figure $5 \mathrm{~b}, \mathrm{p}=0.551$ ) for unplanted soil. There was also no significant difference in respiration rates between surface run-off and tile drainage $(p=0.566)$. Similarly, for planted soil (Figure 5c), respiration of Hyalella azteca in soil elutriates showed no significant difference among any of the treatments $(\mathrm{p}=0.927)$, and no significant difference in respiration rates between surface run-off and tile drainage $(\mathrm{p}=0.667)$. These results indicate that run-off or tile drainage from soil with Kitchener biosolids application might not effect on the respiration rates of Hyalella azteca in adjacent receiving waters, even under conditions of an extreme rainfall event 24 hours after application, and on maximum allowable slope. 
a)

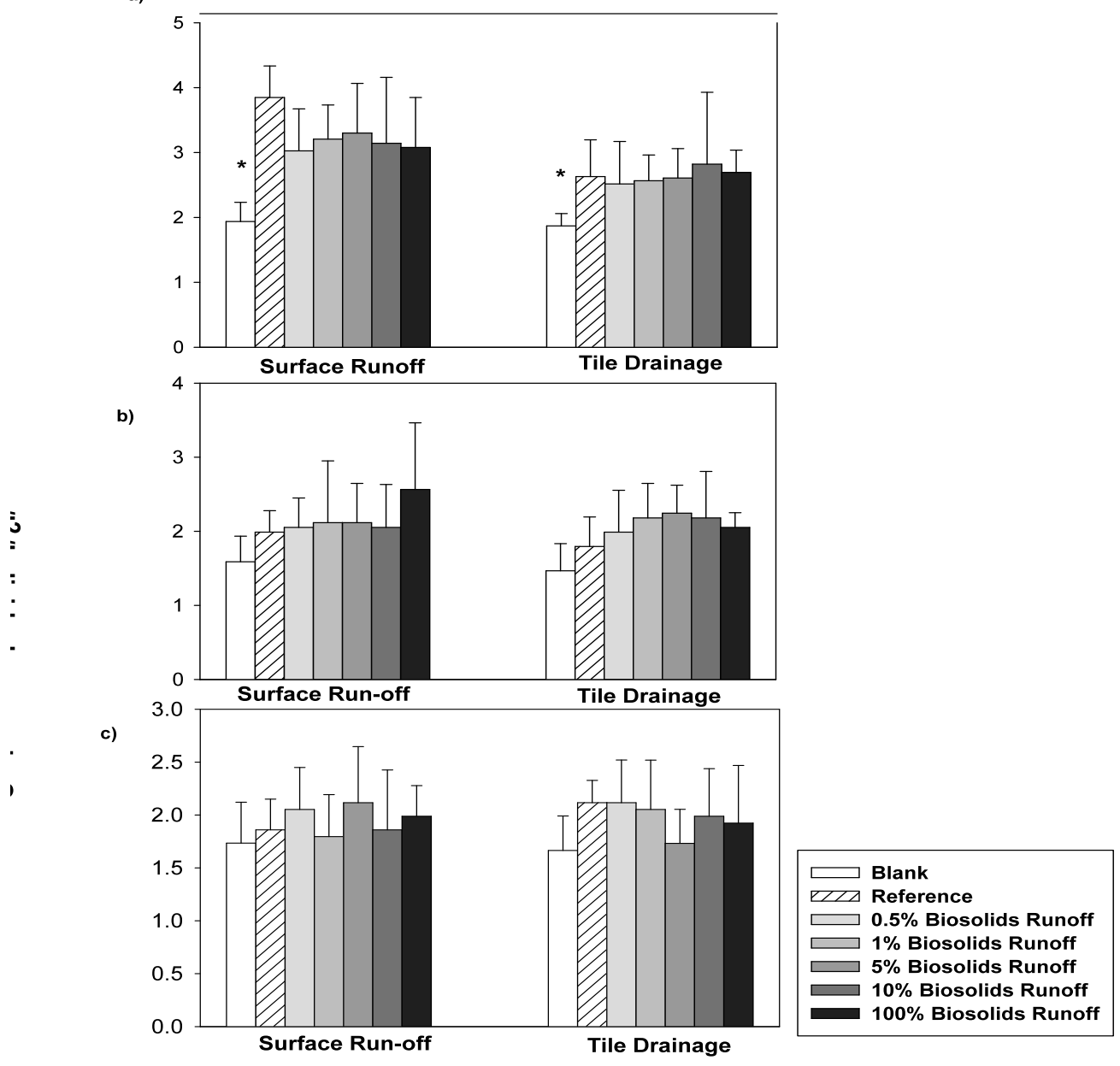

Figure 5. Respiration Rates of Hyalella azteca exposed to varying dilutions of surface run-off and tile drainage from soil with Kitchener biosolids application a)Day 1, all troughs, b)Day 40 unplanted troughs, c)Day 40 planted troughs. Exposure was over hour and a half period, respiration expressed in nanomoles of oxygen consumed per hour per individual. Values are mean \pm standard deviation. Significant differences $(\mathrm{p} \leq 0.05)$ relative to reference denoted by $*$. 


\subsubsection{Conclusions regarding the effects of biosolids run-off and tile drainage on respiration rates in aquatic invertebrates}

The major conclusion of these respiration experiments is that neither biosolid caused significant respiratory impairment when applied at maximum allowable loading and under worstcase conditions (one hundred year storm event 24 hours after application to bare soil with maximum permissible slope), and with elutriates tested at environmentally-relevant dilutions. That noted, there was some difference in response patterns to Guelph and Kitchener biosolids at $100 \%$ biosolids run-off or $100 \%$ biosolids tile drainage. Because there has been no chemical analysis done on the elutriates, as that is not the purpose of this project, it is difficult to pin point the reason between the likely cause of the difference in respiration rate patterns between the two biosolids. However what is known is that these two biosolids come from two different municipalities and that the treatment for obtaining biosolids is different. Kitchener wastewater treatment plant uses a traditional anaerobic digester, where Guelph, on top of the anaerobic digestion, uses "Lystek" processing technology. On the website of Lystek International Inc. it is explained that Lystek biosolids processing technology is an "innovative energy-efficient and cost-effective process involving a combination of heat, alkali and high-shear mixing to produce a high-solid-pathogen-free high-nutrient fertilizer value liquid that meets US EPA "Class A" biosolids standard". From their schematic diagram it is shown that after the usual anaerobic digestion and dewatering process the biosolids are put into the "high-speed mixer" where steam is injected though one hose, and potassium hydroxide from on other. The biosolids are being "processed" here for one hour, after which they are stored for either land filling or reclamation. The "Class A" US EPA standards require biosolids to have a non-detectible amount of pathogens and smaller amount of heavy metals. One of the points that the company brings up on their 
website is that almost all the metals concentrations were decreasing after Lystek treatment. For example, the amount of lead goes from $29 \mathrm{mg} / \mathrm{kg}$ to $26 \mathrm{mg} / \mathrm{kg}$, and copper from $740 \mathrm{mg} / \mathrm{kg}$ to $700 \mathrm{mg} / \mathrm{kg}$. It is possible that the metals are being chelated, but it is unclear if they are partitioned into the waste stream and separated from the residual biosolids, or remain in the biosolids in a less available form. Another interesting point from the website is that "Lystek System not only reduces the odour in biosolids but also modifies the odour to an earthy aroma". They measure the odour by using AC'SCENT International Triangular forced-choice dynamic dilution alfactometer, which read that the odour in Lystek treated biosolids reduced eleven-fold from the regular anaerobically treated biosolids. The amount of metals reduced, or pathogens cannot be addressed in this thesis because chemical or microbial analysis was not done, however odour is something that can be mentioned. The Guelph biosolids, which are treated with Lystek were found to have a very strong and extremely unpleasant smell. The smell was much stronger than that of Kitchener biosolids. A final point regarding class A biosolids (that are apparently obtained by Lystek treatment and can be achieved in anaerobic digestion), is that they require low amounts of detectable metals and no detectable pathogens. However there are numerous other compounds that could be of potential danger and that are found in biosolids despite their metals and microbial content. Some of these chemicals include persistent organic pollutants, pharmaceuticals or personal care products (McLachlan et al, 1996; Pedersen et al, 2005; Topp et al, 2008). Many of these can have acute as well as chronic impact on the invertebrates and vertebrates. That said, neither of these biosolids, tested under worst case scenario environmentally-relevant conditions, was shown to cause physiological stress (as indicated by respiration) to Daphnia magna or Hyalella azteca. 


\subsection{Behavioural Responses of Macroinvertebrates}

\subsubsection{Daphnia magna Behaviour in Guelph Biosolids Elutriate}

The two parameters chosen for evaluation of behaviour in Daphnia magna were swimming height and swimming style. Gill Marshall (Marshall, 2009) has studied the behavioral responses of Daphnia magna to chemical stressors, and has evaluated the importance of various behavioural parameters as part of a project on multi-species early-warning biomonitoring technology. Marshall concluded that swimming height and swimming style are among the most important behavioural parameters to observe for acute toxicity. These parameters were very sensitive to sub-lethal concentrations of chemical stressors, and responses were repeatable. Besides these parameters, Marshall suggested others such as secondary antennae use. However this was not practical since tests were conducted in falcon tubes in which the elutriate had been centrifuged prior to addition of organisms (to include the sediment toxicity if any) and for that reason it was too difficult to see if Daphnia magna were using their secondary antennae. Also, although the elutriate was centrifuged, it retained a yellow-brown color which made it difficult to reliably observe details such as use of antennae (especially in run-off collected on day 1).

\subsubsection{Daphnia magna swimming height.}

Overall in Guelph biosolids elutriate on Day 1(all time points included) there is a significant difference between run-off from reference soil, and all three concentrations of Guelph biosolids run-off $(\mathrm{p}<0.001, \mathrm{p}=0.004$, and $\mathrm{p}=0.002$ for comparisons between reference and $1 \%, 10 \%$, and $100 \%$, respectively) as shown in figure $6 \mathrm{a}$. This difference becomes more pronounced after 4 hours of exposure, with the average percentage of Daphnia magna swimming 
through the water column decreasing with time in all three concentrations of biosolids, where the swimming height remains constant and near $100 \%$ over the span of 24 hours in run-off collected off the reference soil troughs.

There was no significant difference between the swimming height of Daphnia magna in reference and $1 \%$ biosolids run-off $(p=0.089)$ in tile drainage $(6 b)$. However, there was a significant difference in swimming height of Daphnia magna in $10 \%$ biosolids run-off $(\mathrm{p}=$ $0.036)$ and $100 \%$ biosolids run-off $(\mathrm{p}<0.001)$. This result is indicating that whatever impaired the ability of Daphnia magna to swim through the water column (or deterred this behaviour) also penetrated the soil to the tiles. These results complement results of respiration rates measured in Guelph biosolids eluriate collected on day 1, where respiration rate of Daphnia magna decreased significantly between the reference and $100 \%$ biosolids tile drainage. Since it is the same elutriate that was used to test both respiratory and behavioural response, it is most likely the same contaminant that is impaired respiration rates affected swimming height of Daphnia magna. If this is the case, the results suggest that behavioural response, specifically swimming height, may be a more sensitive indicator of stress than respiratory response. Again, as no chemical analysis was done on the Guelph biosolids tile drainage, it can only be speculated that high concentrations of ammonium or chloride and chlorinated compounds account for these responses. These behavioural response results might be of environmental significance because they were observed at concentrations as low as $1 \%$ biosolids run-off. The affected Daphnia magna in surface and tile drainage were staying below the first $4 \mathrm{~cm}$ of the water column, unable to propel themselves throughout the whole water column. For a Daphnia magna to swim throughout the water column is a very important and essential behaviour because this is how they stay away from predators, and find their food patches. These organisms have to be able to move 
vertically as well as horizontally through the water to survive. There are other studies that evaluated swimming height of Daphnia magna as a response to chemicals such as PCP's, pesticides and hydrocarbons (e.g. Michels et al, 2000; Martins et al, 2007a). These studies have similarly shown that Daphnia magna's ability to swim through the water column can be a sensitive and objective parameter that can indicate the extent of a chemical stress.

On day 40, using surface run-off collected from unplanted soil, there remained a significant difference in swimming height between the reference and $100 \%$ biosolids run-off (Figure $7 \mathrm{a}, \mathrm{p}=0.043$ ). There was no significant difference between the reference and the other two concentrations of biosolids. This result is indicating that 40 days after the Guelph biosolids have been applied to the troughs, there remained some toxicity that was able to alter the behaviour of Daphnia magna, specifically limiting use of the entire water column. However, this only happens at the highest concentration of biosolids elutriate, which is, as already mentioned before, not environmentally relevant.

On day 40, using tile drainage collected from unplanted soil, there was no significant difference in swimming heights among treatments (Figure $7 b, p=0.151$ ), indicating that after 40 days, the tile drainage that is caused by a rain-storm potentially will be no impact on Daphnia magna swimming height through the water column of a lake or pond near the fields where this drainage is discharged.

Using elutriate from planted soil, by day 40 there was no remaining effect of biosolids on the percent of Daphnia magna swimming through the water column (Figure 8a, p > 0.95). Comparing these results with unplanted soil on day 40 suggests that plants may have helped mitigate toxicity, eliminating the effect on swimming height observed at the highest 
concentration of biosolids run-off. Results using tile drainage from planted soil on day 40 also showed no impact of biosolids on Daphnia magna swimming height, with no observed differences among treatments (Figure $8 b, p=0.921$ ). 


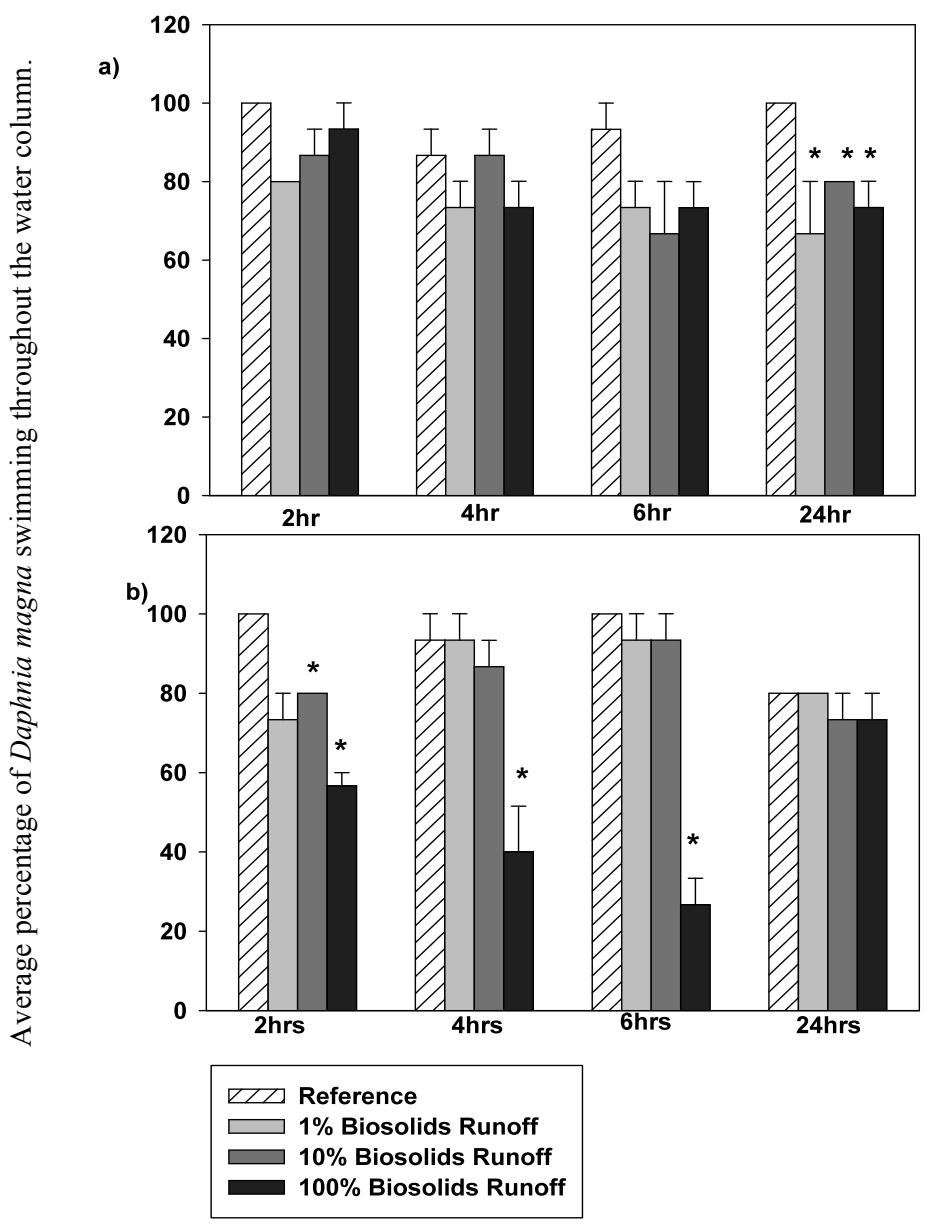

Figure 6. Day 1 swimming height of Daphnia magna exposed to varying dilutions of surface run-off (a) tile drainage (b) from soil with Guelph biosolids application. Exposure was over 24 hours period, expressed in average percentage of Daphnia magna swimming through the water column. Values are mean \pm standard error. Significant differences (Kruskal-Wallis test) in treatments from the reference are denoted by *. 
a)

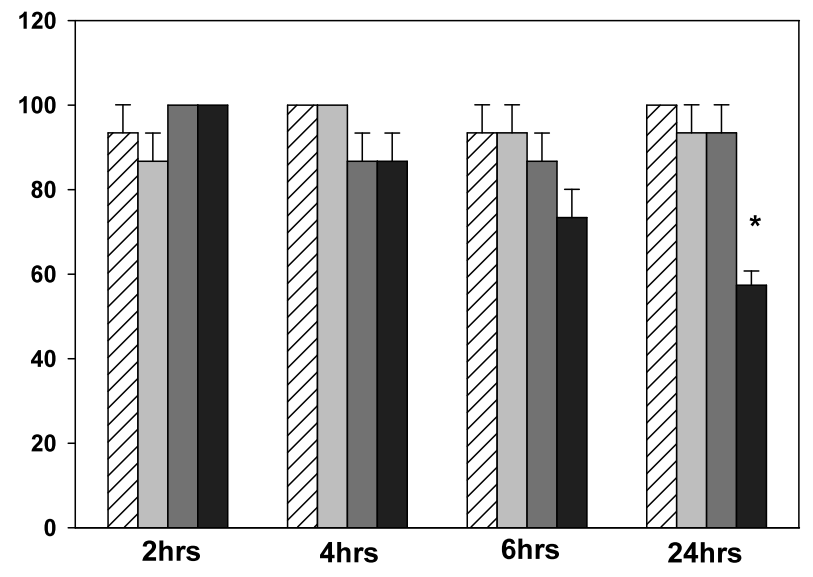

b)

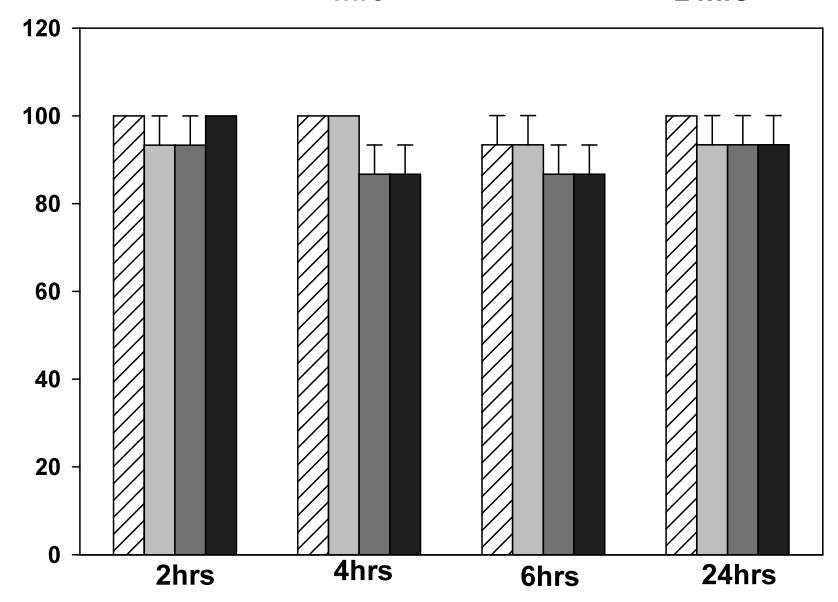

Figure 7. Swimming height of Daphnia magna exposed to varying dilutions of surface run-off (a) tile drainage (b) from soil with Guelph biosolids application in eutriate collected of the unplanted troughs on day 40. Exposure was over 24 hours period, expressed in average percentage of Daphnia magna swimming through the water column. Values are mean \pm standard error . Significant differences (Kruskal-Wallis test) in treatments from the reference are denoted by *. 


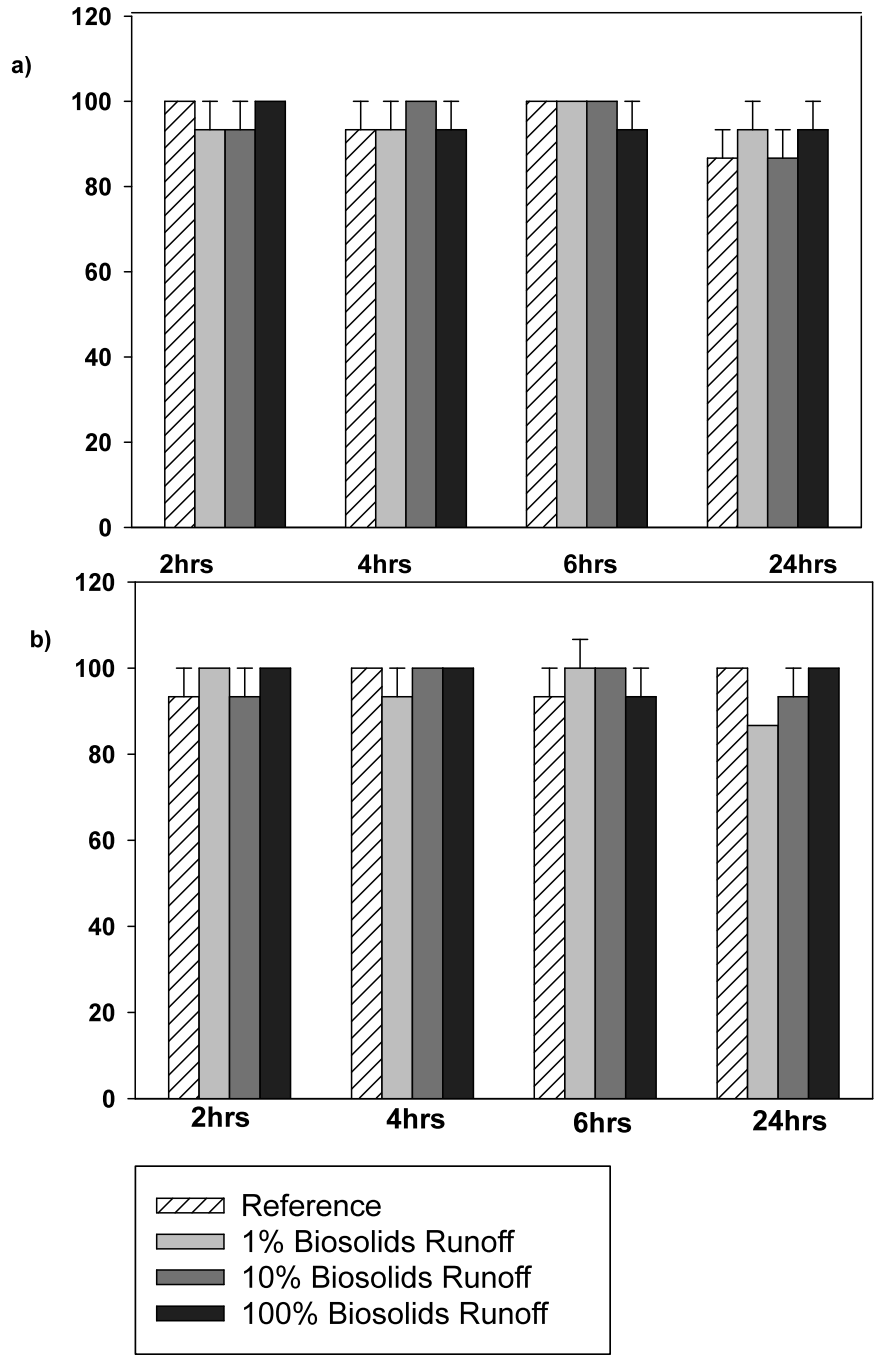

Figure 8. Swimming height of Daphnia magna exposed to varying dilutions of surface run-off (a) tile drainage (b) from soil with Guelph biosolids application in eutriate collected of the planted troughs on day 40. Exposure was over 24 hours period, expressed in average percentage of Daphnia magna swimming through the water column. Values are mean \pm standard error. 


\subsubsection{2 . Daphnia magna Swimming Style in Guelph Biosolids Elutriate}

Daphnia magna have a very distinct saltatory swimming pattern that is a good indicator of their well being. Fish choose their prey based on motion (Szulkin, 2006). Different types of motion or swimming behaviour may lead to "noisier" (Marshall, 2009) swimming and increased vulnerability to predators such as copepods or fish. Therefore Daphnia magna swimming behaviour is an integral part of interactions with predators (Ryan and Dodson, 1998). Their normal saltatory swimming behaviour is essential for their survival because it gives them the ability to find food patches throughout the water column, avoid predators and with this swimming pattern they use the least amount of energy to move efficiently (Ryan and Dodson, 1998). If Daphnia magna is unable to maintain swimming pattern that it has under normal conditions, it means that it is losing equilibrium, which makes it more susceptible to predators (more visibility and slower ability to escape), and less able to travel to food patches as other swimming behaviours require more energy. Because a normal swimming pattern is very distinctive in Daphnia magna, it is not hard to tell when they are not swimming normally. When they are under chemical or physical stress they will start to exhibit faster more erratic movements or spinning behaviour at the bottom of the test vessel. Another indication of abnormal swimming style is if they are not in the up-right position and if they are using the bottom of the vessel to propel themselves through the water (Marshall, 2009). All these were recorded as abnormal swimming style.

There was no significant differences in swimming style between the reference and one and ten percent biosolids surface run-off on Day 1 (Figure 9a), however there was a significant difference between the reference and the $100 \%$ surface biosolids run-off $(p=0.031)$. Similarly, 
there was no significant difference in the percentage of Daphnia magna displaying normal swimming pattern between reference and one percent biosolids elutriate, and between reference and ten percent biosolids tile drainage (Figure 9b). However there was a significant difference between the reference and the $100 \%$ biosolids run-off $(\mathrm{p}<0.001)$. These results were consistent with day 1 tile drainage in respiration experiments as well as swimming height experiments in that the agent(s) causing effects penetrated to the tiles, causing the same effects seen in surface run-off. These results suggest that if Guelph biosolids are applied to an agricultural field, and an extreme rain storm happened the next day, the $100 \%$ run-off and tile drainage might affect the normal swimming pattern of Daphnia magna. However, under environmentally relevant scenarios concerning run-off or drainage from soil, biosolids application would not be expected to affect Daphnia swimming behaviour.

In run-off from unplanted troughs on Day 40, there was no significant difference in the percentage of Daphnia magna displaying normal swimming pattern between reference and 1\% biosolids run-off, and between reference and 10\% biosolids run-off (Figure 10a). However there remained a significant difference between the reference and the $100 \%$ biosolids run-off $(\mathrm{p}=$ 0.002). Similarly, there was no significant difference in the percentage of Daphnia magna displaying normal swimming pattern between reference and $1 \%$ biosolids tile drainage, and between reference and 10\% percent biosolids tile drainage (Figure 10b). However there was a significant difference between the reference and the $100 \%$ biosolids run-off $(\mathrm{p}<0.001)$. While impact on swimming behaviour was only observed at $100 \%$ run-off and tile drainage, it is notable that even after 40 days, some agent(s) in the biosolids could still have a toxic impact on Daphnia magna. 
In planted troughs on Day 40, there was no significant difference in the percentage of Daphnia magna displaying normal swimming pattern between reference, $1 \%, 10 \%$, and $100 \%$ surface biosolids run-off (Figure 11a, $\mathrm{p}=0.162$ ). Tile drainage collected from the planted troughs on day 40 also showed no significant difference among any of the treatments (Figure $11 \mathrm{~b}, \mathrm{p}=0.462)$. This last set of results suggests that plants can ameliorate toxicity of biosolids. Although the significant differences in all the results were only seen in $100 \%$ biosolids run-off, maintaining a vegetated buffer along the edge of waterways would be a good precaution for protecting receiving water. 


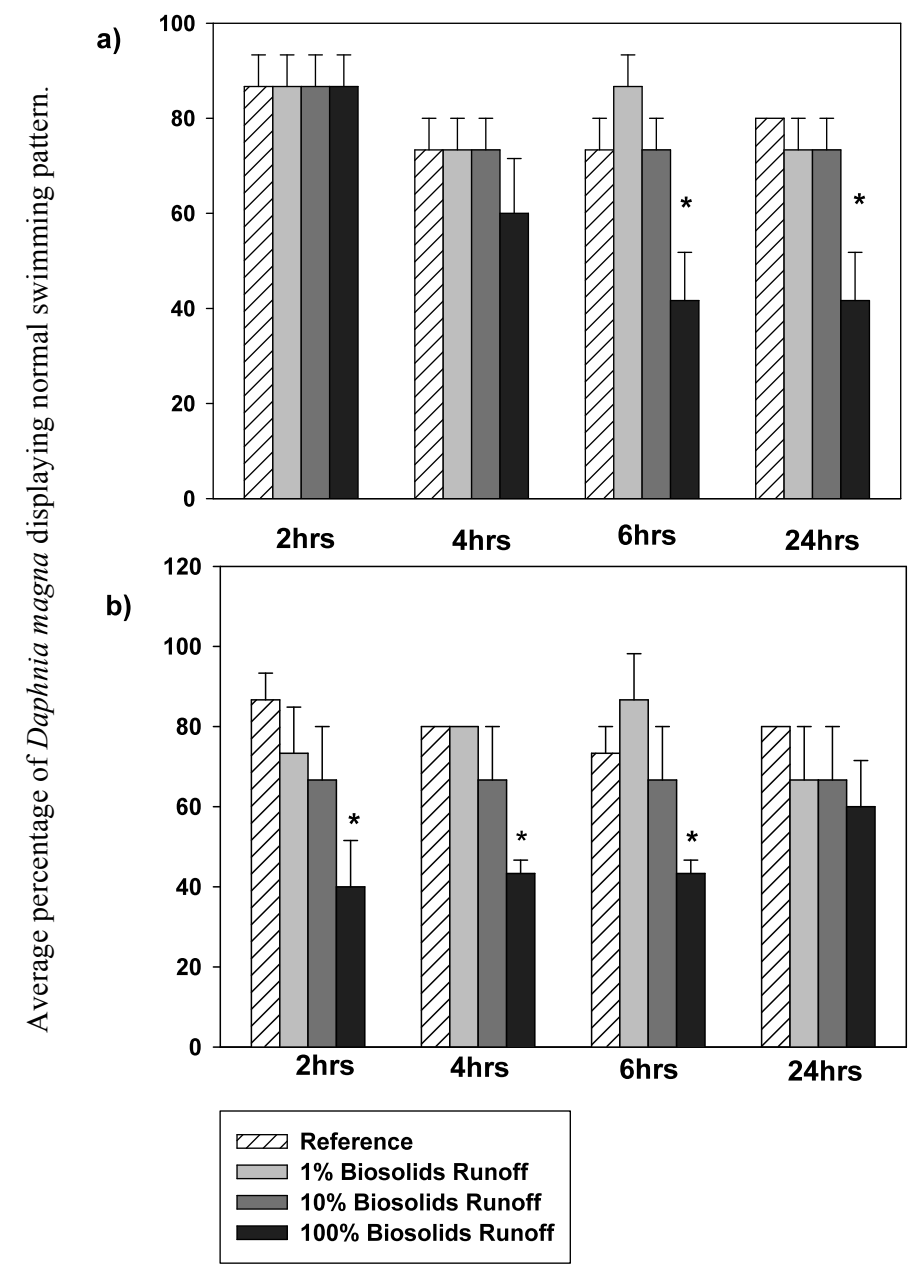

Figure 9. Day 1: swimming style of Daphnia magna exposed to varying dilutions of surface runoff (a) and tile drainage (b) from soil with Guelph biosolids application. Exposure was over 24 hours period, expressed in average percentage of Daphnia magna swimming through the water column. Values are mean \pm standard error. Significant differences (Kruskal-Wallis test) in treatments from the reference are denoted by *. 
a)

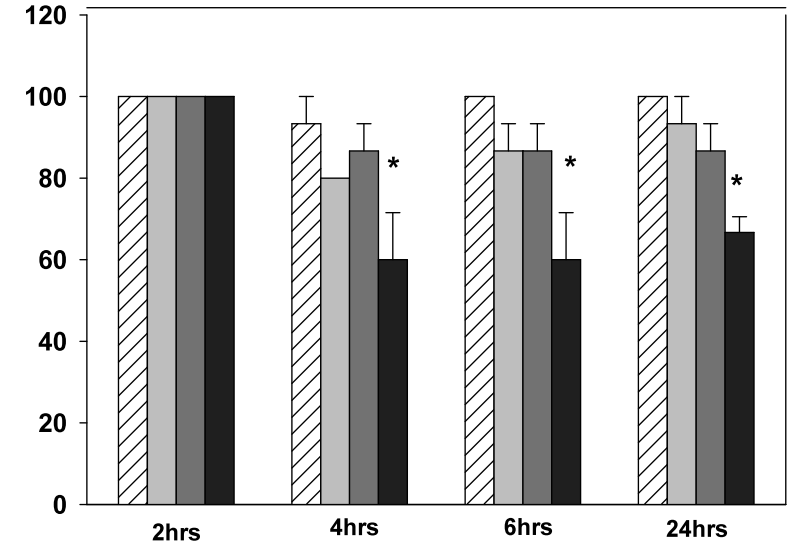

을

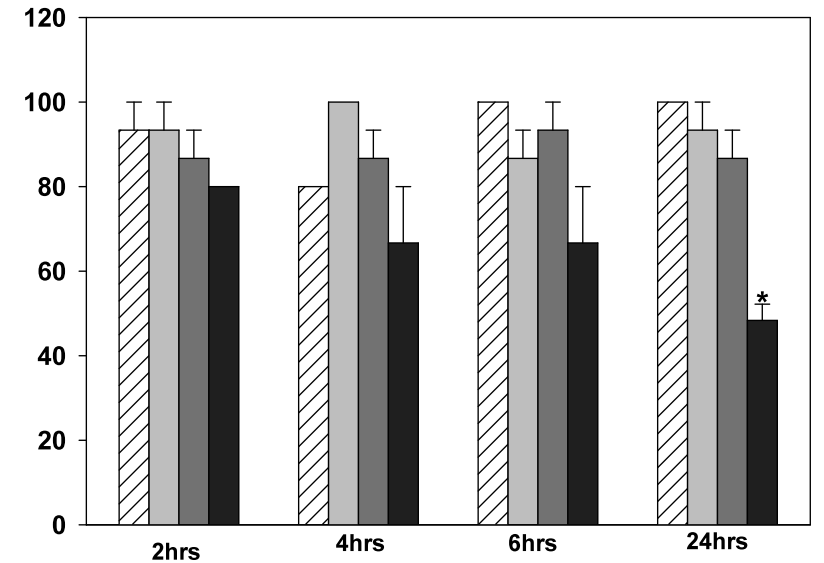

$$
\begin{aligned}
& \square 7 \text { Reference } \\
& 1 \% \text { Biosolids Runoff } \\
& 10 \% \text { Biosolis Runoff } \\
& 100 \% \text { Bisolids Runoff }
\end{aligned}
$$

Figure 10. Day 40 un-planted troughs: swimming style of Daphnia magna exposed to varying dilutions of surface run-off (a) and tile drainage (b) from soil with Guelph biosolids application. Exposure was over 24 hours period, expressed in average percentage of Daphnia magna swimming through the water column. Values are mean \pm standard error. Significant differences (Kruskal-Wallis test) in treatments from the reference are denoted by *. 

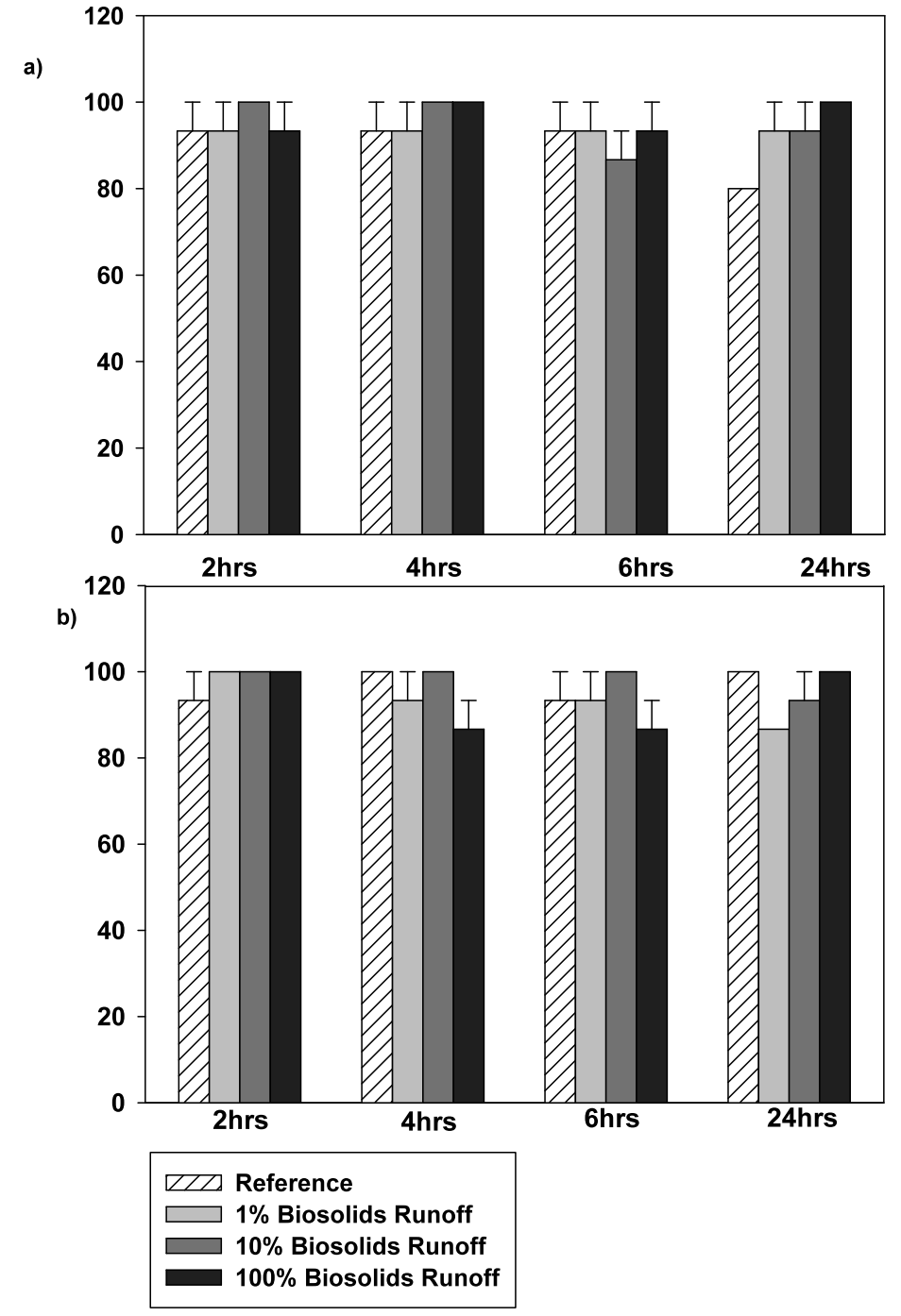

Figure 11. Day 40 planted troughs: swimming style of Daphnia magna exposed to varying dilutions of surface run-off (a) and tile drainage (b) from soil with Guelph biosolids application. Exposure was over 24 hours period, expressed in average percentage of Daphnia magna swimming through the water column. Values are mean \pm standard error. 


\subsubsection{Hyalella azteca Behaviour in Guelph Biosolids Elutriate}

\subsubsection{Hyalella azteca Substrate Crawling in Guelph Biosolids Elutriate}

Under normal conditions Hyalella azteca constantly crawls on the sediments or other substrate searching for food layered on the sediments, such as dead algae and other debris. A lack of this movement, or decrease in foraging activity, indicates stress, and because of this substrate crawling is an important indicator of the organism's overall health (Marshall, 2009). It is also an easy behaviour to observe and quantify, making it a useful behaviour in assessing if a contaminant induces stress.

On Day 1, there was no significant difference in substrate crawling between the reference and any of the three concentrations of the biosolids surface run-off (Figure 12a, $p=0.589$ ) or tile drainage (Figure $12 \mathrm{~b}, \mathrm{p}=0.520$ ). However, in all treatments the organisms became stuck in clay very soon after they were put into the falcon tubes (test chambers), limiting substrate crawling and potentially masking any real effect of biosolids on their behaviour. In all test chambers the Hyalella azteca had a hard time swimming or performing any normal behaviour because their pereopods were covered with clay. Because of this there were no more experiments performed on Hyalella azteca behaviour with Guelph biosolids. 

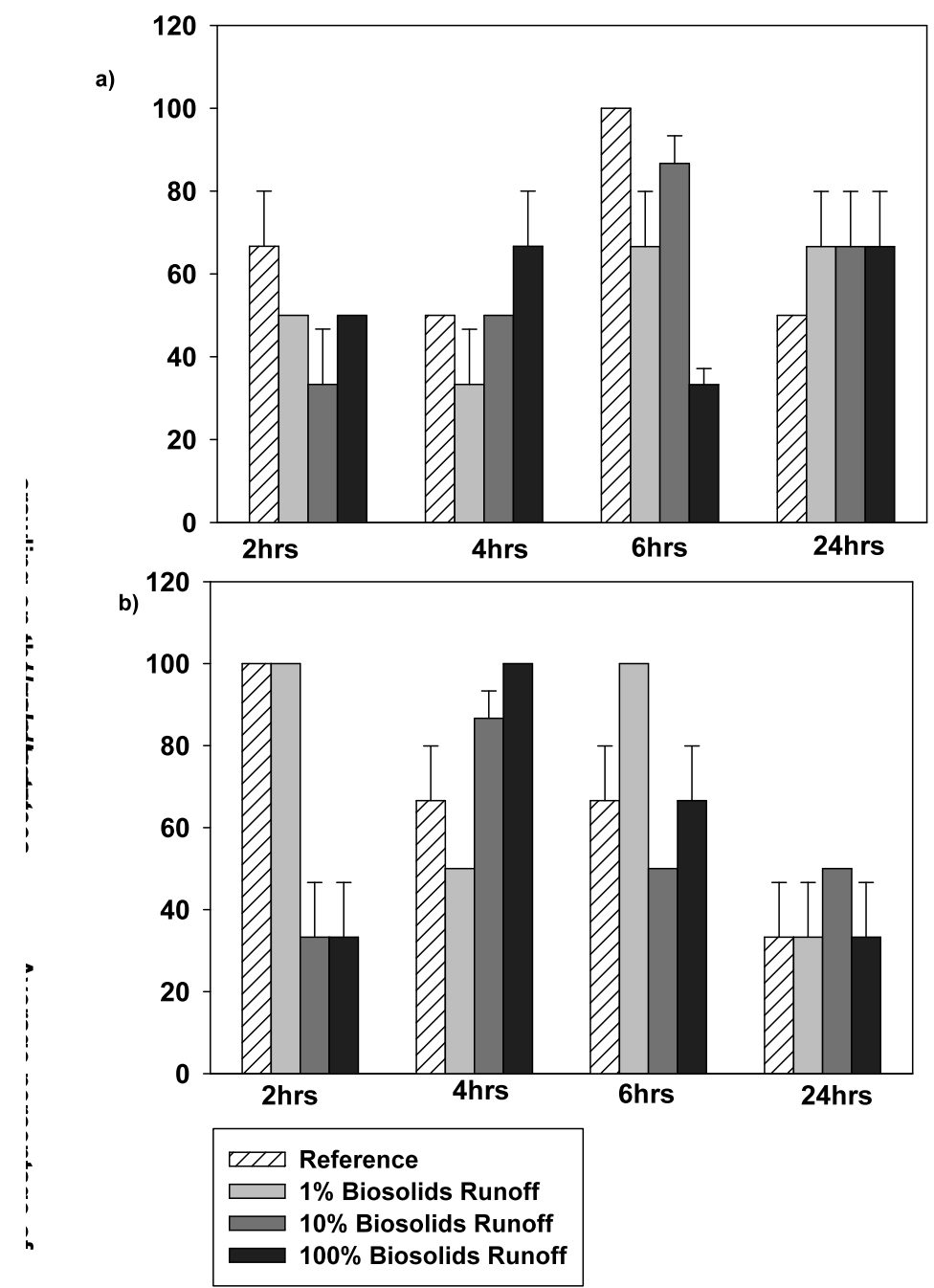

Figure 12. Day 1 crawling on the substrate of Hyalella azteca exposed to varying dilutions of surface run-off (a) and tile drainage (b) from soil with Guelph biosolids application. Exposure was over 24 hours period, expressed in average percentage of Hyalella azteca displaying crawling on the substrate behaviour. Values are mean \pm standard error. 


\subsubsection{Daphnia magna Behaviour in Kitchener Biosolids Elutriate}

\subsubsection{Daphnia magna Swimming Height in Kitchener Biosolids Elutriate}

A set of behavioural experiments was performed using Kitchener biosolids in the same way as with Guelph biosolids. As explained above, swimming height is one of the most indicative parameters for determining stress in Daphnia magna. On Day 1, surface run-off from soil with Kitchener biosolids caused no changes in swimming height (relative to reference) at any of the biosolids concentrations tested (Figure 13a, $\mathrm{p}=0.748$ ). Similarly, tile drainage from soil with applied biosolids had no significant effect on swimming height (Figure 13b, $\mathrm{p}=0.603$ ). For this reason, experimental design was simplified for behavioural bioassays by removing $0.5 \%$ and 5\% treatments in subsequent tests (Day 40, unplanted and planted). For consistency in presentation, only reference, $1 \%, 10 \%$, and $100 \%$ results are shown for Days 1 and 40 . The results indicate that even after only one day and under worst-case scenarios, application of these Kitchener biosolids to agricultural fields would be expected to have no significant impact on the swimming height and foraging activity of Daphnia magna living in the watershed, even after an extreme rain storm

As expected from the Day 1 results, on Day 40 biosolids caused no significant impact on swimming height in run-off (Figure $14 a, p=0.076$ ) or tile drainage (Figure $14 b, p=0.116$ ) from unplanted soil, or in run-off (Figure $14 \mathrm{c}, \mathrm{p}=0.306$ ) or tile drainage (Figure $14 \mathrm{~d}, \mathrm{p}=0.768$ ) from planted soil. 


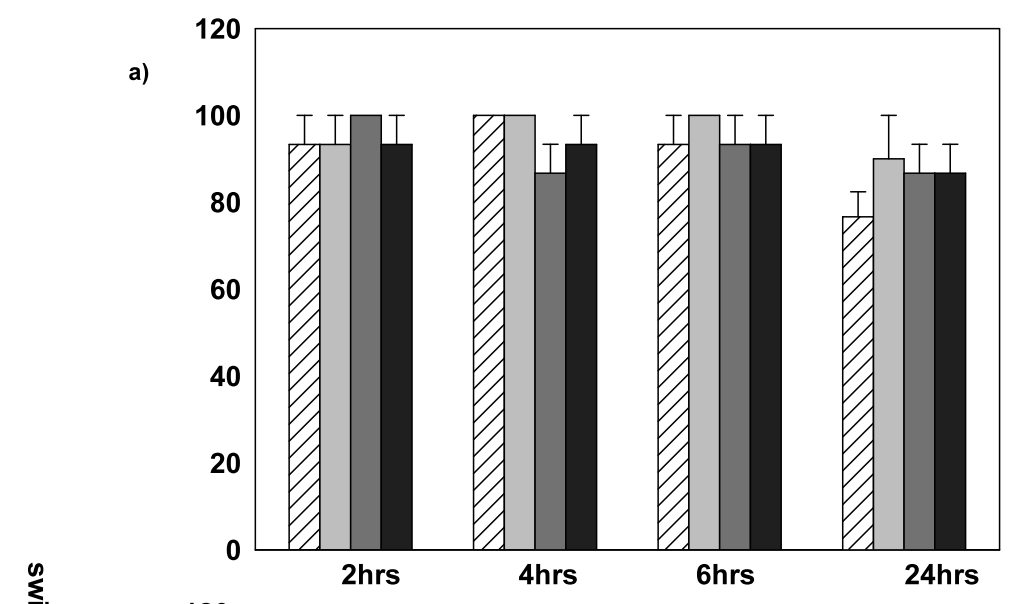

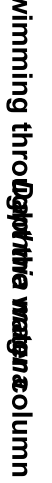
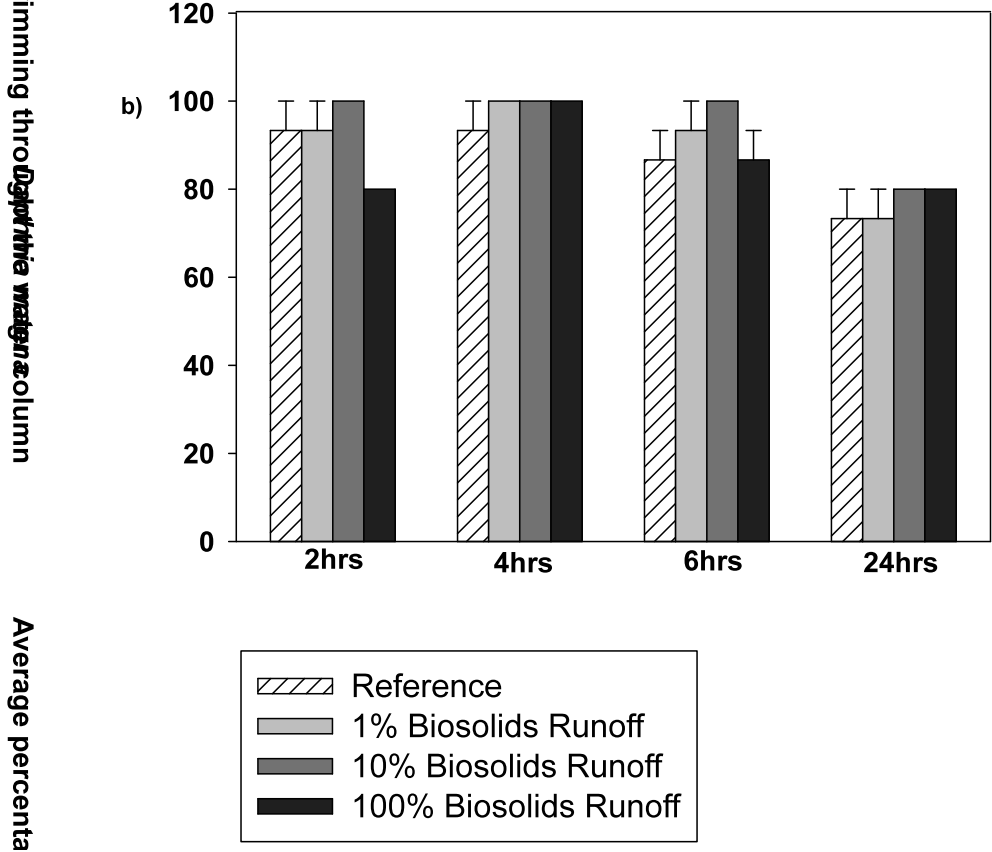

Figure 13. Day 1 swimming height of Daphnia magna exposed to varying dilutions of surface run-off (a) and tile drainage (b) from soil with Kitchener biosolids application. Exposure was over 24 hours period, expressed in average percentage of Daphnia magna swimming through the water column. Values are mean \pm standard error. 
a)
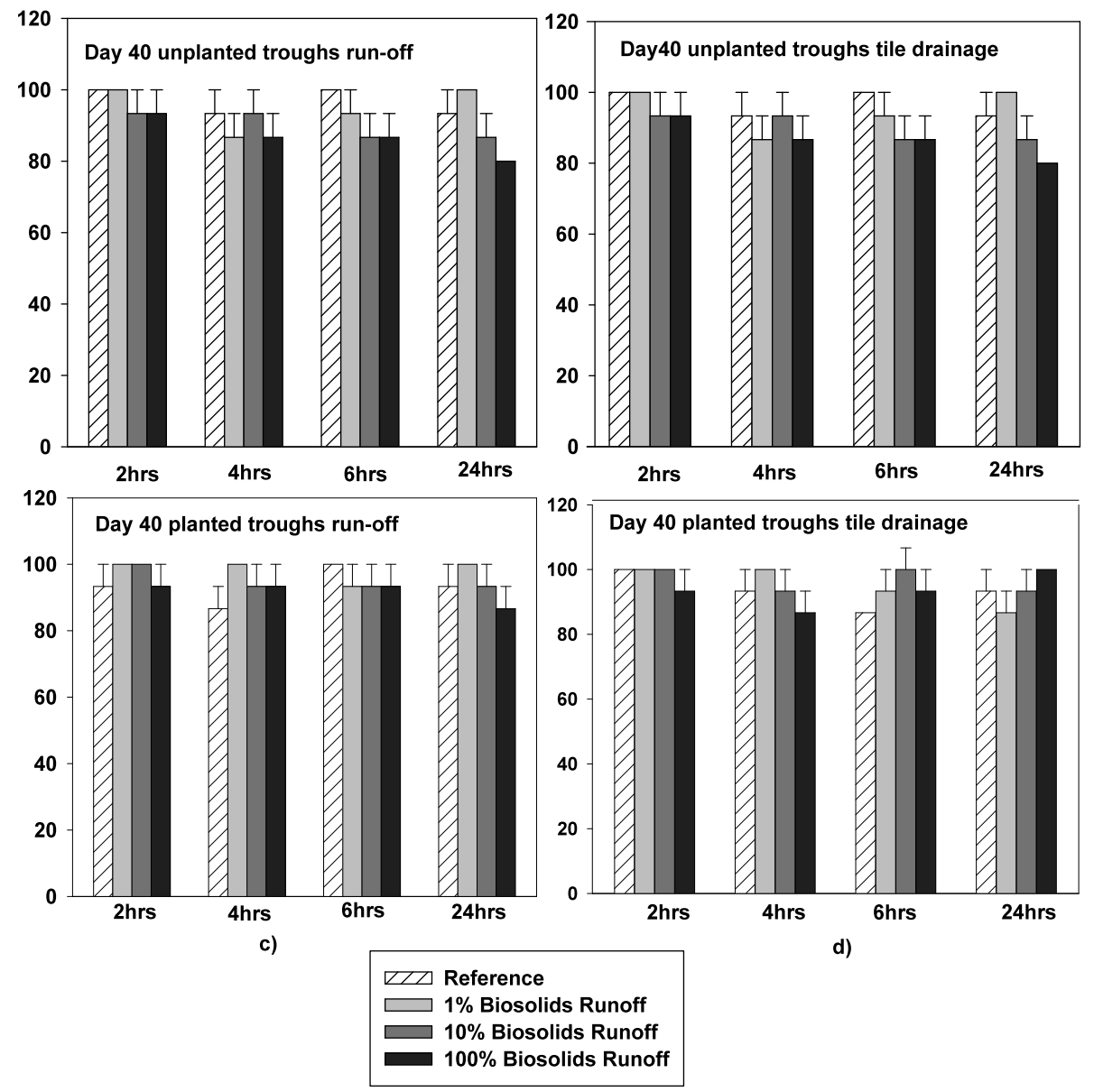

b)

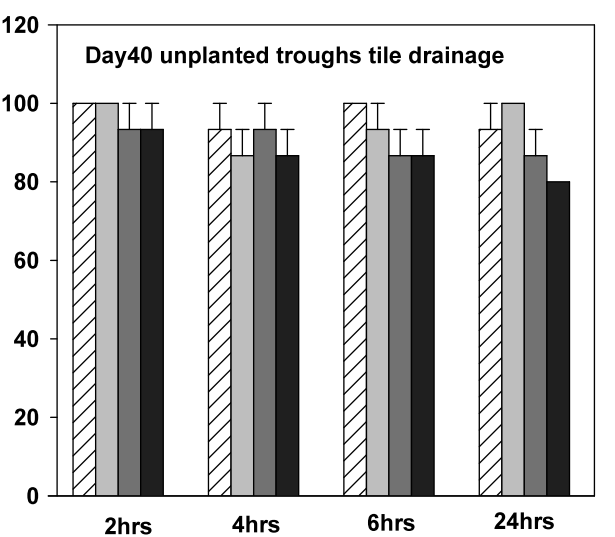

Figure 14. Swimming height of Daphnia magna exposed to varying dilutions of surface run-off $(a, c)$ and tile drainage $(b, d)$ from soil with Kitchener biosolids application biosolids elutriate collected on day 40 of the unplanted and planted troughs. Exposure was over 24 hours period, expressed in average percentage of Daphnia magna swimming through the water column. Values are mean \pm standard error. 


\subsubsection{Daphnia magna Swimming Style in Kitchener Biosolids Elutriate}

As previously discussed, Daphnia magna has a very distinctive swimming style which is a useful indicator of healthy, normal behaviour. When there are changes to that normal swimming style it suggests the organism is under physical or chemical stress.

As with swimming height, swimming style on Day 1 was not affected by any of the biosolids test concentrations in surface run-off (Figure 15a, $\mathrm{p}=0.313$ ) or tile drainage (Figure $15 \mathrm{~b}, \mathrm{p}=0.276$ ). This result suggests that if the Kitchener biosolids were applied to the agricultural field at the highest rate allowable and under the worst possible set of conditions (maximum slope, bare soil, no vegetated buffer strip), there would not be an effect on the swimming style of Daphnia magna in the receiving water after the extreme rain storm.

Because there was no significant impact of biosolids on swimming style of Daphnia magna on Day 1, it was expected that there would be no increase in stress responses later. Consistent with that expectation, biosolids caused no impact on Day 40 in run-off (Figure 16a, p $=0.233$ ) or tile drainage (Figure $16 \mathrm{~b}, \mathrm{p}=0.082)$ from unplanted soil, or in run-off (Figure 16c, $\mathrm{p}$

$=0.210$ ) or tile drainage (Figure $16 \mathrm{~d}, \mathrm{p}=0.323$ ) from planted soil. 


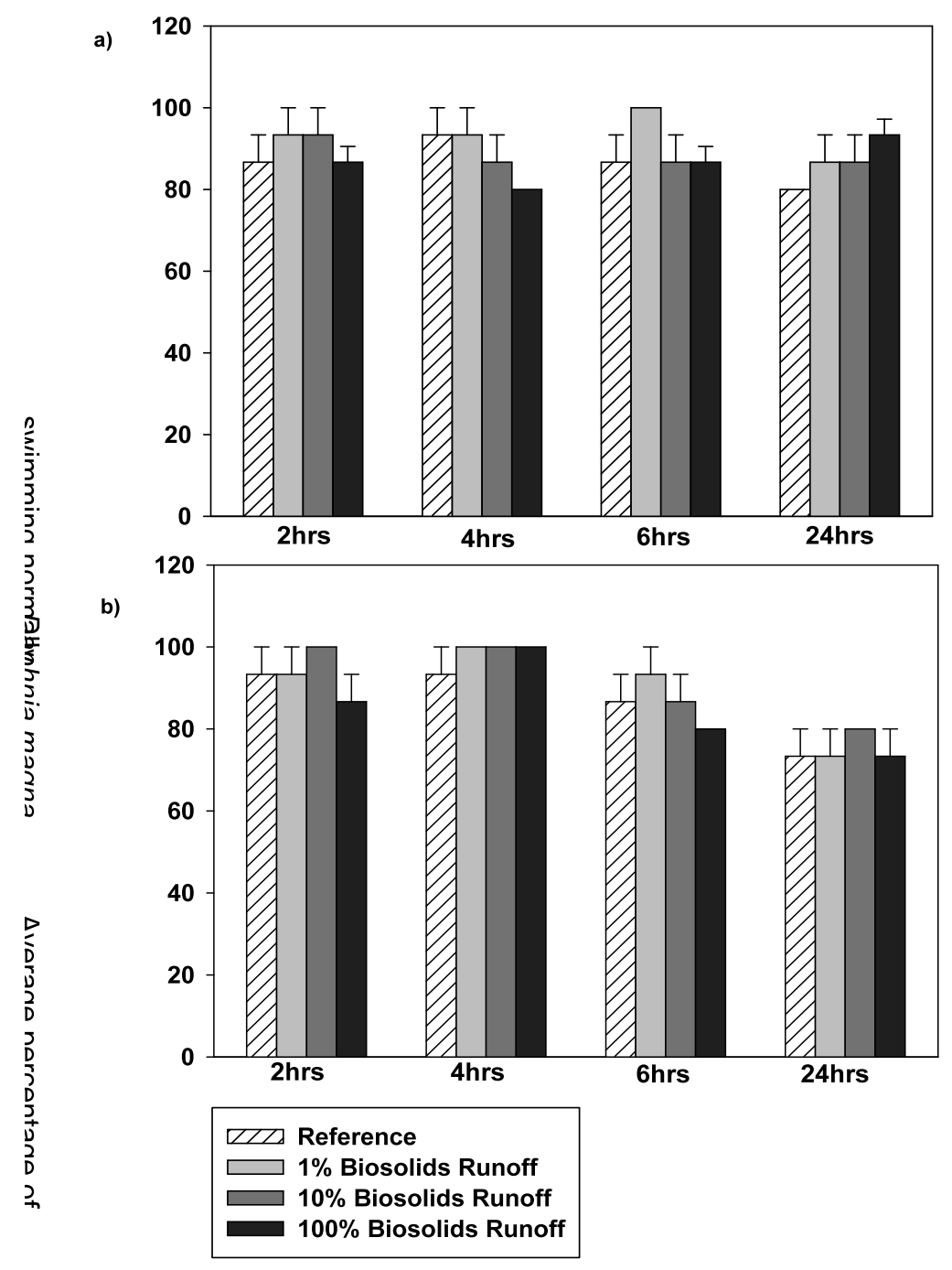

Figure 15. Swimming style of Daphnia magna exposed to varying dilutions of surface run-off (a) and tile drainage (b) from soil with Kitchener biosolids application collected biosolids elutriate on Day 1. Exposure was over 24 hours period, expressed in average percentage of Daphnia magna displaying abnormal swimming behaviour. Values are mean \pm standard error. 
a)
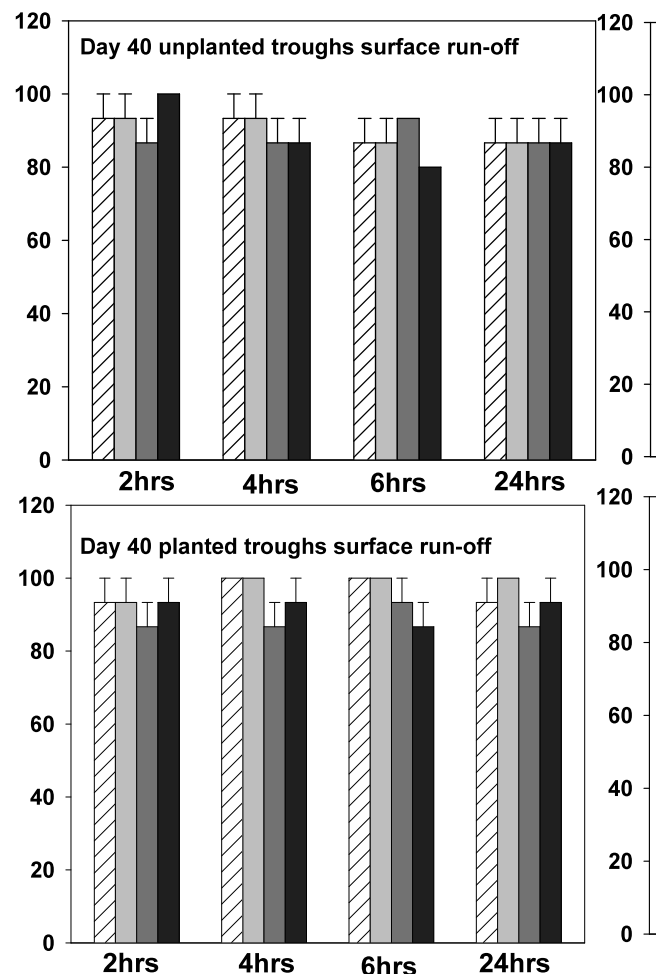

6hrs

100 b)

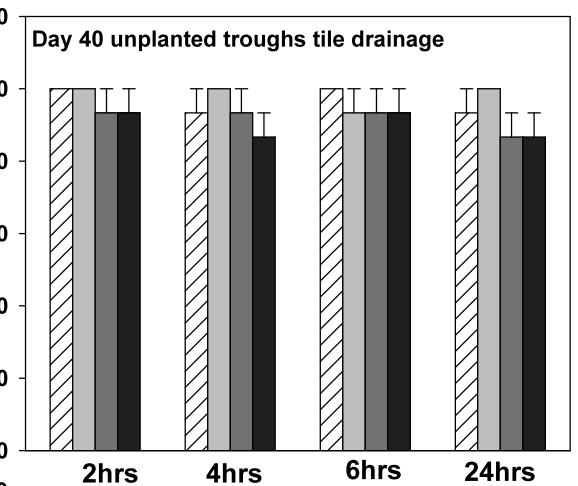

2hrs 4hrs 6hrs 24hrs Day $\mathbf{4 0}$ planted troughs tile drainage 田田

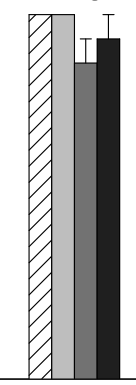

4hrs

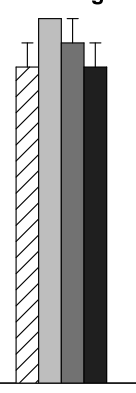

6hrs

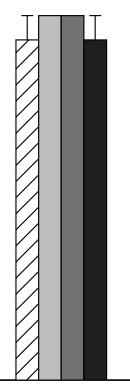

24hrs

c)

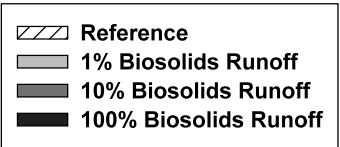

d)

Figure 16. Swimming style of Daphnia magna exposed to varying dilutions of surface run-off (a, c) and tile drainage $(b, c)$ from soil with Kitchener biosolids application. Biosolids elutriate collected on day 40 from unplanted and planted troughs. Exposure was over 24 hours period, expressed in average percentage of Daphnia magna displaying abnormal swimming behaviour. Values are mean \pm standard error. 


\subsubsection{Hyalella azteca Behaviour in Kitchener Biosolids Elutriate 3.2.4.1 Hyalella azteca Substrate Crawling in Kitchener Biosolids Elutriate}

To alleviate the potentially confounding problem of clay sticking to pereopods as occurred in Guelph biosolids experiments, run-off and tile drainage from Kitchener biosolids was centrifuged, followed by transfer of the supernatant to a new vessel, and testing of the Hyalella azteca in this new vessel. As previously discussed Hyalella azteca's normal behaviour is to crawl on the substrate in the sediments of a water body such as a lake or pond. This is how the invertebrate finds food patches of whatever debris falls on the bottom to the sediments, and this is also where the organism hides from predators. For this reason, substrate crawling behaviour is a good indicator of the overall health of the organism.

On Day 1, biosolids constituents in surface run-off did reduce substrate crawling at $10 \%$ $(\mathrm{p}=0.028)$, and $100 \%(\mathrm{p}<0.001)$, but not at $1 \%$ (Figure 40, $\mathrm{p}=0.193)$ as shown in Figure 17a. In tile drainage, biosolids had no effect on substrate crawling behaviour (Figure 17b, $p=0.374$ ). Although effects of biosolids on substrate crawling are only seen at concentrations with marginal $(10 \%)$ or no $(100 \%)$ environmental relevance, the result suggests that there are substances in the biosolids that can impair Hyalella azteca's ability or inclination to crawl and forage. Also, because the Hyalella were tested in run-off that had been centrifuged to remove most particulate matter, results suggest that whatever was impacting the Hyalella azteca is water soluble, small, or has low density, and may be able to get into the environment through run-off. However, the results from tile drainage suggest that the constituent(s) of biosolids impacting the behaviour of Hyalella azteca in surface run-off did not penetrate to the tiles. 
On Day 40, there was no residual effect of biosolids on substrate crawling in surface runoff (Figure 18a, $\mathrm{p}=0.559$ ) or tile drainage (Figure 18b, $\mathrm{p}=0.327$ ) in unplanted soil, or in planted soil (Figure 18c, $\mathrm{p}=0.358$; Figure $18 \mathrm{~d}, \mathrm{p}=0.066$ for surface run-off and tile drainage, respectively). This set of experiments suggests that whatever the constituent(s) of the biosolids impacting substrate crawling by Hyalella azteca on Day 1, it was either gone or reduced due to leaching, adsorption, or decomposition. The results further suggest that the impacts seen on Hyalella only under the most extreme scenarios will be only short-term, disappearing by Day 40 . 


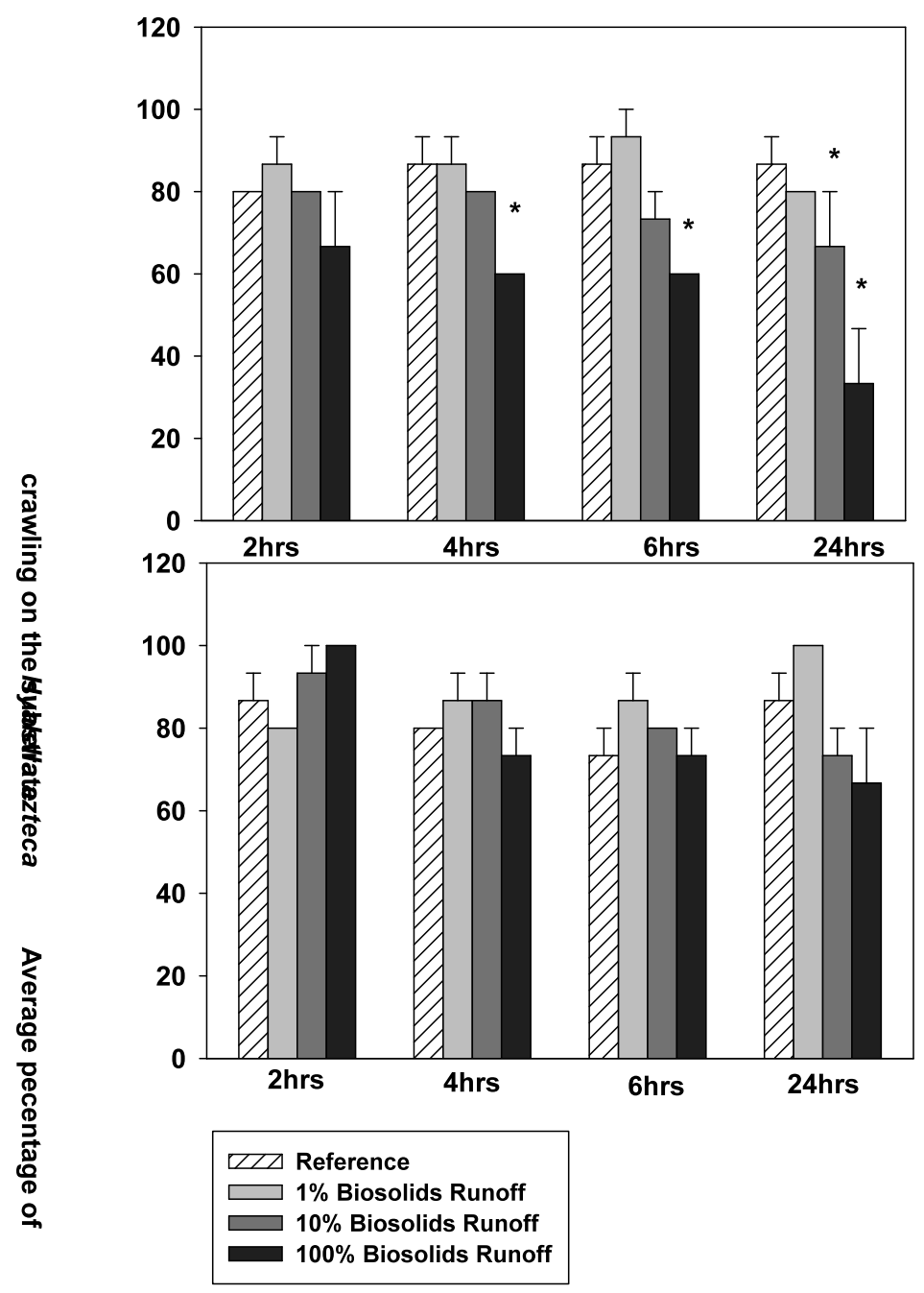

Figure 17: Crawling on the substrate of Hyalella azteca exposed to varying dilutions of surface run-off (a) and tile drainage (b) from soil with Kitchener biosolids application, elutriate collected on day 1. Exposure was over 24 hours period, expressed in average percentage of Hyalella azteca displaying crawling on the substrate behaviour. Values are mean \pm standard error. Significant differences (Kruskal-Wallis test) in treatments from the reference are denoted by*. 
a)

b)
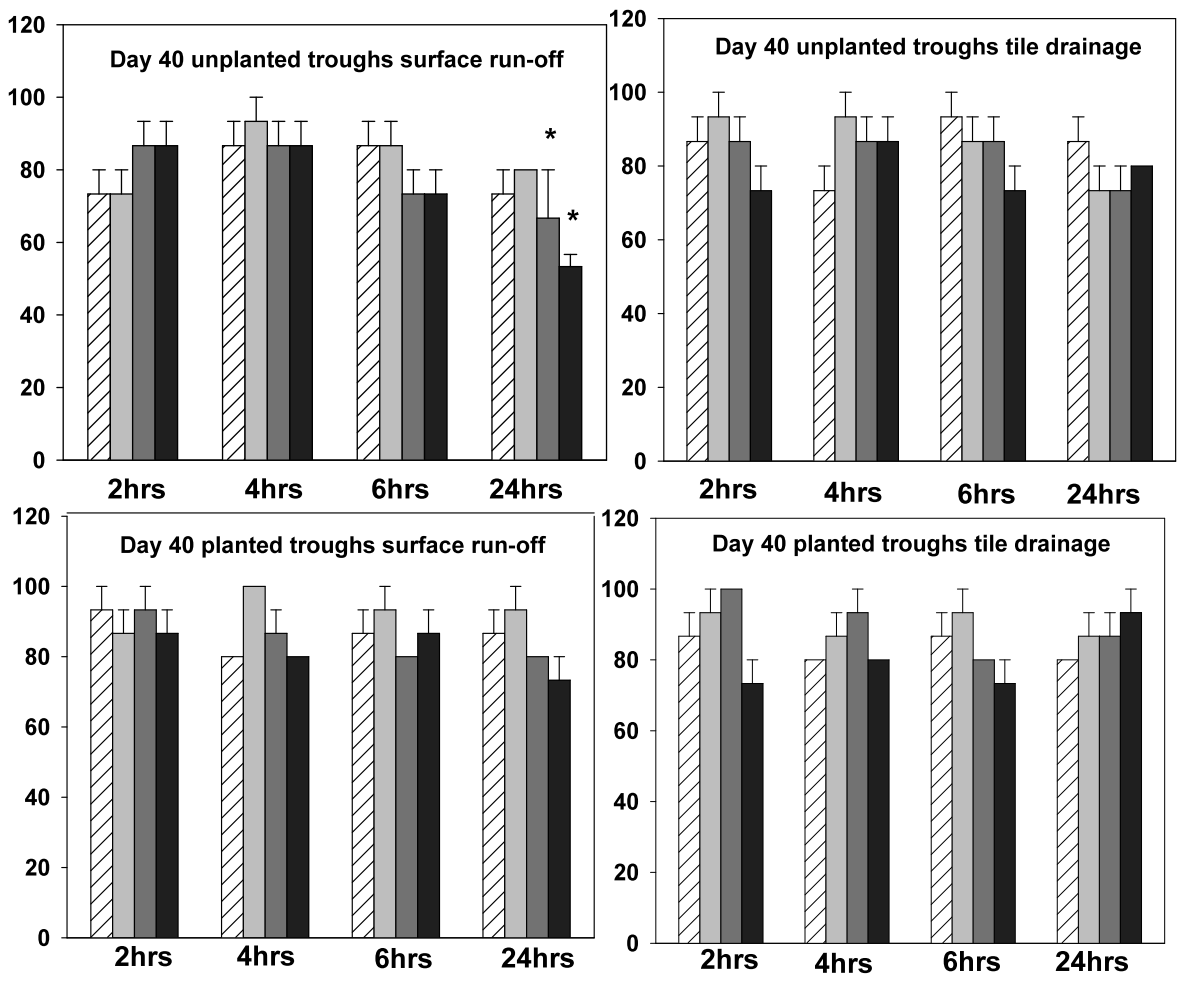

c)

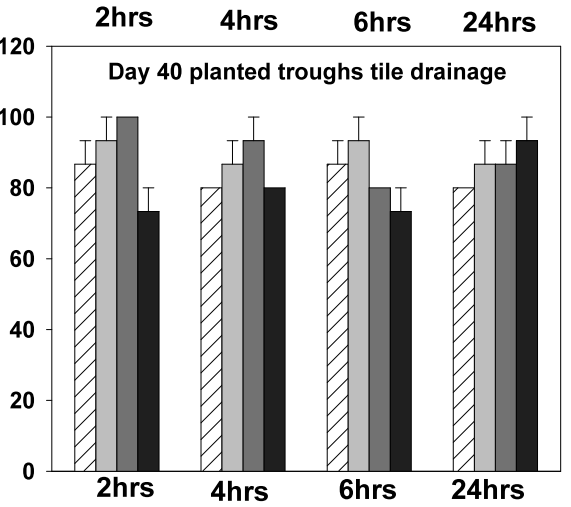

d)

$$
\begin{aligned}
& \square \text { Reference } \\
& 1 \% \text { Biosolids Runoff } \\
& 10 \% \text { Biosolids Runoff } \\
& 100 \% \text { Biosolids Runoff }
\end{aligned}
$$

Figure 18: Crawling on the substrate of Hyalella azteca exposed to varying dilutions of surface run-off and tile drainage from soil with Kitchener biosolids application. Elutriate collected on day 40 off unplanted and planted troughs. Exposure was over 24 hours period, expressed in average percentage of Hyalella azteca displaying crawling on the substrate behaviour. Values are mean \pm standard error. Significant differences (Kruskal-Wallis test) in treatments from the reference are denoted by *. 


\subsubsection{Hyalella azteca Body Length in Kitchener Biosolids Elutriate}

There is a study that has looked at body length of Hyalella azteca as a behavioural stress response (Karouna-Reiner and Sparling, 1997). Body length of Hyalella azteca is also seen as an appropriate indicator of stress for incorporation into multi-organism, early-warning biomonitoring technology (Marshall, 2009). When the organism is in normal reference conditions, it crawls on the substrate, performs swimming events, and its body is curved but elongated. Although the overall body shape is curved a little, there is a very obvious difference between normal body length and shortened body length (due to curling), which makes observations more objective than this simple description might suggest, and easy to notice.

There were no significant differences between reference and $1 \%(\mathrm{p}=0.105)$, and reference and $10 \%(\mathrm{p}=0.180)$, however there is a significant difference between reference and $100 \%$ surface Kitchener biosolids run-off $(\mathrm{p}<0.001)$ shown in figure $19 \mathrm{a}$. In tile drainage (Figure 19b), there was no significant difference between the reference and 1\% (Figure 47, p > $0.99)$, and reference and $10 \%(\mathrm{p}=0.105)$, but there was a significant difference between the reference and $100 \%$ biosolids tile drainage $(\mathrm{p}<0.001)$.

On day 40, the average percentage of Hyalella azteca displaying normal body length was not affected by Kitchener biosolids at any tested surface run-off concentration (Figure 20a, p= 0.215 ) or tile drainage concentration (Figure 20b, $\mathrm{p}=0.087$ ) on bare soil. Similarly, there was no effect of biosolids constituents in surface run-off (Figure 20c, $p=0.183$ ) or tile drainage (Figure 20d, $\mathrm{p}=0.061$ ) from vegetated soil.

The results of this experiment again suggest that whatever constituent(s) of biosolids caused a stress response on Day 1, it was no longer having an effect by Day 40. Likely, this 
constituent either decomposed or was washed off with the first imitated "rain-storm". This is consistent with the experiment that examined Hyalella azteca substrate crawling in the same elutriate. 
a)

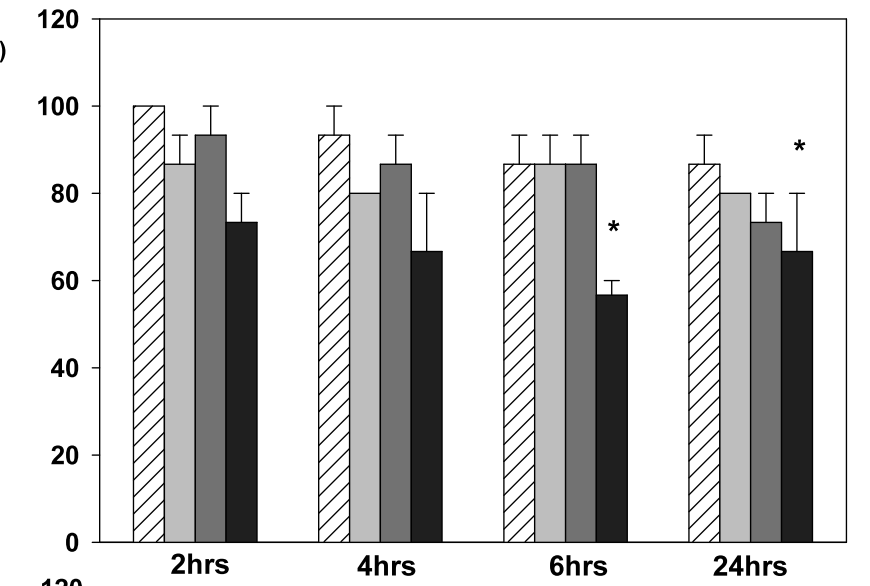

b)

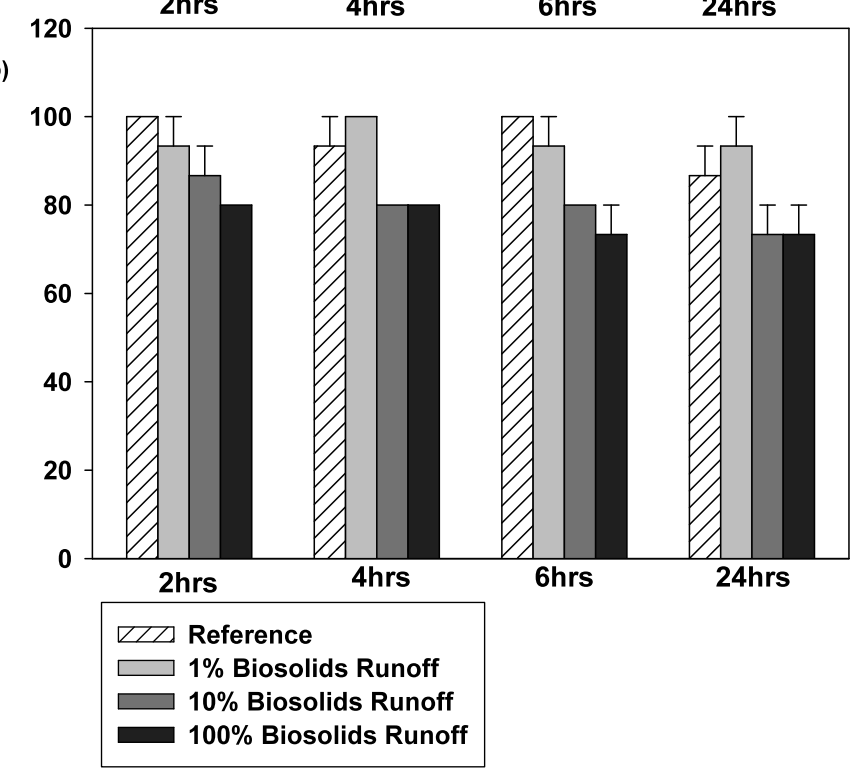

Figure 19. Hyalella azteca exposed to varying dilutions of surface run-off (a) and tile drainage (b)from soil with Kitchener biosolids application, elutriate collected on day 1. Exposure was over 24 hours period, expressed in average percentage of Hyalella azteca displaying normal body length. Values are mean \pm standard error. Significant differences (Kruskal-Wallis test) in treatments from the reference are denoted by *. 
a)

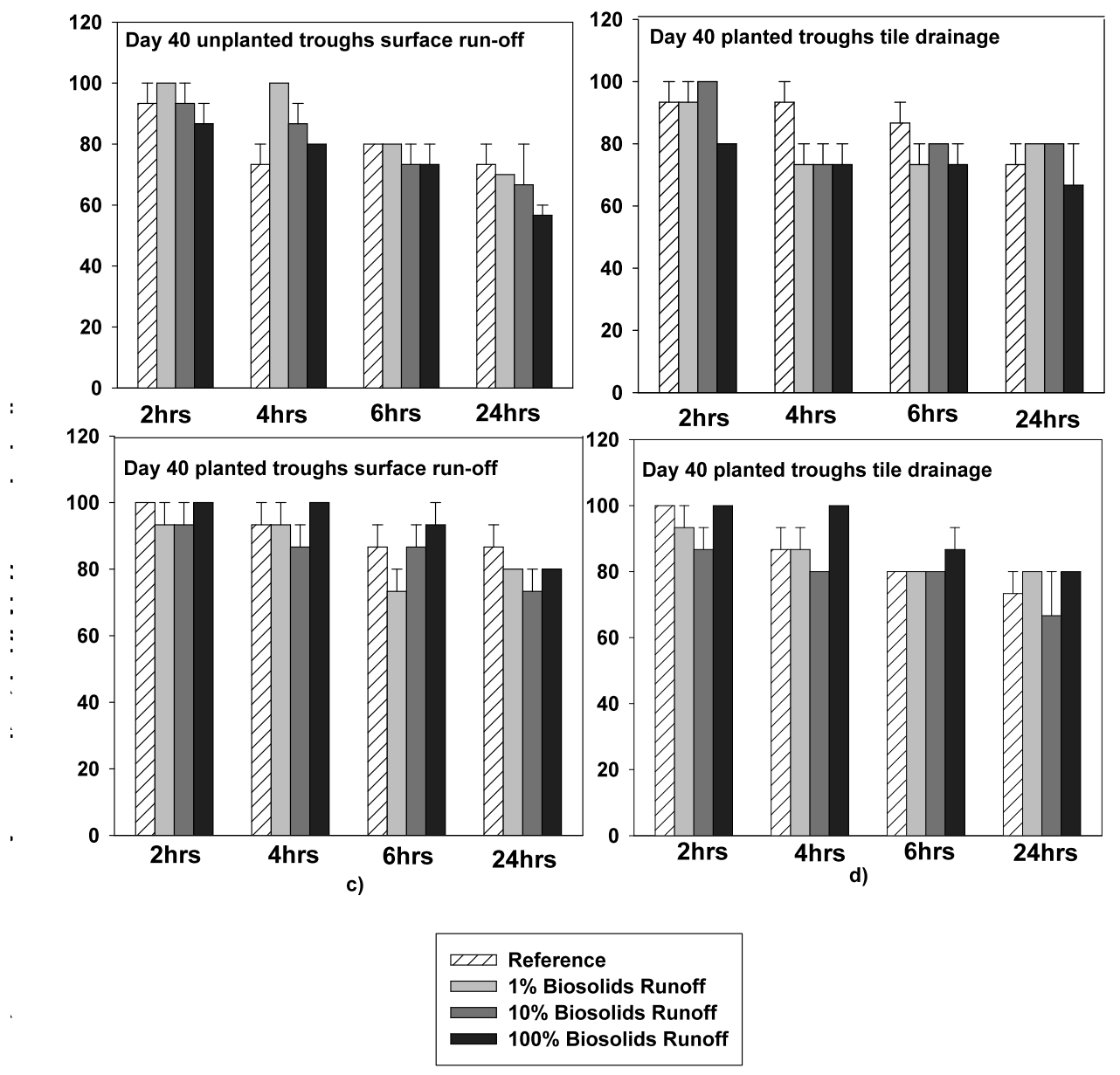

b) 


\subsection{Survivorship and Immobility of Daphnia magna in Biosolids Elutriate}

\subsubsection{Guelph Biosolids Elutriate}

\subsubsection{Daphnia magna Immobility in Guelph Biosolids Elutriate}

Daphnia magna put into test vessels with Day 1 run-off or tile drainage for behaviour experiments (swimming height and swimming style) were observed after 24 hours and 7 days to determine the percentage which remained motile and the percentage surviving at each time point. Overall, motility was affected by the $100 \%$ elutriate from surface run-off after 24 hours ( $p=$ $0.005)$, and 7 days $(\mathrm{p}=0.007)$, and by $100 \%$ elutriate from tile drainage after 24 hours $(\mathrm{p}=$ $0.009)$, and 7 days $(p=0.046)$ (Figure 21a). The same analysis performed without the $100 \%$ elutriate showed that at all lower concentrations, the Guelph biosolids run-off or drainage did not have an impact on the motility on Daphnia magna $(\mathrm{p}=0.075)$.

In the experiment where Daphnia magna were put into test vessels with Day 40 run-off or tile drainage for behaviour experiments (swimming height and swimming style), biosolids run-off and tile drainage showed no impact on motility at any concentration tested, in surface run-off or tile drainage at either time point, in elutriate from unplanted soil (Figure 21b, $\mathrm{p}=$ 0.295 ) or from planted soil (Figure $21 \mathrm{c}, \mathrm{p}=105$ ). These results indicate that after the biosolids have aged on the soil for 40 days, they will not impact the mobility of Daphnia magna even in the $100 \%$ run-off. 


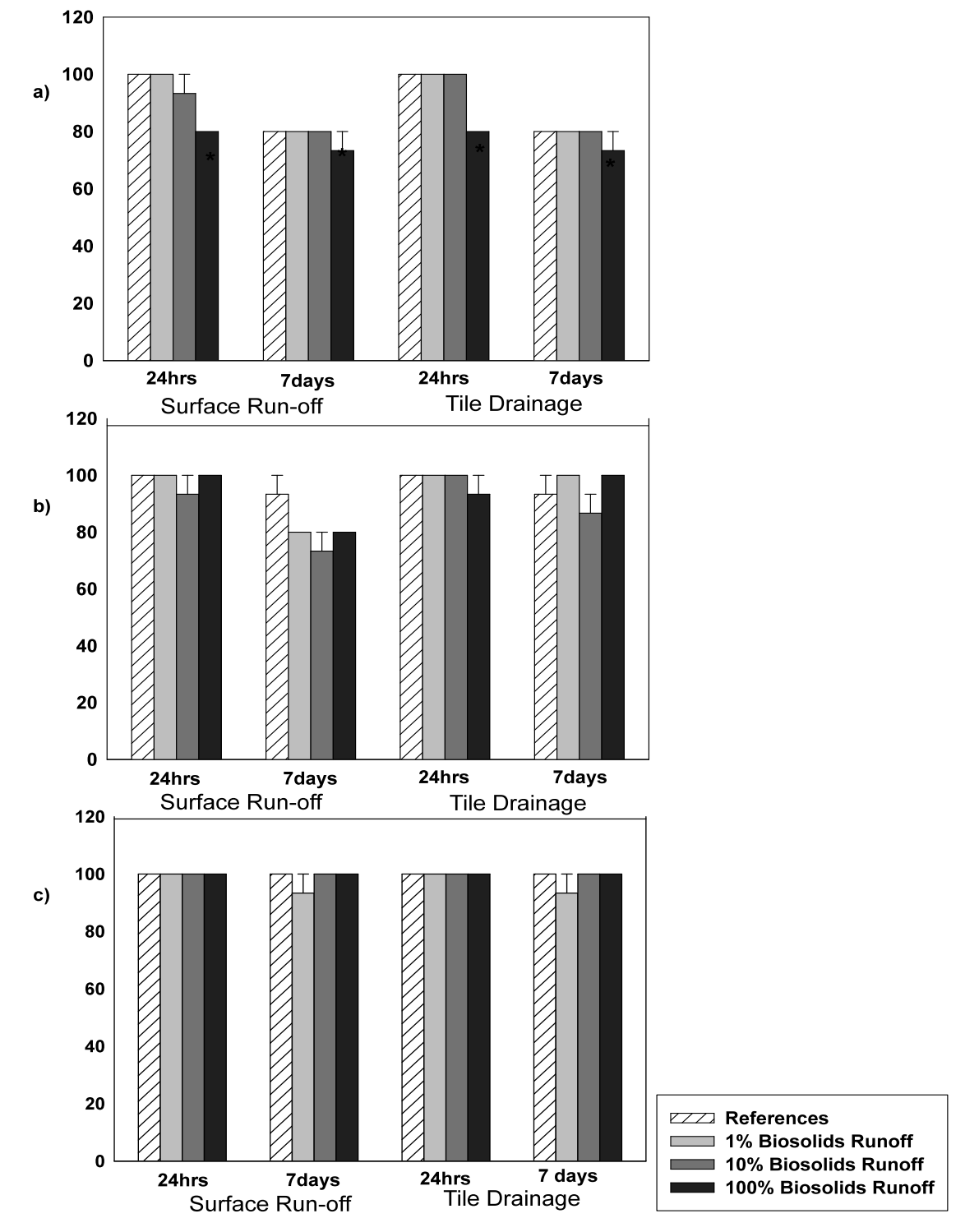

Figure 21. Average percentage of motile Daphnia magna in surface run-off and tile drainage Biosolids elutriate collected on Day 1 (a), Day 40 from unplanted (b) and planted (c) troughs,from Guelph biosolids application after 24 hours and 7 days. Values are mean \pm standard error. 


\subsubsection{Survivorship of Daphnia magna in Guelph Biosolids Elutriate}

After seven days of exposure, there was a significant difference between the surface runoff from reference soil and undiluted surface run-off from soil with biosolids application $(\mathrm{p}<$ 0.001), and between tile drainage from reference soil versus undiluted tile drainage from soil with biosolids applied $(\mathrm{p}=0.002)$ shown in figure $22 \mathrm{a}$. Excluding the $100 \%$ treatment, there was no effect of biosolids run-off or tile drainage on survivorship $(\mathrm{p}=0.405)$. These results indicate that there was no significant difference in mortality rates in Daphnia magna in environmentallyrelevant concentrations of biosolids run-off or tile drainage, even on Day 1, and highlight the importance of testing for chronic endpoints, such as survivorship.

Elutriate collected on Day 40 from unplanted (Figure 22b) and planted soil (Figure 22c) showed no residual effect of biosolids on survivorship, even after seven days exposure $(\mathrm{p}=$ $0.121, \mathrm{p}=0.280$, respectively). This result suggests that the constituent(s) of the biosolids that affected survivorship was either gone or lessened by Day 40, likely due to leaching, adsorption, or degradation. 


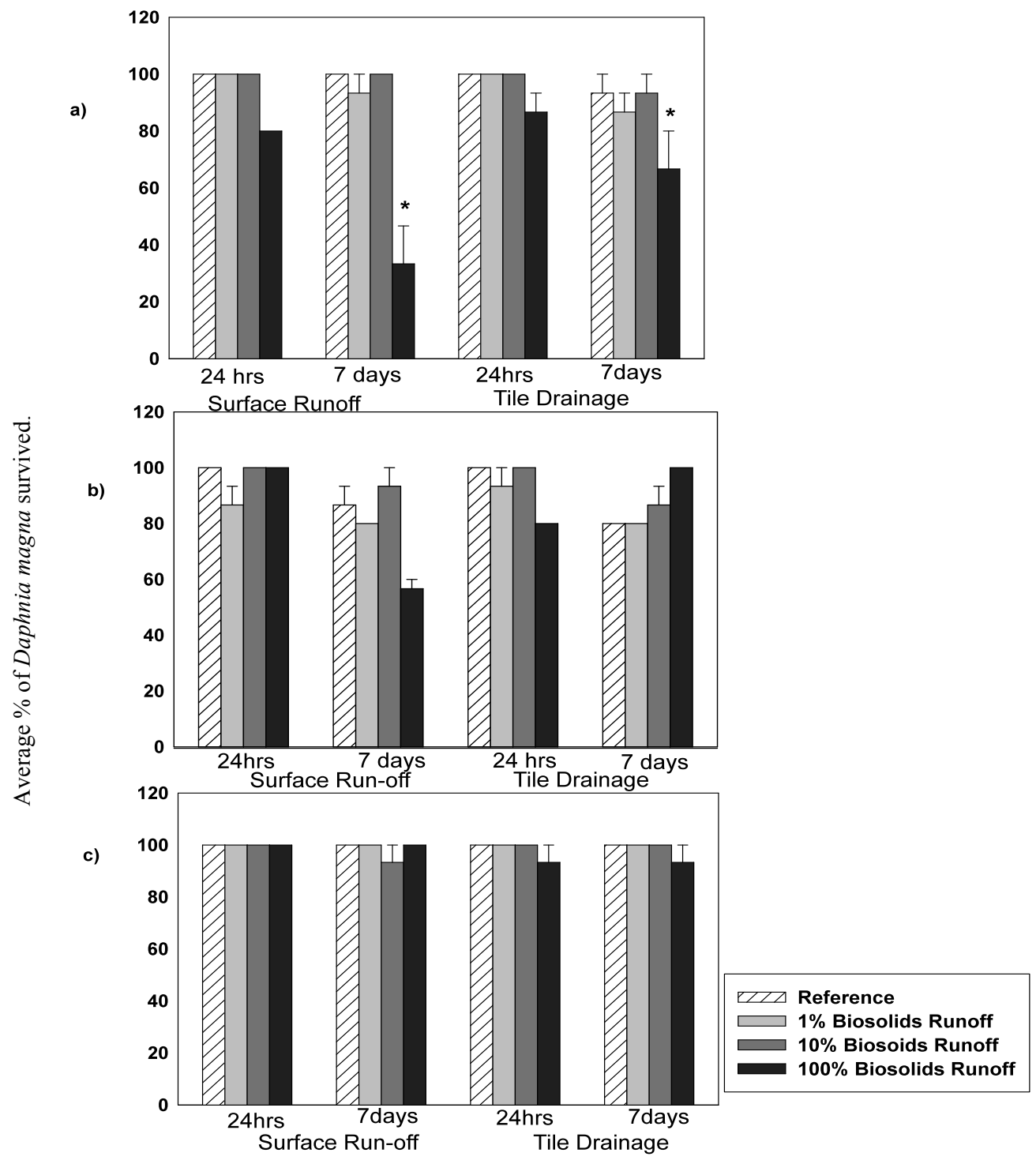

Figure 22. Average percentage of Daphnia magna survived in surface run-off and tile drainage. Biosolids elutriate collected on Day 1(a), Day 40 unplanted (b) and planted (c) troughs, from Guelph biosolids application after 24 hours and 7 days. Values are mean \pm standard error. Significant differences $(\mathrm{p} \leq 0.05)$ relative to reference in treatments from the reference are denoted by *. 
While not measured in this study, additional chronic endpoints such as reproduction could also be important measures of stressor impact. Christopher Bentley has done reproduction studies with Daphnia magna using the same elutriate in complementary studies. His research for the Guelph surface run-off collected on day 40 from unplanted troughs concluded that there was a significant reproductive impairment seen in $\mathrm{F}_{1}$ generation in $5 \%$ and $10 \%$ biosolids run-off (Bentley, 2010) (Figure 23). Even though for the most part, these biosolids concentrations would not be seen in the environment, they might be occasionally seen in ponds near agricultural fields, or other small bodies of water (Bentley, 2010). Christopher Bentley's studies done on Kitchener biosolids, show that even in elutriate collected on day 1, there was no reproductive impairment seen in either the $\mathrm{F}_{0}$ or $\mathrm{F}_{1}$ generation of Daphnia magna.

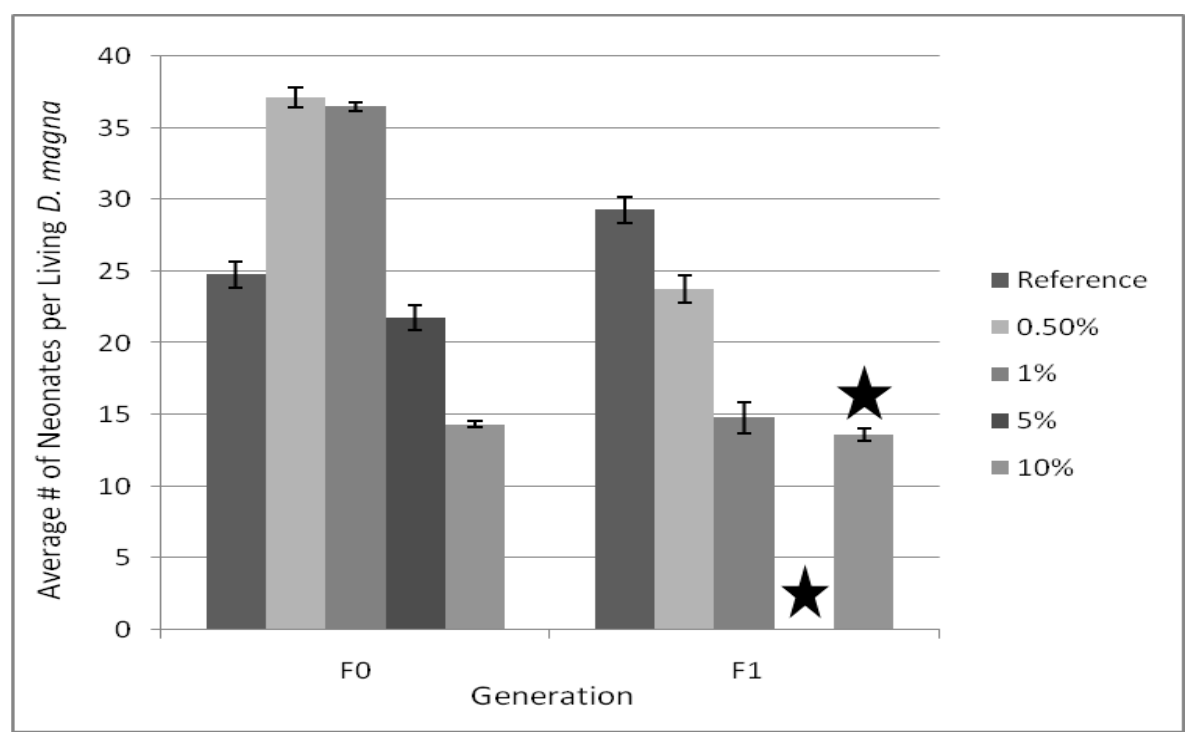

Figure 23. Neonate production in Guelph biosolids surface run-off, F0 and F1 generations (Bentley, 2010). 


\subsubsection{Survivorship and Immobility in Kitchener Biosolids Elutriate}

In an experiment using surface run-off and tile drainage collected on Day 1, there were no Daphnia magna immobilized or dead after 24 hours exposure. Although survivorship decreased over one week, there was no significant difference in survivorship among treatments after 7 days (Figure 24a, $\mathrm{p}=0.167$ ). Similarly, there was no significant impact of biosolids on motility of Daphnia magna after 7 days exposure (Figure 24, $\mathrm{p}=0.158$ ).

These results indicate that even undiluted run-off or tile drainage from soil receiving the maximum allowable application of Kitchener biosolids the day after application does not pose a risk of immobilizing or killing Daphnia magna in receiving waters. This is in contrast to the Guelph biosolids which did cause a significant decrease in motility and survivorship in elutriate collected one day after application.

As expected from results using Day 1 elutriate, Kitchener biosolids had no impact on motility or survivorship in elutriate collected on Day 40. In run-off and tile drainage collected from unplanted soil, were no immobile or dead Daphnia magna after 24 hours. The only organism to die during the experiment was in $100 \%$ surface run-off, giving this treatment a survivorship rate of $93 \%$. In run-off and tile drainage collected from planted soil, there were again no immobile or dead Daphnia magna after 24 hours, and the only organism to die during the experiment was in $10 \%$ tile drainage. This set of results indicated that after aging of the Kitchener biosolids, there was no significant impact on motility or survivorship of Daphnia magna. 


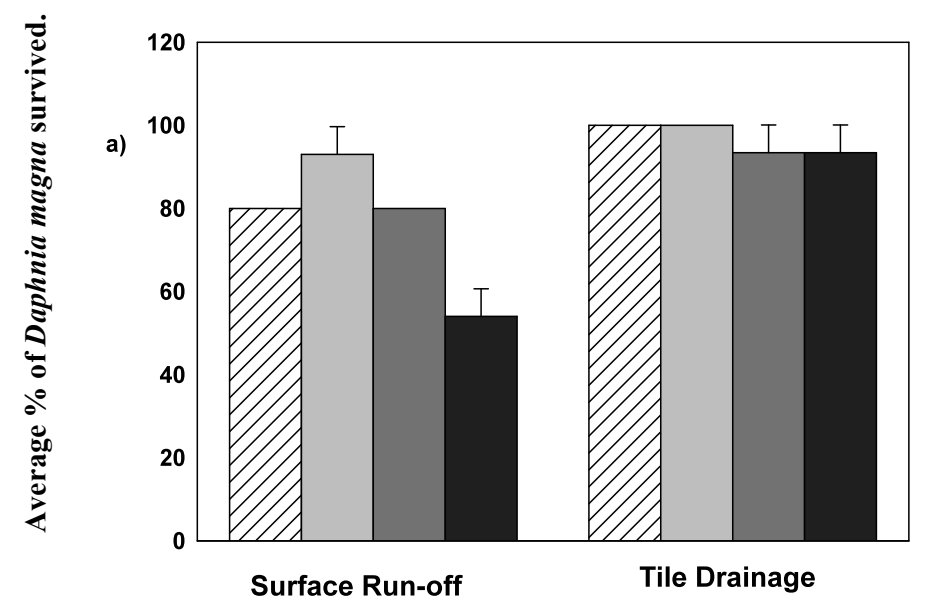

b)

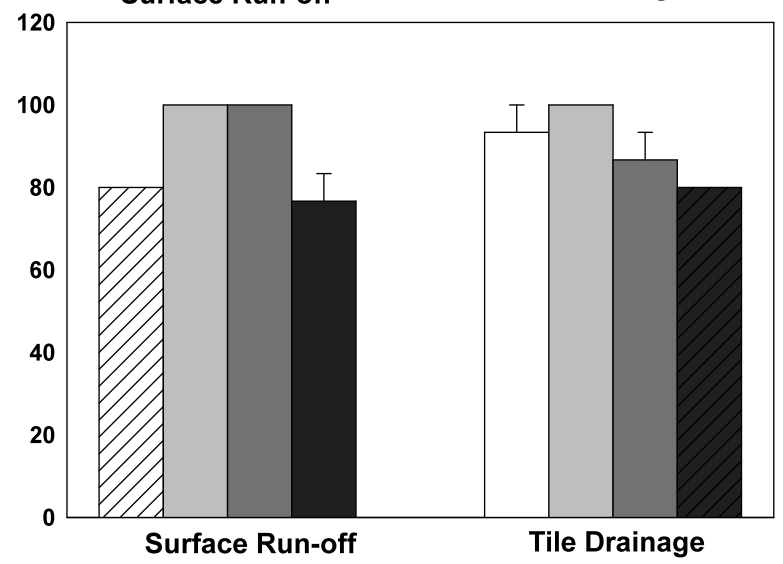

$$
\begin{aligned}
& \text { Reference } \\
& 1 \% \text { Biosolids Runoff } \\
& 10 \% \text { Biosolids Runoff } \\
& 100 \% \text { Biosolids Runoff } \\
& 1 \square
\end{aligned}
$$

Figure 24: Average percentage of Daphnia magna survived in surface run-off and tile drainage (collected on Day 1) from Kitchener biosolids application after 7 days (a). Average percentage of motile Daphnia magna in surface run-off and tile drainage collected on Day1 from Kitchener biosolids application after 7 days (b). Values are mean \pm standard error. 


\section{4 . Summary of Behavioural Responses of Macroinvertebrates to Biosolids Elutriate}

In terms of Guelph biosolids elutriate and effect on behaviour of Daphnia magna, the only result that is of concern, in regards to Guelph biosolids elutriate is the swimming height of Daphnia magna in surface run-off collected on Day 1, where there is a significant difference between the reference and all three biosolids run-off concentrations. This result is of concern because it is showing that a significant number of Daphnia magna were unable to swim through the water column even at $1 \%$ which is environmentally relevant. All other results regarding the swimming height and swimming style of Daphnia magna are at biosolids concentrations that are higher than realistically found in nature, but even so they are a good indicator that Guelph biosolids do have toxic substances that can impair the swimming behaviour of Daphnia magna which is crucial for its survival. Another point that is being raised with these results is that plants not only can help prevent the toxic substances penetrating through the soil, but can also help in reduction of toxicity of surface run-off (probably through the prevention of erosion). This is clearly seen between the surface run-offs from unplanted and planted troughs that were collected on Day 40.

In terms of Kitchener biosolids elutriate and the effect on behaviour of Daphnia magna, there is no significant difference between the swimming height and swimming style in any of the biosolids concentrations at any time of collection. This is also consistent with the respiration in Kitchener elutriate, which is really indicating that even under the worst case scenario at $100 \%$ biosolids elutriate, Kitchener biosolids are not posing a significant risk to Daphnia magna. 
In conclusion for Hyalella azteca behaviour in Kitchener biosolids elutriate it can be said that although there are significant treatment effects, those are only seen at a $100 \%$ run-off and on day 1. Although it is important to recognize this, Hyalella azteca are highly unlikely to encounter raw, undiluted biosolids run-off in nature. Also, this set of results has shown that Hyalella azteca appears to be a more sensitive organism to biosolids run-off and drainage than Daphnia magna, which was shown also in respiration results for Hyalella azteca in Guelph biosolids elutriate.

Both invertebrates are widely used in ecotoxicological studies, however Daphnia magna is more commonly used as it is thought to be more sensitive to a variety of toxicants (Dodson and Hanazato, 1995; Paul et al, 1997; Ren et al, 2007). Hyalella azteca is widely used for sediment toxicity and is also regarded as a sensitive organism (Hatch and Burton, 1999, Wang et al, 2004). From this thesis, and other studies it is clear that different end points and multiple organism have to be used to assess toxicity especially on unknown chemical mixtures and toxicants (Suedel and Rogers, 1996; McCarthy, 2004; Marshall, 2009)

\subsection{Lemna minor 7 day Growth Inhibition Tests in Kitchener Biosolids Surface Run-off}

Three experiments with Lemna minor plants were performed in collected Kitchener biosolids run-off. The experiments were seven day growth inhibition tests that are the standard Lemna minor toxicity experiment (Environment Canada, 2007). Maintaining healthy cultures of Lemna minor with appropriate doubling times to meet the specifications of the protocol proved difficult in the laboratory as already explained in Materials and Methods. Lemna minor experiments were limited to use with Kitchener surface run-off because slow doubling times of Lemna in culture during the times Guelph biosolids elutriates were generated would not have 
produced appropriate results (mean number of frond in the reference must have increased to equal or more than eight times the original number of fronds by the end of 7 day test period in order for the test to be considered valid under the Environment Canada protocol).

There was a significant difference between the reference and the $1 \%(\mathrm{p}<0.001), 10 \%(\mathrm{p}$ $<0.001)$ and $100 \%(\mathrm{p}<0.001)$ concentrations of run-off from biosolids-amended soil collected on Day 1 (Figure 25). There was no significant effect of biosolids in surface run-off collected on Day 40 from unplanted and planted troughs $(\mathrm{p}=0.120)$. This result suggests that run-off from Kitchener biosolids on Day 1 contained enough nutrients to be able to double the growth rate of Lemna minor at $10 \%$, and enough nutrients to significantly increase the growth rate at even $1 \%$ run-off. This stimulation may be due to phosphate, commonly the limiting nutrient in the aquatic systems. What is interesting to note is that the highest growth rate in Lemna minor was seen at $10 \%$ run-off and not in a $100 \%$ run-off. This might suggest growth inhibition by something in undiluted biosolids run-off. Therefore, although there were enough nutrients for rapid growth, there might have been a high enough concentration of something to partially offset the fertilization effect. These results suggest that at even low, environmentally-relevant concentrations of biosolids run-off, there could be a significant increase in growth of duckweed, and likely other autotrophs. This might be worrisome, because it is suggesting eutrophication of receiving waters as a risk of biosolids land application.

The fact that there was no significant stimulation of growth in run-off from Day 40 (figure 25) suggests that the risk of eutrophication may be short-lived, with nutrients leaching from biosolids in a single, large pulse, consistent with the literature (Sydney, 2009). With even short-term aging, the biosolids may not pose significant risk of eutrophication. 


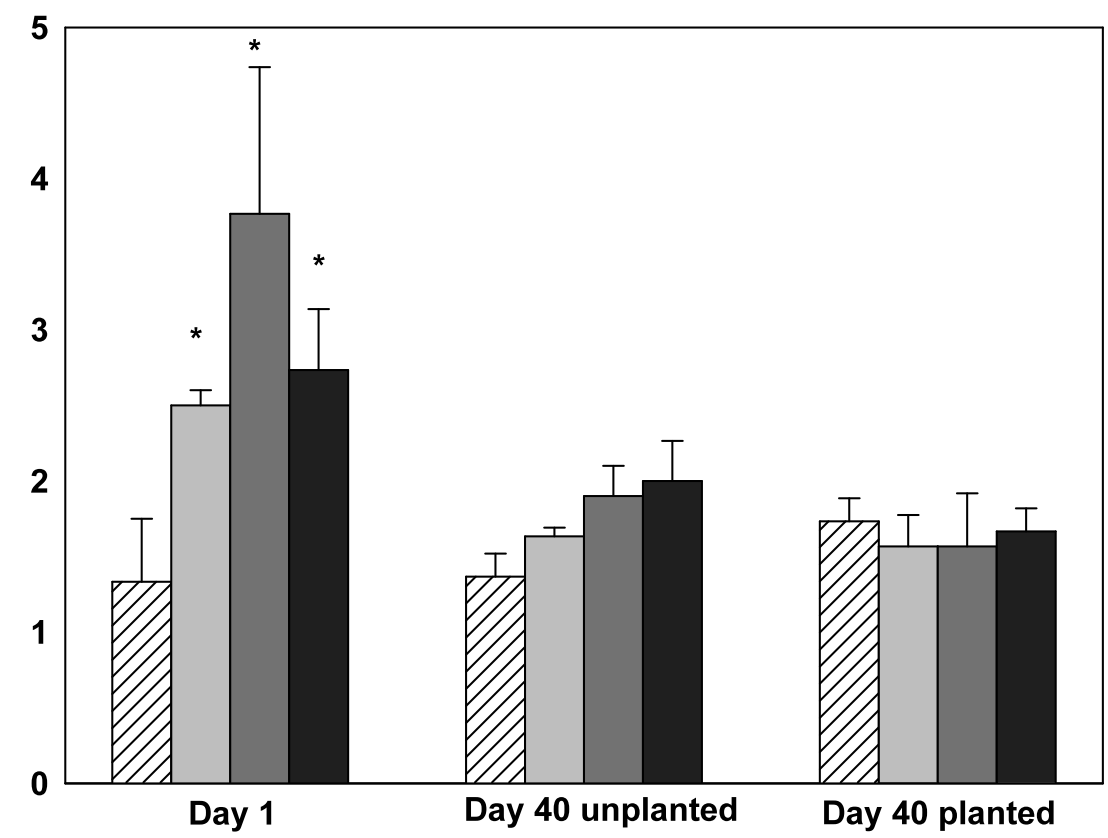

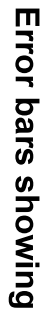

$$
\begin{aligned}
& \square Z I D \text { Reference } \\
& \begin{array}{l}
1 \% \text { Biosolids Runoff } \\
10 \% \text { Biosolids Runoff } \\
100 \% \text { Biosolids Runoff }
\end{array} \\
& \begin{array}{l}
\square \\
100
\end{array}
\end{aligned}
$$

Figure 24. Average dry weight of 3 Lemna minor plants in surface Kitchener biosolids run-off collected on day 1, on day 40 (unplanted and planted troughs). Values are mean \pm standard deviation. Significant differences $(\mathrm{p} \leq 0.05)$ in treatments from the reference are denoted by $*$. 


\subsection{Conclusions}

The purpose of this study was to examine the impact that Guelph and Kitchener biosolids, as representative examples of biosolids produced in Southern Ontario, have on organisms in water receiving run-off and tile drainage from agricultural land. Both of the freshwater invertebrates and the macrophyte used in these experiments, Daphnia magna, Hyalella azteca and Lemna minor are widely used for eco-toxicity testing.

\subsubsection{Hypotheses Revisited}

Respiration is a good physiological endpoint for determining stress, as it integrates whole-organism metabolism and disruptions thereof. It has also been used widely and is a very sensitive indicator of stress (Geiger and Buikema, 1981; Oberlin and Blinn, 1997).

Concentrations of biosolids elutriate that caused a significant effect on respiration rates were not considered environmentally relevant, as run-off and tile drainage from fields with biosolids applied would be diluted upon entering receiving water. Effects on respiration were seen in both invertebrates in only Guelph biosolids run-off and tile drainage. The respiration rates of macroinvertebrates were not affected by run-off or tile drainage from Kitchener biosolids at any time or at any concentrations. Therefore, based on respiratory responses, neither source of biosolids, if applied to agricultural soil, is expected to cause metabolic stress to macroinvertebrates in receiving water.

Behavioural responses were examined since these sub-lethal responses can occur at stressor concentrations below those necessary to induce physiological stress, and these 
behavioural responses can have meaningful consequences for the ecology of an organism. These behavioural responses are also convenient indicators of stress as they can be visually distinguished from normal behaviour, and show very rapid responses to contaminants (Doving, 1991). Most of the behavioural responses to biosolids run-off were from the Guelph biosolids, with effects on both organisms in run-off and tile drainage collected on Days 1 and 40, and some impacts seen in Hyalella azteca behaviour in Kitchener biosolids run-off collected on Day 1. This said, all of the impacts described for biosolids on macroinvertebrate behaviour occurred at concentrations not considered environmentally relevant. These results again suggest that neither source of biosolids, if applied to agricultural soil, is likely to impact behaviour of these invertebrates in receiving water. The results also support the suggestion that behavioural responses are more sensitive indicators of stress, and should be included in future studies to assess safety of substances released into the environment. Finally, the behavioural results suggest that biosolids sources vary in terms of impact on organisms and cannot all be considered equal. While neither of the tested biosolids sources are expected to cause harm to macroinvertebrates in receiving waters under foreseeable conditions, differences in impact observed between Guelph biosolids and Kitchener biosolids calls for a cautious approach with further testing of potential impact using additional sources. This future testing should include macroinvertebrate behaviour assays.

The final endpoints tested for the two invertebrates were survivorship and immobility. The results obtained here were consistent with all the other results previously described in that there is no indication of risk to life or mobility from applying these two sources of biosolids to the agricultural fields, under foreseeable conditions. 
The only potential adverse effects of biosolids run-off under environmentally-relevant conditions was seen in Lemna minor 7-day growth inhibition tests, also widely used around the world for effluent testing and many other eco-toxicological studies. These experiments showed that Kitchener biosolids migh support higher growth at concentrations as low as $1 \%$ biosolids run-off. This effect disappears by Day 40, but the first set of results with Lemna minor are suggesting that Kitchener biosolids might start or contribute to eutrophication in receiving water. This is not a very surprising result, as it is known that all kinds of animal by-products and waste contain large amounts of nutrients. This is also an on-going environmental problem not only from the manure and waste but from commercial fertilizers. Because of this, it would be meaningful to repeat this study but with inclusion of commercial fertilizers used in Southern Ontario and for which biosolids might be substituted when land applied in practice. This would allow a more relevant comparison of likely impact of biosolids on eutrophication. Also the Lemna minor results are supporting the fourth hypothesis of this study, which states that the biosolids will effect the plant, both in stimulatory manner as well as inhibitory.

The results from the study support the first hypothesis which states that elutriate from biosolids will have an effect on behaviour, respiration and survivorship of the invertebrates and plant. Also the results have shown that this effect decreases significantly as the biosolids age (as shown in differences between effects in elutriate from Day 1 versus Day 40. The results from this study also support the hypothesis that the effect seen in elutriate collected from vegetated troughs will have a smaller effect than from troughs that were un-vegetated. Also, the results for the most part have shown that elutriate from tile drainage has less impact on the organisms than surface run-off 
From the stand point of a wide-spread aquatic daphnid and amphipod, the Guelph and Kitchener biosolids do not pose an overall significant risk to their respiration, behaviour, mobility and survival, even when applied at the highest allowable rate and with the run-off generated by a 100 -year storm occurring only one day after application. This is indicating that use of biosolids might be a step towards more sustainable agriculture which is critically needed in today's world, as well as more sustainable waste disposal. However, it is also crucially important to recognize that some impacts from biosolids were seen, albeit at environmentally irrelevant concentrations. The endpoints used in this study were very short-term acute responses and there is a need to assess also the long-term impacts such as reproduction. It is important to use plants and organism such as Daphnia magna, Hyalella azteca, Lemna minor and others such as algae and primary producers and consumers because they are the building foundation of the food web and if there is a negative impact seen on these organisms, the whole food web is likely to be impacted. For the biosolids to be used on a larger scale there must be many more analytical as well as eco-toxicological studies done that are relevant to the laws, regulations and topography in Ontario. It is important to realize that the laws regarding the allowable limits of contaminants were established in the 1970s and regulate only for eleven metals and pathogens, and that is simply not enough to cover the potential contaminants that be found in biosolids today. Because of this, it is imperative that plants and animals are used to assess toxicity since they can tell about many more contaminants than that on the list for regulation of biosolids.

The use of biosolids as a soil amendment is, in its core, a great idea. It is more sustainable than the use of commercial fertilizers produced by mining and with intensive inputs of fossil fuels; instead of digging millions of tones of phosphorus out of the ground that ultimately ends up in rivers, lakes and oceans, using biosolids is using something that we produce and can 
recycle. Saying this, it is important to improve public perception of biosolids and educate that it is time to start closing the enormous gaps that exist between producers and consumers if it can be accomplished safely. The results of this thesis support that it may be accomplished safely, at least from the admittedly narrow perspective of impacts of biosolids run-off on aquatic organisms. 


\section{References}

Alloway, B.J., Jackson, A.P. (1991) The behaviour of heavy metals in sewage sludgeamended soils. Science of the Total Environment. 100: 76-105.

Andrews, D. (2003) Wastewater Operations and Maintenance Contracts Performance. E03-063, Region of Waterloo Transportation and Environmental Sciences, Water Services, Region of Waterloo, ON.

Axelrod, D., Burns, K., Davis, D., von Larebeke, N. ( 2004) "Hormesis"—an inappropriate extrapolation from the specific to the universal" International Journal of Occupational and Environmental Health 10: 335-339.

Banerjee, M.R., Burton, D.L., Depoe, S. (1997) Impact of sewage sludge application on soil application characteristics. Agriculture and Ecosystem Environment 66: 241-249.

Bartling, H. (2008) Sustainability .The Ontario-Michigan Trash wars.

http://hughbartling.com/blog/?p=19 (Accessed October 2009).

Bentley, C. (2010) A Multigenerational Study on the Effects of Biosolids on Daphnia magna's Reproduction and Survivorship. Ryerson University Undergraduate Thesis. Department of Chemistry and Biology. Ryerson University.

Bozkurt, M.A., Yarilgac, T. (2003) The effect of sewage sludge application on the yield, growth, nutrition and heavy metal accumulation in apple trees growing in dry condition. Journal of Agriculture 27: 285-292.

Brunec-Turk, V. (1998) Effect of Cadmium and Zinc exposure on the freshwater amphipod Hyalella azteca. University of Calgary master thesis. Deparment of Biology. University of Calgary.

Calabrese, E.J. (2005) Paradigm lost, paradigm found: the re-emergence of hormesis s a fundamental dose response model in toxicological sciences. Environmental Pollution 138: $379-412$.

City of Guelph (2010) Grow your future in the city of Guelph. http://guelph.ca/business.cfm?smocid=1555 (Accessed July 2010)

City of Toronto (2009) Biosolids and Residual Master Plan.

http://www.toronto.ca/wes/techservices/involved/wws/biosolids/pdf/brmp/brmp i-viii.pdf

(Accessed November, 2009)

City of Toronto (2010) Living in Toronto. Early History of wastewater treatment in Toronto http://www.toronto.ca/water/wastewater treatment/history.htm (Accessed July, 2010). 
Dodson, S.I. and Hanazato, T. (1995) Commentary on Effects of Anthropogenic and Natural Organic Chemicals on Development, Swimming Behavior, and Reproduction of Daphnia, a Key Member of Aquatic Ecosystems. Environmental Health Perspectives 103: 711.

Doving, K. (1991) Assessment of animal behaviour as a method to indicate environmental toxicity. Comparative Biochemistry and Physiology 1/2: 247-252.

Draggan, S. (2009) Nutrient management. U.S. Department of Agriculture . Washington, D.C.: Environmental Information Coalition, National Council for Science and the Environment.

Environment Canada (1996) Biological Test Method : Acute Lethality Test Using Daphnia spp. Method Development and Applications Section, Environmental Technology Centre. Report EPS 1/RM/11.

Environment Canada (1997) Biological Test Method: Test for Survival and Growth in Sediment Using the Freshwater Amphipod Hyalella azteca. Method Development and Applications Section, Environmental Technology Centre. Report EPS 1/RM/33.

Environment Canada (2005) Biological Test Method: Test for Measuring Emergence and Growth of Terrestrial Plants Exposed to Contaminants in Soil. Method Development and Applications Section, Environmental Technology Centre. Report EPS 1/RM/45.

Environment Canada (2007) Biological Test Method: Test for Measuring the Inhibition of Growth Using the Freswater Macrophyte, Lemna minor. Method Development and Applications Section, Environmental Technology Centre. Report EPS 1/RM/37.

Environment Canada (2009) Canada's National Climate Archive. Canadian Climate Normals and Averages. Ontario Weather Review.

http://climate.weatheroffice.gc.ca/climate_normals/index_e.html (Accessed September, 2009)

European Commission (2006) Is Sewage Sludge Fuel or a Waste? Science for Environment Policy. News Alert Issue 37.

http://ec.europa.eu/environment/integration/research/newsalert/pdf/37na1.pdf(Acessed June 2010)

European Commission (2010). Environment. Waste. Sewage Sludge.

http://ec.europa.eu/environment/waste/sludge/index.htm. Accessed July 2010. 
Epistein, E., Taylor, J.M., Chaney, R. L. (1976). Effects of Sewage sludge and sludge compost applied to soil on some soil physical and chemical properties. Journal of Environmental Quality. 5: 422-426.

Fischer, J.M., Fields, P.A., Pryzbylkowski, P.G., Nicolai, J.L. and Neale, P.J. (2006) Sublethal exposure to UV radiation affects respiration rates of the freshwater cladoceran Daphnia catawba. Photochemistry and Photobiology 82: 547-550.

Fjallborg, B., Dave, G. (2003). Toxicity of Sb and Cu in Sewage sludge to Terrestrial Plants ( Lettuce, Oat, Radish), and of Sludge Elutriate to Aquatic Organisms (Daphnia and Lemna) and its interactions. Water, Air and Soil Pollution 155: 3-20.

Fjallborg, B., Ahlberg, G., Nilsson, E., Dave, G. (2005). Identification of metal toxicity in sewage sludge leachate. Environment International 31: 25-31.

Geiger, J.G. and Buikema, A.L. (1981) Oxygen consumption and filtering rate of Daphnia pulex after exposure to water-soluble fractions of naphthalene, phenathrene, No. 2 Fuel Oil and coal-tar creosote. Bulletin of Environmental Contamination and Toxicology 27: 783-789.

Hakanson, L., Eckhell, J. (2005). Suspended particulate matter (SPM) in the Baltic Sea-New emipirical data and models. Ecological Modeling 189: 130-150.

Hatch, A.C, and Burton, G.A. (1999) Photo-induced toxicity of PAHs to Hyalella azteca and Chironomus tentans: effects of mixtures and behavior. Environmental Pollution 106: 157-167.

Hebert, M. (2004). Guidelines for the beneficial use of fertilizing residuals: Reference criteria and regulatory standards. Quebec Ministry of Environment. QB. p138-140.

Holt, L.M., Laursen, A.E., McCarthy H.L., Bostan, V.I., Spongberg, A.L. (2010). Effects of land application of municipal biosolids on nitrogen-fixing bacteria in agricultural soil. Biology and Fertility of Soils. 46:407-413.

Holt, L.M. (2007). The Ecological Effects of Land-Applying Municipal Biosolids on Nitrogen Fixing Bacteria. Master's Thesis in Environmental Applied Science and Management. Ryerson University.

Jenness, N. (2001). Mine Reclamation Using Biosolids. United States Environmental Protection Agency - Office of Solid Waste and Emergency Response Technology Innovation Office.

Washington, DC.

Joshua, W.D., Michalk, D.L., Curtis, I.H., Salt, M., Osborne, G.J. (1998). The potential for contamination of soil and surfacewaters from sewage sludge biosolids/ in a sheep grazing study, Australia. Geoderma 84:135-156. 
Kacprzak, M., Neczaj, E., Okoneiwska, E. (2005). The comparative mycological analysis of wastewater and sewage sludges from selected wastewater treatment plants. Desalination 185: $363-370$.

Kagan, D., Ozment, S., Turner, F. (2004) The Western Heritage. $8^{\text {th }}$ Edition. London: Prentice Hall. pp 535-542.

Karouna-Reiner, N.K., Sparling, D.W. (1997) Toxicity of Storm-water treated Pond

Sediments to Hyalella azteca (Amphipoda) Bulletin of Environmental Contamination and Toxicology. 58: 550-557.

Kefford, B.J., Zalizniak, L., Warne, M.J., Nugegoda, D. (2008) Is the integration of hormesis and essentiality into ecotoxicology now opening Pandora's Box? Environmental Pollution 151: 516-523.

Khan, R., McMahom, M., DeCanio S.J. (1987) Sewage Sludge: A Fascinating Feedstock for Clean Energy. Texaco Research and Development.

Kim, B., McBride, M.B., Richards, B.K., Steenhuis, T.S. (2007). The long-term effect of sludge application on $\mathrm{Cu}, \mathrm{Zn}$ and $\mathrm{Mo}$ behavior in soils and accumulation in soybean seeds. Plant Soil. 299:227-236.

Kinney, C., Furlong, T., Zaugg, M., Werner, S., Cahill, H., Jorgensen, G. (2006) Survey of Organic Wastewater Contaminants in Biosolids Destined for Land Application.

Environmental Science and Technology: 40: 7207-7215.

Kostich, M., Lazorchak, J. (2008) Risks to aquatic organisms posed by human pharmaceutical use. Science of the Total Environment. 389: 329-339.

Lewis, A. (2006). Regulatory Framework for Biosolids Management in Canada. Prepared for the Greater Vancuver Regional District, Burnaby, BC.

Logan, T.J., Harrison, B.J. (1995). Physical characteristics of alkaline stabilized sewage sludge and their effects on soil properties. Journal of Environmental Quality. 24, 153-164.

Lystek International. 2010. www.lystek.com (Accessed July 2010)

Marshall, G.C. (2009) Assessing behavioural and physiological responses of three aquatic invertebrates to atrazine and tributyl tin in a multi-species, early-warning biomonitoring technology. Master's of Applied Science in the Program of Environmental Applied Science and Management. Ryerson University. 
Martins, J., Soares, M.L., Saker, M.L., Oliva-Teles, L. and Vasconelos, V.M. (2007a)

Phototactic behavior in Daphnia magna Straus as an indicator of toxicants in the aquatic environment. Ecotoxicology and Environmental Safety 67: 417-422.

Martins, J.C., Saker, M.L., Teles, L.F.O. and Vasconcelos, V.M. (2007b) Oxygen consumption by Daphnia magna Straus as a marker of chemical stress in the aquatic environment.

Environmental Toxicology and Chemistry 26: 1987-1991.

McBride, M. (1998). Growing food crops in sludge-amended soils: problems with the US environmental Protection agency method of estimating toxic metal transfer. Environmental Toxicology and Chemistry. 17: 2274-2281.

McCarthy, L., Bostan, V., Liss, S.(2004). Assessing the impact of land-applied biosolids from a thermomechanical (TMP) pulp mill to a suite of terrestrial and aquatic bioassay organisms under laboratory conditions. Waste Management. 25:89-100

McLachlan, M., Horstmann, M., Hinkel, M. (1996). Polychlorinated dibenzo-p-diozins and dibenzofurans in sewage sludge: sources and fate following sludge application to land. Science of the Total Environment. 185: 109-123.

Mendoza C., Assadian N., Lideman W. (2006) The fate of nitrogen in a moderately alkaline and calcerous soil amended with biosolids and urea. Chemosphere. 63:1933-1941.

Metcalf and Eddy, Inc. (2003). Wastewater engineering: Treatment, Disposal, and Reuse, Fourth ed. McGraw-Hill Publishing Company Ltd., New York.

Michels, E., Semsari, S., Bin, C., De Meester, L. (2000) Effect of Sublethal Doses of Cadmium on the Phototactic Behavior of Daphnia magna. Ecotoxicology and Environmental Safety 47: 261-265.

Oberlin, G.E. and Blinn, D.W. (1997) The affect of temperature on the metabolism and behaviour of an endemic amphipod, Hyalella montezuma, from Montezuma Well, Arizona, U.S.A. Freshwater Biology 37: 55-59.

Okun, D. (1962) Wastewater Treatment in Europe. Water Pollution Control Federation 34:704722.

Olekszewics, J.A. Mavinic, D.S. (2002) Wastewater biosolids: an overview of processing, treatment and management. Environmental Science and Engineering 28: 102-104.

Ontario Ministry of Agriculture Food and Rural Affairs (2010a) Field Crop Statistics, Area and Production Estimates by County

http://www.omafra.gov.on.ca/english/stats/crops/index.html accessed July, 2010 
Ontario Ministry of Agriculture Food and Rural Affairs (2010b) Sewage Biosolids - Managing Urban Nutrients Responsibly for Crop Production.

http://www.omafra.gov.on.ca/english/nm/nasm/info/brochure.htm. Accessed July 2010.

Ontario Ministry of Environment, and Ontario Ministry of Agriculture and Food (2004) Guide for the Beneficial Use of Non-Agricultural Source Materials on Agricultural Land. Materials Policy/ Nutrient Management Unit, Waste Management Policy Branch, Ontario Ministry of Environment, Toronto, ON.

Ontario Ministry of Environment (2010) Land - Biosolids.

http://www.ene.gov.on.ca/en/land/biosolids/index.php Accessed July, 2010.

Organization for Economic Co-operation and Development (2004) OECD Guideline for testing of chemicals: Daphnia sp., Acute Immobilization Test. No 202.

Paul, R.J., Colmorgen, M., Huller, S., Tyroller, F. and Zinkler, D. (1997) Circulation and respiratory control in millimeter-sized animals (Daphnia magna, Folsomia candida) studied by optical methods. Journal of Comparative Physiology 167:399-408.

Pedersen, J.A., Soliman, M., Suffet, I.H. (2005) Human pharmaceuticals, Hormones and Personal Care Products ingredients in runoff from agricultural fields irrigated with treated wastewater. Journal of Agricultural Food and Chemistry. 53: 1625-1632.

Qasim, K., Javed, N., Subhan, M. (2001) Effect of sewage sludge on the growth of maize crop. Journal of Biosolical Sciences. 2: 52-54.

Region of Waterloo and Earth Tech (2007) Region of Waterloo's Public Information Centre. Wastewater treatment master plan. Regional Municipality of Waterloo, ON.

Ren, Z., Zha, J., Ma, M., Wang, Z., Gerhardt, A. (2007) The early warning of aquatic organophosphorus pesticide contamination by on-line monitoring behavioural changes of Daphnia magna. Environmental Monitoring and Assessment 134: 373-383.

Ryan, S.M. and Dodson, S.I. (1998) Seasonal analysis of Daphnia pulicaria swimming behavior. Hydrobiologia 384: 11-118.

Sastre, I., Vincete, A., Lobo, M. (1996) Influence of the Application of Sewage Sludgs on Soil Microbial Activity. Bioresouse Technology 57:19-23.

Schmidt, K., Steinberg, C.E.W., Staaks, G.B.O. Pflugmacher, S. (2005) Influence of Xenobiotic Mixture (PCB and TBT) Compared to Single Substances on Swimming 
Behaviour or Reproduction of Daphnia magna. Acta Hydrochimica and Hydrobiologia 33: 287-300.

Singh, R.P. and Agrawal, M. (2008) Potenital benefits and risks of land application of sewage sludge. Waste Management. 28: 347-358.

Spier, T.W., Schaik, A.P., Lloyd-Jones, A.R. (2003) Temporal response of soild biochemical properties in a pastoral soil after cultivation following high application rates of undigested sewage sludge. Biology and Fertility of Soil 38: 377-385.

Statistics Canada (2010) Census of Agriculture 1986 to 2006. Total Farm Area, Land Tenure, and Land in Crops by Province. http://www40.statcan.ca/101/cst01/agrc25g-eng.htm (accessed July, 2010).

Suedel, B.C. and Rodgers, J.H. (1996) Toxicity of Fluoranthene to Daphnia magna, Hyalella azteca, Chironomus tentans, and Stylaria lacustris in water-only and whole sediment exposures. Bulletin of Environmental Contamination and Toxicology 57: 132-138.

Sullivan, C., Mitchelmore, C., Hale, R., Veld, V. ( 2007) Induction of CYP1A and DNA damage in the fathead minnow (Pimephales promelas) following exposure to biosolids. Science of the Total Environment 384: 221-228.

Suresh, D.P. (2007) Bioaerosols from Land-Applied Biosolids: Issues and Needs. Water Environment Research. Wilson Applied Science \& Technology Abstracts. 79: 270.

Szulkin, M., Dawidowicz, P. and Dodson, S.I. (2006) Behavioural uniformity as a response to cues of predation risk. Animal Behaviour 71: 1013-1019.

Terasaki, M., Makino, M., Tatarazako, N. (2008) Acute Toxicity of parabens and their chlorinated by products with Daphnia magna and Vibrio Fischeri bioassays. Journal of Applied Toxicology 29: 242-247.

Topp, E., Monteiro, S., Beck, A., Coelho, B., Boxall, A., Kleywegt, S., Lapen, D., Payne, M., Sabourin, L., Hongxia, L., Metcalfe, D. (2008) Run-off of pharmaceuticals and personal care products following application of biosolids on an agricultural field. The Science of the Total Environment 396: 52-59.

Toronto Star (2008) - The Sludge Series. July 2008.

http://www.thestar.com/article/459085. Accessed May 2010.

Veldhoen, N., Skirrow, R.C., Oschoff, H., Clapson, D.J., Gunderson, M.P. (2006). The bactericidal agent triclosan modulates thyroid hormone-associated gene expression and disrupts postembryonic anuran development. Aquatic Toxicology 80: 217-227.

UN-HABITAT (2008) Global Atlas of Excreta, Wastewater Sludge, and Biosolids Management: Moving Forward the Sustainable and Welcome Uses of a Global Resource 
http://esa.un.org/iys/docs/san_lib_docs/habitat2008.pdf. Accessed July 20th, 2010.

United States Environmental Protection Agency (1994a) A Plain English Guide to the EPA

Part 503 Biosolids Rule. EPA/832/R-93/003. Office of Waste Management, Washington, DC.

United States Environmental Protection Agency (1994b) Land Application of Sewage Sludge.

Washington, District of Columbia.

United States Environmental Protection Agency (1999) Biosolids generation, use and disposal in the United States. Washington, District of Columbia.

United States Environmental Protection Agency (2002) Methods for measuring acute toxicity of effluents and receiving waters to freshwater and marine organisms.

United States Environmental Protection Agency (2006) Biosolids Technology Fact Sheet, Multi-Stage Anaerobic Digestion. Office of Water.

Wang, F., Goulet, R.R. Chapman, P.M. (2004) Testing sediment biological effects with the freshwater amphipod Hyalella azteca: the gap between laboratory and nature. Chemosphere 57: 1713-1724.

Wong, J.W., Li, X., Wong, M.H. (1996) The growth of Brassica chinensis in heavy-metalcontaminated sewage sludge compost from Hong Kong. Bioresource Biology 58: 309-313. 


\section{Appendices}

\section{Appendix A. Biosolids Dry to Wet Weight Ration Calculation and Trough Application Quantity}

Soil Surface area on the trough $=40 \mathrm{~cm} \times 100 \mathrm{~cm}=4000 \mathrm{~cm}^{2}$

Application Rate maximum $=22$ dry tones per hectare $=22000$ Dry $\mathrm{kg} / 1 \times 10^{8} \mathrm{~cm}^{2}$

Let $\mathrm{x}$ represent the amount of dry weight biosolids to be land-applied to the ramp:

$220000 \mathrm{~kg}($ Dry $) / 1 \times 10^{8} \mathrm{~cm}^{2}=\mathrm{x} \mathrm{kg}($ Dry $) / 4000 \mathrm{~cm}^{2}$

$\mathrm{x}=0.88 \mathrm{~kg}$ (Dry) weight of biosolids to be applied per trough

1. Guelph Biosolids average dry weight to wet weight ratio:

$9.85 \mathrm{gwet} / 0.88 \mathrm{gdry}=\mathrm{Xgwet} / 880 \mathrm{~g}$ dry

$\mathrm{X}$ wet $=8.934 \mathrm{~kg}$ weight

Conversion wet weight to volume

Let y represent the amount of wet biosolids to be applied on the trough

$1.106 \mathrm{~kg} / \mathrm{L}=8.934 \mathrm{~kg} / \mathrm{Y}$

$\mathrm{Y}=8.08 \mathrm{~L}$ of Guelph biosolids are applied to the troughs

2. Kitchener Biosolids average dry weight to wet weight ratio:

$10.432 \mathrm{gwet} / 0.632 \mathrm{dry}=\mathrm{Xgwet} / 880 \mathrm{~g}$ dry

$\mathrm{X}=14.527 \mathrm{~kg}$ wet per trough

Conversion wet weight to volume

Let y represent the amount of wet biosolids to be applied on the trough

$1.043 \mathrm{~kg} / \mathrm{L}=14.525 \mathrm{~kg} / \mathrm{Y}$

$\mathrm{Y}=13.9 \mathrm{~L}$ of Kitchener biosolids are applied to the troughs 


\section{Appendix B. Simulated Rainfall Quantity Calculations}

"Multi-annual extreme storm event for South Ontario" $=49.5 \mathrm{~mm}$ of rain

$49.5 \mathrm{~mm}=4.95 \mathrm{~cm}$

Area of the trough $=4000 \mathrm{~cm}^{2}$

Amount of water to be poured on the trough

$4.95 \mathrm{~cm} \times 40 \mathrm{~cm} \times 100 \mathrm{~cm}=198000 \mathrm{~cm}^{3}$

Let $\mathrm{Y}$ represent the amount of water per trough in Liters

1L has $100 \mathrm{~cm}^{3}, Y=198000 \mathrm{~cm}^{3} / 100 \mathrm{~cm}^{3}=19.8 \mathrm{~L}$ 


\section{Appendix C. Modified Hoagland's E+ medium for Lemna minor}

Chemical Composition of Nutrient Stock for Preparing Modified Hoagland's E+ medium, Used for Culturing Lemna minor (Environment Canada, 2007)

\begin{tabular}{|l|l|l|}
\hline Substance & Stock Solution & Medium(mg/L) \\
\hline Ca(NO3)*4H2o & 59.00 & 1180.0 \\
\hline KNO3 & 75.76 & 1515.2 \\
\hline KH2PO4 & 34.00 & 680.0 \\
\hline Tartatic Acid & 3.0 & 3.0 \\
\hline FeC12*6H2O & 1.21 & 24.20 \\
\hline Na2EDTA*2H2O & 3.35 & 67.00 \\
\hline MgSO4*7H2O & 50.00 & 500.0 \\
\hline H3BO3 & 2.86 & 2.86 \\
\hline ZnSO4*7H2O & 0.22 & 0.22 \\
\hline Na2MoO4 *2H2O & 0.12 & 0.12 \\
\hline CuSO4 *5H2O & 0.08 & 0.08 \\
\hline MnCl2*4H2O & 3.62 & 3.62 \\
\hline Sucrose & - & $0.60 \mathrm{~g} / \mathrm{L} / \mathrm{L}$ \\
\hline Yeast Extract & - & \\
\hline Bactotryptone & & \\
\hline
\end{tabular}




\section{Appendix D Unisense Oxygen Microelectrode Function (Marshall, 2009)}

A Clark-type oxygen microelectrode (Unisense, Denmark) was used in the bioassays performed on Daphnia magna and Hyalella azteca respiration studies. The probe functions as follows.

Oxygen from the sample diffuses across a silicone membrane to an oxygen reducing cathode, which is polarized against an $\mathrm{Ag} / \mathrm{AgCl}$ anode (Figure 1) (Unisense, 2009). An internal guard cathode is also present to remove all oxygen which diffuses toward the tip from the internal electrolyte reservoir, allowing for greater stability and sensitivity of the probe (Revsbech, 1989). The flow of electrons from anode to cathode reflects the partial pressure of oxygen at the tip of the probe and is measured in picoamperes by a highly sensitive picoammeter attached to the probe (Unisense, 2009). Exact concentrations of oxygen in a given sample can then be determined by creating a calibration curve based on samples saturated with oxygen and saturated with nitrogen (no oxygen present).

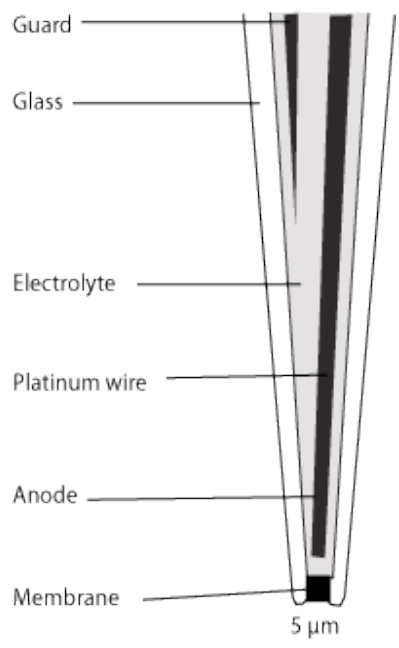

Figure 1: Schematic diagram of Unisense Clark-type oxygen microelectrode (Unisense, 2010) 


\section{Appendix E: Invertebrate Respiration Data - Guelph}

Daphnia magna Respiration Data (Surface Run-off collected Day 1)

Rate of Oxygen consumption (nanomoles $\mathrm{O}_{2} / \mathrm{hr}$ )

\begin{tabular}{|l|c|c|c|c|}
\hline & Reference & \multicolumn{2}{|c|}{$\begin{array}{l}\text { \% Biosolids Run- } \\
\text { off }\end{array}$} & $\begin{array}{l}10 \% \text { Biosolids } \\
\text { Runoff }\end{array}$ \\
\hline Replicate 1 & 8.3 & 7.6 & 7.6 & 7.1 \\
\hline Replicate 2 & 9.9 & 7.8 & 7.6 & 4.63 \\
\hline Replicate 3 & 5.5 & 7.8 & 4.8 & 7.8 \\
\hline Replicate 4 & 9.9 & 7.6 & 7.6 & 6.4 \\
\hline Replicate 5 & 9.0 & 9.2 & 9.2 & 5.5 \\
\hline Replicate 6 & 8.3 & 7.8 & 7.6 & 7.8 \\
\hline
\end{tabular}

Daphnia magna Respiration Data (Tile Drainage collected Day 1)

Rate of Oxygen consumption (nanomoles $\mathrm{O}_{2} / \mathrm{hr}$ )

\begin{tabular}{|c|c|c|c|c|}
\hline & Reference & $\begin{array}{l}\text { 1\% Biosolids } \\
\text { elutriate }\end{array}$ & $\begin{array}{l}\text { 10\% Biosolids } \\
\text { elutriate }\end{array}$ & $\begin{array}{l}100 \% \text { Biosolids } \\
\text { elutriate }\end{array}$ \\
\hline Replicate 1 & 5.7 & 1.8 & 6.2 & 5.8 \\
\hline Replicate 2 & 9.0 & 2.5 & 4.4 & 4.6 \\
\hline Replicate 3 & 6.0 & 6.5 & 6.7 & 3.5 \\
\hline Replicate 4 & 3.9 & 3.0 & 6.2 & 4.4 \\
\hline Replicate 5 & 6.9 & 3.5 & 4.2 & 4.4 \\
\hline Replicate 6 & 6.0 & 6.6 & 6.7 & \\
\hline
\end{tabular}


Daphnia magna Respiration Data (Surface Run-off collected Day 40 off unplanted troughs)

Rate of Oxygen consumption (nanomoles $\mathrm{O}_{2} / \mathrm{hr}$ )

\begin{tabular}{|l|c|c|c|c|}
\hline & Reference & $\begin{array}{l}1 \% \text { Biosolids Run- } \\
\text { off }\end{array}$ & $\begin{array}{l}10 \% \text { Biosolids Run- } \\
\text { off }\end{array}$ & $\begin{array}{l}100 \% \text { Biosolids Run- } \\
\text { off }\end{array}$ \\
\hline Replicate 1 & 7.2 & 4.8 & 5.1 & 5.9 \\
\hline Replicate 2 & 5.4 & 5.6 & 6.9 & 7.1 \\
\hline Replicate 3 & 4.2 & 5.1 & 4.8 & 5.4 \\
\hline Replicate 4 & 5.1 & 4.3 & 4.7 & 5.9 \\
\hline Replicate 5 & 5.3 & 2.9 & 3.6 & 6.1 \\
\hline Replicate 6 & 6.2 & 2.8 & 4.4 & \\
\hline
\end{tabular}

Daphnia magna Respiration Data (Tile Drainage collected Day 40 off unplanted troughs)

Rate of Oxygen consumption (nanomoles $\mathrm{O}_{2} / \mathrm{hr}$ )

\begin{tabular}{|l|c|c|c|c|}
\hline & Reference & $\begin{array}{l}\text { 1\% Biosolids } \\
\text { Elutriate }\end{array}$ & $\begin{array}{l}\text { 10\% Biosolids } \\
\text { Elutriate }\end{array}$ & $\begin{array}{l}\text { 100\% Biosolids } \\
\text { Elutriate }\end{array}$ \\
\hline Replicate 1 & 4.1 & 4.3974 & 3.6 & 4.5 \\
\hline Replicate 2 & 3.5 & 3.5 & 2.9 & 3.1 \\
\hline Replicate 3 & 2.9 & 3.5 & 4.2 & 4.2 \\
\hline Replicate 4 & 3.4 & 3.7 & 3.3 & 3.2 \\
\hline Replicate 5 & 4.1 & 3.5 & 3.9 & 3.3 \\
\hline Replicate 6 & 3.5 & 3.9 & 3.6 & \\
\hline
\end{tabular}


Daphnia magna Respiration Data (Surface Run-off collected Day 40 off planted troughs)

Rate of Oxygen consumption (nanomoles $\mathrm{O}_{2} / \mathrm{hr}$ )

\begin{tabular}{|l|c|c|c|c|}
\hline & Reference & $\begin{array}{l}1 \% \text { Biosolids Run- } \\
\text { off }\end{array}$ & $\begin{array}{l}10 \% \text { Biosolids Run- } \\
\text { off }\end{array}$ & $\begin{array}{l}100 \% \text { Biosolids Run- } \\
\text { off }\end{array}$ \\
\hline Replicate 1 & 3.1 & 6.3 & 5.3 & 3.8 \\
\hline Replicate 2 & 6.2 & 6.3 & 3.8 & 4.1 \\
\hline Replicate 3 & 3.8 & 6.2 & 6.95 & 6.2 \\
\hline Replicate 4 & 5.4 & 6.1 & 4.6 & 4.6 \\
\hline Replicate 5 & 6.2 & 6.1 & 6.9 & 4.6 \\
\hline Replicate 6 & 6.1 & 6.1 & 6.1 & \\
\hline
\end{tabular}

Daphnia magna Respiration Data (Tile Drainage collected Day 40 off planted troughs)

Rate of Oxygen consumption (nanomoles $\mathrm{O}_{2} / \mathrm{hr}$ )

\begin{tabular}{|l|c|c|c|c|}
\hline & Reference & $\begin{array}{l}\text { 1\% Biosolids } \\
\text { Elutriate }\end{array}$ & $\begin{array}{l}\text { 10\% Biosolids } \\
\text { Elutriate }\end{array}$ & $\begin{array}{l}\text { 100\% Biosolids } \\
\text { Elutriate }\end{array}$ \\
\hline Replicate 1 & 6.2 & 6.9 & 5.4 & 5.1 \\
\hline Replicate 2 & 6.2 & 4.6 & 3.8 & 4.9 \\
\hline Replicate 3 & 3.8 & 4.1 & 3.8 & 4.7 \\
\hline Replicate 4 & 5.4 & 6.2 & 4.6 & 3.6 \\
\hline Replicate 5 & 6.2 & 6.2 & 6.9 & 4.4 \\
\hline Replicate 6 & 6.2 & 3.4 & 6.2 & \\
\hline
\end{tabular}


Hyalella azteca Respiration rates - Guelph Biosolids

Hyalella azteca Respiration Data (Surface Run-off collected Day 1)

Rate of Oxygen consumption (nanomoles $\mathrm{O}_{2} / \mathrm{hr}$ )

\begin{tabular}{|l|c|c|c|c|}
\hline & Reference & $\begin{array}{l}\text { 1\% Biosolids } \\
\text { Runoff }\end{array}$ & $\begin{array}{l}\text { 10\% Biosolids } \\
\text { Runoff }\end{array}$ & $\begin{array}{l}\text { Ro0\% Biosolids } \\
\text { Runoff }\end{array}$ \\
\hline Replicate 1 & 7.6 & 8.1 & 3.7 & 2.3 \\
\hline Replicate 2 & 4.4 & 8.3 & 8.1 & 5.1 \\
\hline Replicate 3 & 6.2 & 6.5 & 6.6 & 1.6 \\
\hline Replicate 4 & 6.2 & 6.9 & 6.0 & 2.5 \\
\hline Replicate 5 & 5.8 & 7.8 & 5.3 & 3.0 \\
\hline Replicate 6 & 4.4 & 6.5 & 6.0 & \\
\hline
\end{tabular}

\section{Hyalella azteca Respiration Data (Tile Drainage collected Day 1)}

Rate of Oxygen consumption (nanomoles $\mathrm{O}_{2} / \mathrm{hr}$ )

\begin{tabular}{|l|c|c|c|c|}
\hline & Reference & $\begin{array}{l}\text { 1\% Biosolids } \\
\text { Runoff }\end{array}$ & $\begin{array}{l}\text { l0\% Biosolids } \\
\text { Runoff }\end{array}$ & $\begin{array}{l}\text { 100\% Biosolids } \\
\text { Runoff }\end{array}$ \\
\hline Replicate 1 & 7.6 & 3.7 & 8.1 & 2.3 \\
\hline Replicate 2 & 4.4 & 8.1 & 8.3 & 3.3 \\
\hline Replicate 3 & 5.5 & 6.5 & 6.5 & 3.0 \\
\hline Replicate 4 & 6.2 & 6.0 & 6.9 & 2.5 \\
\hline Replicate 5 & 5.8 & 5.3 & 7.8 & 5.1 \\
\hline Replicate 6 & 5.8 & 6.5 & 6.9 & \\
\hline
\end{tabular}


Hyalella azteca Respiration Data (Surface Run-off collected Day 40 from unplanted troughs)

Rate of Oxygen consumption (nanomoles $\mathrm{O}_{2} / \mathrm{hr}$ )

\begin{tabular}{|l|c|c|c|c|}
\hline & Reference & $\begin{array}{l}1 \% \text { Biosolids - } \\
\text { Run-off }\end{array}$ & $\begin{array}{l}10 \% \text { Biosolids } \\
\text { Runoff }\end{array}$ & $\begin{array}{l}100 \% \text { Biosolids } \\
\text { Runoff }\end{array}$ \\
\hline Replicate 1 & 7.6 & 8.1 & 3.7 & 2.3 \\
\hline Replicate 2 & 4.4 & 8.3 & 8.1 & 3.1 \\
\hline Replicate 3 & 6.2 & 6.5 & 6.6 & 1.6 \\
\hline Replicate 4 & 6.2 & 6.9 & 6.0 & 2.5 \\
\hline Replicate 5 & 5.8 & 7.8 & 5.3 & 3.0 \\
\hline Replicate 6 & 4.4 & 6.5 & 6.0 & \\
\hline
\end{tabular}

\section{Hyalella azteca Respiration Data (Tile Drainage collected Day 40 from unplanted troughs)}

Rate of Oxygen consumption (nanomoles $\mathrm{O}_{2} / \mathrm{hr}$ )

\begin{tabular}{|l|c|c|c|c|}
\hline & Reference & $\begin{array}{l}\text { 1\% Biosolids } \\
\text { Runoff }\end{array}$ & $\begin{array}{l}\text { l0\% Biosolids } \\
\text { Runoff }\end{array}$ & $\begin{array}{l}\text { 100\% Biosolids } \\
\text { Runoff }\end{array}$ \\
\hline Replicate 1 & 2.8 & 3.5 & 2.9 & 4.7 \\
\hline Replicate 2 & 3.0 & 4.0 & 2.9 & 3.1 \\
\hline Replicate 3 & 3.6 & 2.8 & 4.3 & 4.1 \\
\hline Replicate 4 & 3.9 & 1.9 & 4.2 & 6.6 \\
\hline Replicate 5 & 2.9 & 3.4 & 3.9 & 4.4 \\
\hline Replicate 6 & 2.9 & 4.2 & 3.7 & \\
\hline
\end{tabular}


Hyalella azteca Respiration Data (Surface Runoff collected Day 40 from planted troughs)

Rate of Oxygen consumption (nanomoles $\mathrm{O}_{2} / \mathrm{hr}$ )

\begin{tabular}{|l|c|c|c|c|}
\hline & Reference & $\begin{array}{l}\text { 1\% Biosolids } \\
\text { Runoff }\end{array}$ & $\begin{array}{l}10 \% \text { Biosolids } \\
\text { Runoff }\end{array}$ & $\begin{array}{l}100 \% \text { Biosolids } \\
\text { Runoff }\end{array}$ \\
\hline Replicate 1 & 4.1 & 4.8 & 4.6 & 3.1 \\
\hline Replicate 2 & 3.3 & 3.8 & 4.1 & 3.6 \\
\hline Replicate 3 & 4.1 & 3.1 & 3.6 & 3.8 \\
\hline Replicate 4 & 4.1 & 4.4 & 3.3 & 3.6 \\
\hline Replicate 5 & 3.3 & 3.8 & 3.3 & 3.3 \\
\hline Replicate 6 & 3.3 & 3.8 & 3.6 & \\
\hline
\end{tabular}

Hyalella azteca Respiration Data (Tile Drainage collected Day 40 from planted troughs)

Rate of Oxygen consumption (nanomoles $\mathrm{O}_{2} / \mathrm{hr}$ )

\begin{tabular}{|l|c|c|c|c|}
\hline & Reference & $\begin{array}{l}\text { 1\% Biosolids } \\
\text { Runoff }\end{array}$ & $\begin{array}{l}\text { 10\% Biosolids } \\
\text { Runoff }\end{array}$ & $\begin{array}{l}100 \% \text { Biosolids } \\
\text { Runoff }\end{array}$ \\
\hline Replicate 1 & 4.1 & 4.9 & 4.6 & 3.1 \\
\hline Replicate 2 & 3.3 & 3.8 & 4.1 & 3.6 \\
\hline Replicate 3 & 4.1 & 3.1 & 3.6 & 3.8 \\
\hline Replicate 4 & 4.1 & 4.4 & 3.3 & 3.6 \\
\hline Replicate 5 & 3.3 & 3.8 & 3.3 & 3.3 \\
\hline Replicate 6 & 3.3 & 3.8 & 3.6 & \\
\hline
\end{tabular}


Appendix F. Invertebrate Respiration Data - Kitchener biosolids

Daphnia magna Respiration Data (Surface Runoff Collected on Day 1)

Rate of Oxygen consumption (nanomoles $\mathrm{O}_{2} / \mathrm{hr}$ )

\begin{tabular}{|c|c|c|c|c|c|c|c|}
\hline & Blank & Reference & $\begin{array}{l}0.5 \% \\
\text { Biosolids } \\
\text { Elutriate }\end{array}$ & $\begin{array}{l}1 \% \\
\text { Biosolids } \\
\text { Elutriate }\end{array}$ & $\begin{array}{l}5 \% \\
\text { Biosolids } \\
\text { Elutriate }\end{array}$ & $\begin{array}{l}10 \% \\
\text { Biosolids } \\
\text { Elutriate }\end{array}$ & $\begin{array}{l}100 \% \\
\text { Biosolids } \\
\text { Elutriate }\end{array}$ \\
\hline $\begin{array}{c}\text { Replicate } \\
1\end{array}$ & 6.1 & 9.2 & 7.7 & 9.2 & 8.5 & 6.9 & 6.9 \\
\hline $\begin{array}{c}\text { Replicate } \\
2\end{array}$ & 6.9 & 10.0 & 7.7 & 7.7 & 9.2 & 9.2 & 9.2 \\
\hline $\begin{array}{c}\text { Replicate } \\
3\end{array}$ & 7.7 & 8.5 & 10.0 & 10.0 & 7.7 & 9.2 & 9.2 \\
\hline $\begin{array}{c}\text { Replicate } \\
4\end{array}$ & 7.7 & 8.5 & 9.2 & 11.5 & 7.7 & 9.2 & 7.7 \\
\hline $\begin{array}{c}\text { Replicate } \\
5\end{array}$ & 6.9 & 7.7 & 7.7 & 10.0 & 8.5 & 8.5 & 8.5 \\
\hline $\begin{array}{c}\text { Replicate } \\
6\end{array}$ & 6.9 & 7.7 & 6.9 & 10.0 & 9.2 & 8.5 & 8.5 \\
\hline
\end{tabular}


Daphnia magna Respiration Data (Tile Drainage Collected on Day 1)

Rate of Oxygen consumption (nanomoles $\mathrm{O}_{2} / \mathrm{hr}$ )

\begin{tabular}{|c|c|c|c|c|c|c|c|}
\hline & Blank & Reference & $\begin{array}{l}0.5 \% \\
\text { Biosolids } \\
\text { Elutriate }\end{array}$ & $\begin{array}{l}1 \% \\
\text { Biosolids } \\
\text { Elutriate }\end{array}$ & $\begin{array}{l}5 \% \\
\text { Biosolids } \\
\text { Elutriate }\end{array}$ & $\begin{array}{l}10 \% \\
\text { Biosolids } \\
\text { Elutriate }\end{array}$ & $\begin{array}{l}100 \% \\
\text { Biosolids } \\
\text { Elutriate }\end{array}$ \\
\hline $\begin{array}{c}\text { Replicate } \\
1\end{array}$ & 3.8 & 10.8 & 8.5 & 6.9 & 8.5 & 10.0 & 10.8 \\
\hline $\begin{array}{c}\text { Replicate } \\
2\end{array}$ & 3.8 & 8.5 & 7.7 & 8.5 & 8.5 & 8.5 & 8.5 \\
\hline $\begin{array}{c}\text { Replicate } \\
3\end{array}$ & 5.4 & 7.5 & 5.4 & 8.5 & 9.2 & 9.2 & 7.7 \\
\hline $\begin{array}{c}\text { Replicate } \\
4\end{array}$ & 7.7 & 8.5 & 7.7 & 8.5 & 8.5 & 9.2 & 8.5 \\
\hline $\begin{array}{c}\text { Replicate } \\
5\end{array}$ & 6.2 & 7.7 & 6.9 & 9.2 & 5.4 & 7.7 & 7.7 \\
\hline $\begin{array}{c}\text { Replicate } \\
6\end{array}$ & 5.4 & 9.2 & 9.2 & 7.7 & 7.7 & 8.5 & 9.2 \\
\hline
\end{tabular}


Daphnia magna Respiration Data (Surface Run-off Collected on Day 40 from unplanted troughs)

Rate of Oxygen consumption (nanomoles $\mathrm{O}_{2} / \mathrm{hr}$ )

\begin{tabular}{|c|c|c|c|c|c|c|c|}
\hline & Blank & Reference & $\begin{array}{l}0.5 \% \\
\text { Biosolids } \\
\text { Elutriate }\end{array}$ & $\begin{array}{l}1 \% \\
\text { Biosolids } \\
\text { Elutriate }\end{array}$ & $\begin{array}{l}5 \% \\
\text { Biosolids } \\
\text { Elutriate }\end{array}$ & $\begin{array}{l}10 \% \\
\text { Biosolids } \\
\text { Elutriate }\end{array}$ & $\begin{array}{l}100 \% \\
\text { Biosolids } \\
\text { Elutriate }\end{array}$ \\
\hline $\begin{array}{c}\text { Replicate } \\
1\end{array}$ & 5.4 & 6.2 & 4.8 & 5.4 & 4. & 5.4 & 3.8 \\
\hline $\begin{array}{c}\text { Replicate } \\
2\end{array}$ & 6.2 & 4.6 & 5.4 & 5.4 & 6.9 & 6.2 & 3.1 \\
\hline $\begin{array}{c}\text { Replicate } \\
3\end{array}$ & 6.9 & 5.4 & 5.6 & 4.6 & 6.9 & 4.6 & 6.2 \\
\hline $\begin{array}{c}\text { Replicate } \\
4\end{array}$ & 7.7 & 6.2 & 6.2 & 6.9 & 5.4 & 6.2 & 6.2 \\
\hline $\begin{array}{c}\text { Replicate } \\
5\end{array}$ & 5.4 & 6.2 & 6.3 & 6.2 & 6.2 & 6.2 & 6.9 \\
\hline $\begin{array}{c}\text { Replicate } \\
6\end{array}$ & 6.9 & 5.4 & 5.4 & 3.8 & 6.2 & 6.2 & 5.4 \\
\hline
\end{tabular}


Daphnia magna Respiration Data (Tile Drainage Collected on Day 40 from unplanted troughs)

Rate of Oxygen consumption (nanomoles $\mathrm{O}_{2} / \mathrm{hr}$ )

\begin{tabular}{|c|c|c|c|c|c|c|c|}
\hline & Blank & Reference & $\begin{array}{l}0.5 \% \\
\text { Biosolids } \\
\text { Elutriate }\end{array}$ & $\begin{array}{l}\text { l\% } \\
\text { Biosolids } \\
\text { Elutriate }\end{array}$ & $\begin{array}{l}5 \% \\
\text { Biosolids } \\
\text { Elutriate }\end{array}$ & $\begin{array}{l}10 \% \\
\text { Biosolids } \\
\text { Elutriate }\end{array}$ & $\begin{array}{l}100 \% \\
\text { Biosolids } \\
\text { Elutriate }\end{array}$ \\
\hline $\begin{array}{c}\text { Replicate } \\
1\end{array}$ & 7.7 & 5.5 & 4.8 & 6.9 & 5.4 & 6.2 & 5.5 \\
\hline $\begin{array}{c}\text { Replicate } \\
2\end{array}$ & 5.4 & 6.2 & 6.9 & 6.2 & 3.9 & 6.3 & 3.8 \\
\hline $\begin{array}{c}\text { Replicate } \\
3\end{array}$ & 6.9 & 4.8 & 6.1 & 5.4 & 4.6 & 5.3 & 3.8 \\
\hline $\begin{array}{c}\text { Replicate } \\
4\end{array}$ & 3.8 & 5.7 & 6.2 & 5.6 & 6.9 & 5.3 & 6.2 \\
\hline $\begin{array}{c}\text { Replicate } \\
5\end{array}$ & 5.4 & 6.2 & 5.4 & 5.8 & 5.6 & 6.1 & 5.4 \\
\hline $\begin{array}{c}\text { Replicate } \\
6\end{array}$ & 6.2 & 5.5 & 3.8 & 6.9 & 6.1 & 6.1 & 3.0 \\
\hline
\end{tabular}


Daphnia magna Respiration Data (Surface Run-off Collected on Day 40 from planted troughs)

\begin{tabular}{|c|c|c|l|l|l|l|l|}
\hline \multicolumn{2}{|c|}{ Rate of Oxygen consumption (nanomoles $\left.\mathrm{O}_{2} / \mathrm{hr}\right)$} \\
\hline $\begin{array}{c}\text { Replicate } \\
1\end{array}$ & Blank & Reference & $\begin{array}{l}0.5 \% \\
\text { Biosolids } \\
\text { Elutriate }\end{array}$ & $\begin{array}{l}1 \% \\
\text { Biosolids } \\
\text { Elutriate }\end{array}$ & $\begin{array}{l}5 \% \\
\text { Biosolids } \\
\text { Elutriate }\end{array}$ & $\begin{array}{l}10 \% \\
\text { Biosolids } \\
\text { Elutriate }\end{array}$ & $\begin{array}{l}100 \% \\
\text { Biosolids } \\
\text { Elutriate }\end{array}$ \\
\hline $\begin{array}{c}\text { Replicate } \\
2\end{array}$ & 4.8 & 6.2 & 6.2 & 7.7 & 3.8 & 6.2 & 5.4 \\
\hline $\begin{array}{c}\text { Replicate } \\
3\end{array}$ & 5.4 & 5.4 & 4.6 & 3.8 & 7.7 & 4.6 & 7.7 \\
\hline $\begin{array}{c}\text { Replicate } \\
4\end{array}$ & 5.4 & 5.4 & 5.4 & 5.4 & 6.9 & 5.4 & 6.4 \\
\hline $\begin{array}{c}\text { Replicate } \\
5\end{array}$ & 6.9 & 3.8 & 3.8 & 3.8 & 6.1 & 4.6 & 4.6 \\
\hline $\begin{array}{c}\text { Replicate } \\
6\end{array}$ & 3.8 & 6.1 & 4.6 & 5.3 & 6.1 & 6.2 & 6.9 \\
\hline
\end{tabular}


Daphnia magna Respiration Data (Tile Drainage Collected on Day 40 from planted troughs)

\begin{tabular}{|c|c|c|l|l|l|l|l|}
\hline \multicolumn{2}{|c|}{ Rate of Oxygen consumption (nanomoles $\left.\mathrm{O}_{2} / \mathrm{hr}\right)$} \\
\hline $\begin{array}{c}\text { Replicate } \\
1\end{array}$ & Blank & Reference & $\begin{array}{l}0.5 \% \\
\text { Biosolids } \\
\text { Elutriate }\end{array}$ & $\begin{array}{l}1 \% \\
\text { Biosolids } \\
\text { Elutriate }\end{array}$ & $\begin{array}{l}5 \% \\
\text { Biosolids } \\
\text { Elutriate }\end{array}$ & $\begin{array}{l}10 \% \\
\text { Biosolids } \\
\text { Elutriate }\end{array}$ & $\begin{array}{l}100 \% \\
\text { Biosolids } \\
\text { Elutriate }\end{array}$ \\
\hline $\begin{array}{c}\text { Replicate } \\
2\end{array}$ & 3.9 & 5.1 & 5.3 & 7.6 & 7.6 & 6.9 & 6.9 \\
\hline $\begin{array}{c}\text { Replicate } \\
3\end{array}$ & 4.6 & 6.1 & 3.8 & 6.9 & 4.6 & 4.6 & 5.4 \\
\hline $\begin{array}{c}\text { Replicate } \\
4\end{array}$ & 5.4 & 5.4 & 5.4 & 5.4 & 6.2 & 7.7 & 5.4 \\
\hline $\begin{array}{c}\text { Replicate } \\
5\end{array}$ & 7.7 & 3.8 & 6.1 & 5.3 & 5.3 & 3.8 & 6.1 \\
\hline $\begin{array}{c}\text { Replicate } \\
6\end{array}$ & 5.3 & 7.6 & 7.6 & 4.6 & 5.3 & 5.3 & 6.1 \\
\hline
\end{tabular}


Hyalella azteca Kithener Respiration Data

Hyalella azteca Respiration Data (Surface Run-off Collected on Day 1)

Rate of Oxygen consumption (nanomoles $\mathrm{O}_{2} / \mathrm{hr}$ )

\begin{tabular}{|c|c|c|c|c|c|c|l|}
\hline & Blank & Reference & $\begin{array}{l}0.5 \% \\
\text { Biosolids } \\
\text { Elutriate }\end{array}$ & $\begin{array}{l}1 \% \\
\text { Biosolids } \\
\text { Elutriate }\end{array}$ & $\begin{array}{l}5 \% \\
\text { Biosolids } \\
\text { Elutriate }\end{array}$ & $\begin{array}{l}10 \% \\
\text { Biosolids } \\
\text { Elutriate }\end{array}$ & $\begin{array}{l}100 \% \\
\text { Biosolids } \\
\text { Elutriate }\end{array}$ \\
\hline $\begin{array}{c}\text { Replicate } \\
1\end{array}$ & 3.8 & 8.5 & 3.8 & 7.7 & 9.2 & 7.7 & 8.5 \\
\hline $\begin{array}{c}\text { Replicate } \\
2\end{array}$ & 5.4 & 9.2 & 9.2 & 5.4 & 3.8 & 9.2 & 6.9 \\
\hline $\begin{array}{c}\text { Replicate } \\
3\end{array}$ & 3.8 & 6.9 & 6.9 & 5.4 & 4.6 & 3.8 & 6.9 \\
\hline $\begin{array}{c}\text { Replicate } \\
4\end{array}$ & 3.8 & 7.7 & 4.6 & 6.2 & 5.4 & 4.6 & 4.6 \\
\hline $\begin{array}{c}\text { Replicate } \\
5\end{array}$ & 4.6 & 6.9 & 4.6 & 7.7 & 6.9 & 6.9 & 4.6 \\
\hline $\begin{array}{c}\text { Replicate } \\
6\end{array}$ & 3.8 & 6.9 & 7.7 & 6.1 & 4.6 & 5.4 & 5.4 \\
\hline
\end{tabular}


Hyalella azteca Respiration Data (Tile Drainage Collected on Day 1)

Rate of Oxygen consumption (nanomoles $\mathrm{O}_{2} / \mathrm{hr}$ )

\begin{tabular}{|c|c|c|c|c|c|c|c|}
\hline & Blank & Reference & $\begin{array}{l}0.5 \% \\
\text { Biosolids } \\
\text { Elutriate }\end{array}$ & $\begin{array}{l}\text { l\% } \\
\text { Biosolids } \\
\text { Elutriate }\end{array}$ & $\begin{array}{l}5 \% \\
\text { Biosolids } \\
\text { Elutriate }\end{array}$ & $\begin{array}{l}10 \% \\
\text { Biosolids } \\
\text { Elutriate }\end{array}$ & $\begin{array}{l}100 \% \\
\text { Biosolids } \\
\text { Elutriate }\end{array}$ \\
\hline $\begin{array}{c}\text { Replicate } \\
1\end{array}$ & 3.8 & 6.9 & 6.1 & 5.4 & 7.8 & 6.9 & 6.2 \\
\hline $\begin{array}{c}\text { Replicate } \\
2\end{array}$ & 5.4 & 4.6 & 3.8 & 6.2 & 5.4 & 9.2 & 5.4 \\
\hline $\begin{array}{c}\text { Replicate } \\
3\end{array}$ & 3.8 & 6.2 & 4.6 & 5.4 & 5.4 & 5.4 & 6.2 \\
\hline $\begin{array}{c}\text { Replicate } \\
4\end{array}$ & 3.8 & 3.8 & 6.9 & 4.6 & 6.9 & 3.8 & 5.4 \\
\hline $\begin{array}{c}\text { Replicate } \\
5\end{array}$ & 4.6 & 5.4 & 6.2 & 3.8 & 4.6 & 3.0 & 4.6 \\
\hline $\begin{array}{c}\text { Replicate } \\
6\end{array}$ & 3.8 & 4.6 & 5.4 & 5.4 & 5.4 & 5.4 & 4.6 \\
\hline
\end{tabular}


Hyalella azteca Respiration Data (Surface Run-off Collected on Day 40 from unplanted troughs)

\begin{tabular}{|c|c|c|c|c|c|c|c|}
\hline \multicolumn{8}{|c|}{ Rate of Oxygen consumption (nanomoles $\mathrm{O}_{2} / \mathrm{hr}$ ) } \\
\hline & Blank & Reference & $\begin{array}{l}0.5 \% \\
\text { Biosolids } \\
\text { Elutriate }\end{array}$ & $\begin{array}{l}1 \% \\
\text { Biosolids } \\
\text { Elutriate }\end{array}$ & $\begin{array}{l}5 \% \\
\text { Biosolids } \\
\text { Elutriate }\end{array}$ & $\begin{array}{l}10 \% \\
\text { Biosolids } \\
\text { Elutriate }\end{array}$ & $\begin{array}{l}100 \% \\
\text { Biosolids } \\
\text { Elutriate }\end{array}$ \\
\hline $\begin{array}{c}\text { Replicate } \\
1\end{array}$ & 3.1 & 3.1 & 3.1 & 6.2 & 6.2 & 3.1 & 2.3 \\
\hline $\begin{array}{c}\text { Replicate } \\
2\end{array}$ & 5.4 & 4.6 & 3.8 & 5.4 & 4.6 & 3.8 & 7.7 \\
\hline $\begin{array}{c}\text { Replicate } \\
3\end{array}$ & 3.8 & 3.8 & 3.8 & 5.4 & 3.8 & 3.8 & 4.6 \\
\hline $\begin{array}{c}\text { Replicate } \\
4\end{array}$ & 3.8 & 3.8 & 5.4 & 2.3 & 3.8 & 6.2 & 5.4 \\
\hline $\begin{array}{c}\text { Replicate } \\
5\end{array}$ & 4.6 & 3.8 & 4.6 & 2.3 & 3.1 & 4.6 & 4.6 \\
\hline $\begin{array}{c}\text { Replicate } \\
6\end{array}$ & 4.6 & 4.6 & 3.8 & 3.8 & 3.8 & 3.1 & 6.2 \\
\hline
\end{tabular}


Hyalella azteca Respiration Data (Tile Drainage Collected on Day 40 from unplanted troughs)

\begin{tabular}{|c|c|c|c|c|c|c|c|}
\hline \multicolumn{8}{|c|}{ Rate of Oxygen consumption (nanomoles $\mathrm{O}_{2} / \mathrm{hr}$ ) } \\
\hline & Blank & Reference & $\begin{array}{l}0.5 \% \\
\text { Biosolids } \\
\text { Elutriate }\end{array}$ & $\begin{array}{l}1 \% \\
\text { Biosolids } \\
\text { Elutriate }\end{array}$ & $\begin{array}{l}5 \% \\
\text { Biosolids } \\
\text { Elutriate }\end{array}$ & $\begin{array}{l}10 \% \\
\text { Biosolids } \\
\text { Elutriate }\end{array}$ & $\begin{array}{l}100 \% \\
\text { Biosolids } \\
\text { Elutriate }\end{array}$ \\
\hline $\begin{array}{c}\text { Replicate } \\
1\end{array}$ & 3.1 & 3.1 & 3.1 & 3.8 & 5.4 & 4.6 & 3.8 \\
\hline $\begin{array}{c}\text { Replicate } \\
2\end{array}$ & 5.4 & 2.3 & 6.2 & 5.4 & 3.8 & 3.8 & 3.8 \\
\hline $\begin{array}{c}\text { Replicate } \\
3\end{array}$ & 3.8 & 4.6 & 3.1 & 3.1 & 3.8 & 6.2 & 3.8 \\
\hline $\begin{array}{c}\text { Replicate } \\
4\end{array}$ & 3.8 & 3.8 & 3.8 & 4.6 & 5.4 & 5.4 & 4.6 \\
\hline $\begin{array}{c}\text { Replicate } \\
5\end{array}$ & 4.6 & 3.8 & 3.8 & 5.4 & 4.6 & 3.1 & 4.6 \\
\hline $\begin{array}{c}\text { Replicate } \\
6\end{array}$ & 4.6 & 3.8 & 3.8 & 3.8 & 3.8 & 3.1 & 3.8 \\
\hline
\end{tabular}


Hyalella azteca Respiration Data (Surface Run-off Collected on Day 40 from planted troughs)

\begin{tabular}{|c|c|c|c|c|c|c|c|}
\hline \multicolumn{8}{|c|}{ Rate of Oxygen consumption (nanomoles $\mathrm{O}_{2} / \mathrm{hr}$ ) } \\
\hline & Blank & Reference & $\begin{array}{l}0.5 \% \\
\text { Biosolids } \\
\text { Elutriate }\end{array}$ & $\begin{array}{l}1 \% \\
\text { Biosolids } \\
\text { Elutriate }\end{array}$ & $\begin{array}{l}5 \% \\
\text { Biosolids } \\
\text { Elutriate }\end{array}$ & $\begin{array}{l}10 \% \\
\text { Biosolids } \\
\text { Elutriate }\end{array}$ & $\begin{array}{l}100 \% \\
\text { Biosolids } \\
\text { Elutriate }\end{array}$ \\
\hline $\begin{array}{c}\text { Replicate } \\
1\end{array}$ & 2.3 & 3.1 & 3.8 & 4.6 & 4.6 & 5.4 & 3.8 \\
\hline $\begin{array}{c}\text { Replicate } \\
2\end{array}$ & 3.8 & 3.1 & 3.1 & 2.3 & 4.6 & 3.1 & 3.1 \\
\hline $\begin{array}{c}\text { Replicate } \\
3\end{array}$ & 4.6 & 4.6 & 3.8 & 3.8 & 3.8 & 3.8 & 3.8 \\
\hline $\begin{array}{c}\text { Replicate } \\
4\end{array}$ & 4.6 & 3.8 & 3.8 & 3.8 & 2.3 & 3.1 & 3.8 \\
\hline $\begin{array}{c}\text { Replicate } \\
5\end{array}$ & 3.1 & 3.8 & 4.6 & 3.8 & 5.4 & 4.6 & 4.6 \\
\hline $\begin{array}{c}\text { Replicate } \\
6\end{array}$ & 4.6 & 3.8 & 5.4 & 3.1 & 4.6 & 2.3 & 4.6 \\
\hline
\end{tabular}


Hyalella azteca Respiration Data (Tile Drainage Collected on Day 40 from planted troughs)

\begin{tabular}{|c|c|c|l|l|l|l|l|}
\hline \multicolumn{2}{|c|}{ Rate of Oxygen consumption (nanomoles $\left.\mathrm{O}_{2} / \mathrm{hr}\right)$} \\
\hline $\begin{array}{c}\text { Replicate } \\
1\end{array}$ & Blank & Reference & $\begin{array}{l}0.5 \% \\
\text { Biosolids } \\
\text { Elutriate }\end{array}$ & $\begin{array}{l}1 \% \\
\text { Biosolids } \\
\text { Elutriate }\end{array}$ & $\begin{array}{l}5 \% \\
\text { Biosolids } \\
\text { Elutriate }\end{array}$ & $\begin{array}{l}10 \% \\
\text { Biosolids } \\
\text { Elutriate }\end{array}$ & $\begin{array}{l}100 \% \\
\text { Biosolids } \\
\text { Elutriate }\end{array}$ \\
\hline $\begin{array}{c}\text { Replicate } \\
2\end{array}$ & 3.8 & 3.8 & 4.6 & 3.8 & 3.1 & 5.4 & 5.4 \\
\hline $\begin{array}{c}\text { Replicate } \\
3\end{array}$ & 4.6 & 4.6 & 3.8 & 3.1 & 3.1 & 3.1 & 3.1 \\
\hline $\begin{array}{c}\text { Replicate } \\
4\end{array}$ & 4.6 & 4.6 & 3.1 & 4.6 & 3.1 & 3.8 & 3.8 \\
\hline $\begin{array}{c}\text { Replicate } \\
5\end{array}$ & 3.1 & 3.8 & 4.6 & 5.4 & 3.1 & 3.8 & 3.8 \\
\hline $\begin{array}{c}\text { Replicate } \\
6\end{array}$ & 4.6 & 3.8 & 5.3 & 4.6 & 3.8 & 4.6 & 4.6 \\
\hline
\end{tabular}




\section{Appendix G. Invertebrate Behaviour Data}

Daphnia magna Behaviour in Guelph Biosolids Elutriate (BE)

Percent of Daphnia magna swimming through the water column (Day 1)

\begin{tabular}{|c|c|c|c|c|c|c|c|c|}
\hline \multicolumn{6}{|c|}{ Surface Run-off } & \multicolumn{3}{|c|}{ Tile Drainage } \\
\hline & $2 \mathrm{hrs}$ & $4 \mathrm{hrs}$ & $6 \mathrm{hrs}$ & $24 \mathrm{hrs}$ & $2 \mathrm{hrs}$ & $4 \mathrm{hrs}$ & $6 \mathrm{hrs}$ & $24 \mathrm{hrs}$ \\
\hline Reference & & & & & & & & \\
\hline Replicate 1 & 100 & 80 & 100 & 100 & 100 & 100 & 100 & 80 \\
\hline Replicate2 & 100 & 80 & 100 & 100 & 100 & 100 & 100 & 80 \\
\hline Replicate3 & 100 & 100 & 80 & 100 & 100 & 80 & 100 & 80 \\
\hline $1 \% \mathrm{BE}$ & & & & & & & & \\
\hline Replicate 1 & 80 & 60 & 60 & 80 & 60 & 100 & 100 & 80 \\
\hline Replicate2 & 80 & 80 & 80 & 40 & 80 & 100 & 100 & 80 \\
\hline Replicate3 & 80 & 80 & 80 & 80 & 80 & 80 & 80 & 80 \\
\hline $10 \% \mathrm{BE}$ & & & & & & & & \\
\hline Replicate 1 & 80 & 80 & 80 & 80 & 80 & 80 & 100 & 60 \\
\hline Replicate2 & 80 & 80 & 40 & 80 & 80 & 80 & 100 & 80 \\
\hline Replicate3 & 100 & 100 & 80 & 80 & 80 & 100 & 80 & 80 \\
\hline $100 \% \mathrm{BE}$ & & & & & & & & \\
\hline Replicate1 & 100 & 60 & 60 & 60 & 50 & 40 & 40 & 60 \\
\hline Replicate2 & 100 & 80 & 80 & 80 & 40 & 60 & 20 & 80 \\
\hline Replicate3 & 80 & 80 & 80 & 80 & 40 & 80 & 20 & 80 \\
\hline
\end{tabular}


Percent of Daphnia magna swimming through the water column (Day 40 unplanted troughs)

\begin{tabular}{|c|c|c|c|c|c|c|c|c|}
\hline & \multicolumn{5}{|c|}{ Surface Run-off } & \multicolumn{3}{|c|}{ Tile Drainage } \\
\hline & $2 \mathrm{hrs}$ & $4 \mathrm{hrs}$ & $6 \mathrm{hrs}$ & $24 \mathrm{hrs}$ & $2 \mathrm{hrs}$ & $4 \mathrm{hrs}$ & $6 \mathrm{hrs}$ & $24 \mathrm{hrs}$ \\
\hline Reference & & & & & & & & \\
\hline Replicate1 & 100 & 80 & 80 & 100 & 100 & 100 & 100 & 100 \\
\hline Replicate2 & 100 & 80 & 80 & 100 & 100 & 100 & 100 & 100 \\
\hline Replicate3 & 100 & 80 & 100 & 100 & 80 & 100 & 80 & 100 \\
\hline $1 \% \mathrm{BE}$ & & & & & & & & \\
\hline Replicate 1 & 100 & 80 & 100 & 100 & 80 & 100 & 100 & 100 \\
\hline Replicate2 & 100 & 80 & 100 & 100 & 80 & 100 & 100 & 100 \\
\hline Replicate3 & 100 & 100 & 80 & 100 & 100 & 100 & 80 & 80 \\
\hline $10 \% \mathrm{BE}$ & & & & & & & & \\
\hline Replicate1 & 100 & 100 & 80 & 100 & 100 & 80 & 80 & 100 \\
\hline Replicate2 & 100 & 100 & 80 & 100 & 100 & 80 & 80 & 100 \\
\hline Replicate3 & 100 & 80 & 100 & 100 & 100 & 100 & 100 & 80 \\
\hline $100 \% \mathrm{BE}$ & & & & & & & & \\
\hline Replicate1 & 100 & 80 & 80 & 80 & 100 & 80 & 60 & 50 \\
\hline Replicate2 & 100 & 80 & 40 & 80 & 100 & 80 & 80 & 60 \\
\hline Replicate3 & 100 & 100 & 80 & 80 & 100 & 100 & 80 & 60 \\
\hline
\end{tabular}


Percent of Daphnia magna swimming through the water column (Day 40 planted troughs)

\begin{tabular}{|c|c|c|c|c|c|c|c|c|}
\hline & \multicolumn{5}{|c|}{ Surface Run-off } & \multicolumn{3}{|c|}{ Tile Drainage } \\
\hline & $2 \mathrm{hrs}$ & 4hrs & $6 \mathrm{hrs}$ & $24 \mathrm{hrs}$ & $2 \mathrm{hrs}$ & $4 \mathrm{hrs}$ & $6 \mathrm{hrs}$ & $24 \mathrm{hrs}$ \\
\hline Reference & & & & & & & & \\
\hline Replicate1 & 100 & 80 & 100 & 80 & 80 & 100 & 80 & 100 \\
\hline Replicate2 & 100 & 100 & 100 & 80 & 100 & 100 & 100 & 100 \\
\hline Replicate3 & 100 & 100 & 100 & 100 & 100 & 100 & 100 & 100 \\
\hline $1 \% \mathrm{BE}$ & & & & & & & & \\
\hline Replicate 1 & 80 & 80 & 100 & 80 & 100 & 80 & 80 & 100 \\
\hline Replicate2 & 100 & 100 & 100 & 100 & 100 & 100 & 100 & 100 \\
\hline Replicate3 & 100 & 100 & 100 & 100 & 100 & 100 & 100 & 100 \\
\hline $10 \% \mathrm{BE}$ & & & & & & & & \\
\hline Replicate1 & 80 & 100 & 100 & 80 & 80 & 100 & 100 & 80 \\
\hline Replicate2 & 100 & 100 & 100 & 80 & 100 & 100 & 100 & 100 \\
\hline Replicate3 & 100 & 100 & 100 & 100 & 100 & 100 & 100 & 100 \\
\hline $100 \% \mathrm{BE}$ & & & & & & & & \\
\hline Replicate1 & 100 & 80 & 80 & 80 & 100 & 100 & 80 & 100 \\
\hline Replicate2 & 100 & 100 & 100 & 100 & 100 & 100 & 100 & 100 \\
\hline Replicate3 & 100 & 100 & 100 & 100 & 100 & 100 & 100 & 100 \\
\hline
\end{tabular}


Percent of Daphnia magna swimming normally (Biosolids Elutriate Collected on Day 1 )

\begin{tabular}{|c|c|c|c|c|c|c|c|c|}
\hline & \multicolumn{5}{|c|}{ Surface Run-off } & \multicolumn{3}{|c|}{ Tile Drainage } \\
\hline & $2 \mathrm{hrs}$ & $4 \mathrm{hrs}$ & $6 \mathrm{hrs}$ & $24 \mathrm{hrs}$ & $2 \mathrm{hrs}$ & $4 \mathrm{hrs}$ & $6 \mathrm{hrs}$ & $24 \mathrm{hrs}$ \\
\hline Reference & & & & & & & & \\
\hline Replicate1 & 80 & 80 & 100 & 80 & 80 & 80 & 80 & 80 \\
\hline Replicate2 & 80 & 60 & 60 & 80 & 80 & 80 & 60 & 80 \\
\hline Replicate3 & 100 & 80 & 60 & 80 & 100 & 80 & 80 & 80 \\
\hline $1 \% \mathrm{BE}$ & & & & & & & & \\
\hline Replicate 1 & 80 & 80 & 80 & 80 & 80 & 80 & 80 & 80 \\
\hline Replicate2 & 80 & 60 & 80 & 60 & 60 & 80 & 80 & 40 \\
\hline Replicate3 & 100 & 80 & 100 & 80 & 80 & 80 & 100 & 80 \\
\hline $10 \% \mathrm{BE}$ & & & & & & & & \\
\hline Replicate1 & 80 & 80 & 80 & 80 & 80 & 80 & 80 & 80 \\
\hline Replicate2 & 80 & 60 & 60 & 60 & 40 & 40 & 40 & 40 \\
\hline Replicate3 & 100 & 80 & 80 & 80 & 80 & 80 & 80 & 80 \\
\hline $100 \% \mathrm{BE}$ & & & & & & & & \\
\hline Replicate1 & 80 & 60 & 25 & 25 & 20 & 50 & 50 & 40 \\
\hline Replicate2 & 80 & 40 & 40 & 40 & 40 & 40 & 40 & 60 \\
\hline Replicate3 & 100 & 80 & 60 & 60 & 60 & 40 & 40 & 80 \\
\hline
\end{tabular}


Percent of Daphnia magna swimming normally (Biosolids Elutriate Collected on Day 40 from unplanted troughs)

\begin{tabular}{|c|c|c|c|c|c|c|c|c|}
\hline \multicolumn{6}{|c|}{ Surface Run-off } & \multicolumn{3}{|c|}{ Tile Drainage } \\
\hline & $2 \mathrm{hrs}$ & $4 \mathrm{hrs}$ & $6 \mathrm{hrs}$ & $24 \mathrm{hrs}$ & $2 \mathrm{hrs}$ & $4 \mathrm{hrs}$ & $6 \mathrm{hrs}$ & $24 \mathrm{hrs}$ \\
\hline Reference & & & & & & & & \\
\hline Replicate1 & 100 & 100 & 100 & 100 & 100 & 80 & 100 & 100 \\
\hline Replicate2 & 100 & 80 & 100 & 100 & 80 & 80 & 100 & 100 \\
\hline Replicate3 & 100 & 100 & 100 & 100 & 100 & 80 & 100 & 100 \\
\hline $1 \% \mathrm{BE}$ & & & & & & & & \\
\hline Replicate 1 & 100 & 80 & 80 & 100 & 100 & 100 & 80 & 100 \\
\hline Replicate2 & 100 & 80 & 80 & 80 & 80 & 100 & 80 & 80 \\
\hline Replicate3 & 100 & 80 & 100 & 100 & 100 & 100 & 100 & 100 \\
\hline $10 \% \mathrm{BE}$ & & & & & & & & \\
\hline Replicate1 & 100 & 80 & 80 & 80 & 80 & 80 & 100 & 80 \\
\hline Replicate2 & 100 & 80 & 80 & 80 & 80 & 80 & 80 & 80 \\
\hline Replicate3 & 100 & 100 & 100 & 100 & 100 & 100 & 100 & 100 \\
\hline $100 \% \mathrm{BE}$ & & & & & & & & \\
\hline Replicate1 & 100 & 40 & 40 & 80 & 80 & 80 & 80 & 60 \\
\hline Replicate2 & 100 & 60 & 60 & 50 & 80 & 40 & 40 & 60 \\
\hline Replicate3 & 100 & 80 & 80 & 70 & 80 & 80 & 80 & 25 \\
\hline
\end{tabular}


Percent of Daphnia magna swimming normally (Biosolids Elutriate Collected on Day 40 from planted troughs)

\begin{tabular}{|c|c|c|c|c|c|c|c|c|}
\hline \multicolumn{6}{|c|}{ Surface Run-off } & \multicolumn{3}{|c|}{ Tile Drainage } \\
\hline & $2 \mathrm{hrs}$ & $4 \mathrm{hrs}$ & $6 \mathrm{hrs}$ & $24 \mathrm{hrs}$ & $2 \mathrm{hrs}$ & $4 \mathrm{hrs}$ & $6 \mathrm{hrs}$ & $24 \mathrm{hrs}$ \\
\hline Reference & & & & & & & & \\
\hline Replicate 1 & 100 & 100 & 60 & 80 & 100 & 100 & 100 & 100 \\
\hline Replicate2 & 80 & 80 & 80 & 80 & 80 & 100 & 80 & 100 \\
\hline Replicate3 & 100 & 100 & 80 & 80 & 100 & 100 & 100 & 100 \\
\hline $1 \% \mathrm{BE}$ & & & & & & & & \\
\hline Replicate 1 & 100 & 100 & 100 & 100 & 100 & 100 & 100 & 100 \\
\hline Replicate2 & 80 & 80 & 80 & 80 & 100 & 80 & 80 & 100 \\
\hline Replicate3 & 100 & 100 & 100 & 100 & 100 & 100 & 100 & 100 \\
\hline $10 \% \mathrm{BE}$ & & & & & & & & \\
\hline Replicate1 & 100 & 100 & 80 & 100 & 100 & 100 & 100 & 100 \\
\hline Replicate2 & 100 & 100 & 80 & 80 & 100 & 100 & 100 & 80 \\
\hline Replicate3 & 100 & 100 & 100 & 100 & 100 & 100 & 100 & 100 \\
\hline $100 \% \mathrm{BE}$ & & & & & & & & \\
\hline Replicate1 & 100 & 100 & 100 & 100 & 100 & 80 & 80 & 100 \\
\hline Replicate2 & 80 & 100 & 80 & 100 & 100 & 80 & 80 & 100 \\
\hline Replicate3 & 100 & 100 & 100 & 100 & 100 & 100 & 100 & 100 \\
\hline
\end{tabular}


Hyalella azteca behaviour data - Guelph Biosolids

Percent of Hyalella azteca crawling on the substrate (Biosolids Elutriate Collected on Day 1)

\begin{tabular}{|c|c|c|c|c|c|c|c|c|}
\hline \multicolumn{6}{|c|}{ Surface Run-off } & \multicolumn{3}{|c|}{ Tile Drainage } \\
\hline & $2 \mathrm{hrs}$ & $4 \mathrm{hrs}$ & $6 \mathrm{hrs}$ & $24 \mathrm{hrs}$ & $2 \mathrm{hrs}$ & $4 \mathrm{hrs}$ & $6 \mathrm{hrs}$ & $24 \mathrm{hrs}$ \\
\hline Reference & & & & & & & & \\
\hline Replicate1 & 80 & 50 & 100 & 50 & 100 & 50 & 100 & 20 \\
\hline Replicate2 & 40 & 50 & 100 & 50 & 100 & 50 & 100 & 60 \\
\hline Replicate3 & 80 & 50 & 100 & 50 & 100 & 50 & 100 & 20 \\
\hline $1 \% \mathrm{BE}$ & & & & & & & & \\
\hline Replicate 1 & 50 & 20 & 80 & 80 & 20 & 80 & 50 & 50 \\
\hline Replicate2 & 50 & 60 & 40 & 40 & 60 & 80 & 50 & 50 \\
\hline Replicate3 & 50 & 20 & 80 & 80 & 20 & 100 & 50 & 50 \\
\hline $10 \% \mathrm{BE}$ & & & & & & & & \\
\hline Replicate1 & 20 & 50 & 80 & 80 & 20 & 100 & 80 & 20 \\
\hline Replicate2 & 60 & 50 & 80 & 40 & 60 & 100 & 40 & 60 \\
\hline Replicate3 & 20 & 50 & 100 & 80 & 20 & 100 & 80 & 20 \\
\hline $100 \% \mathrm{BE}$ & & & & & & & & \\
\hline Replicate1 & 50 & 80 & 20 & 80 & 100 & 50 & 100 & 20 \\
\hline Replicate2 & 50 & 40 & 60 & 40 & 100 & 50 & 100 & 60 \\
\hline Replicate3 & 50 & 80 & 20 & 80 & 100 & 50 & 100 & 20 \\
\hline
\end{tabular}




\section{Hyalella azteca behaviour data - Kitchener Biosolids}

Percent of Hyalella azteca crawling on the substrate (Biosolids Elutriate Collected on Day 1)

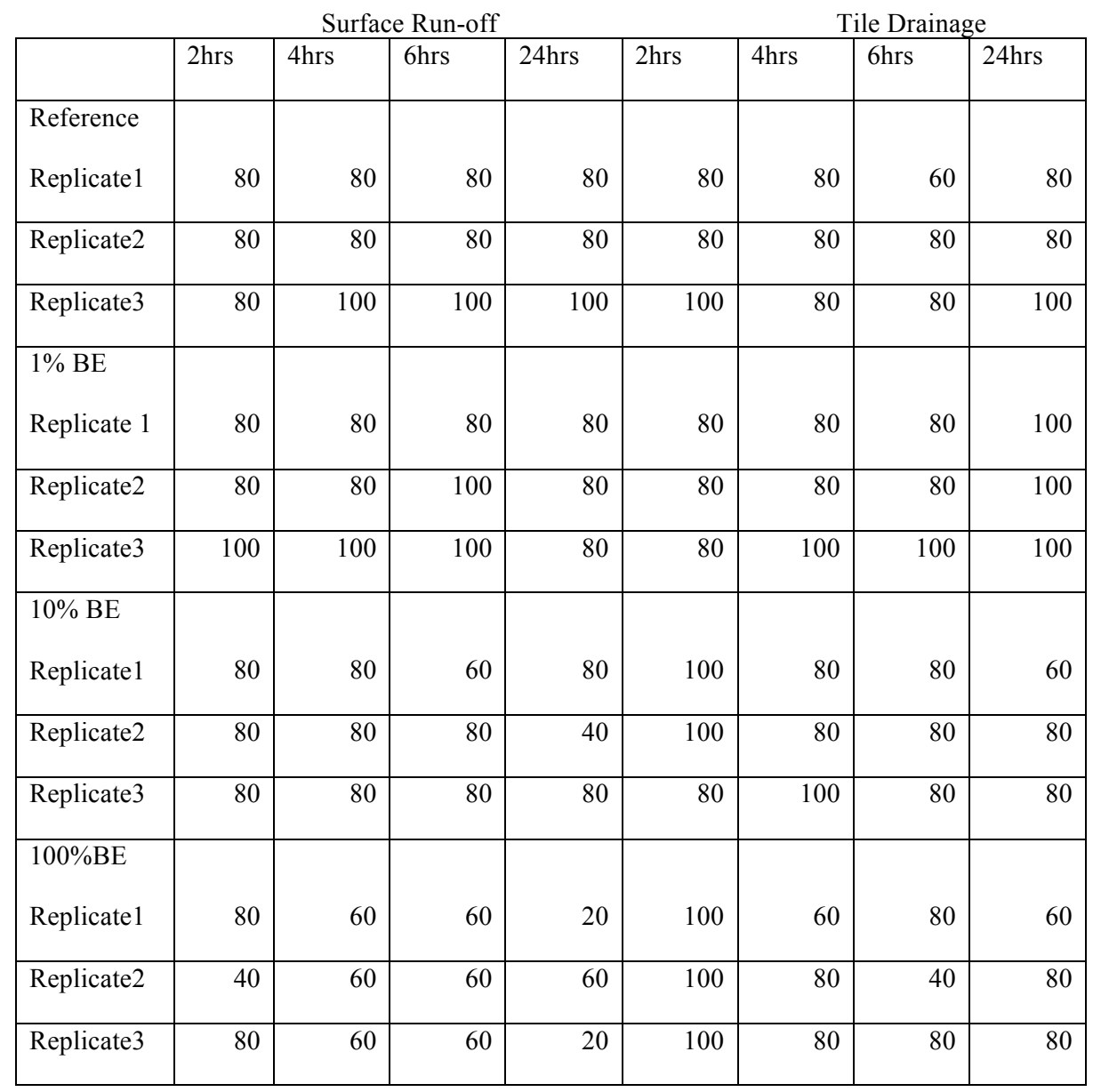


Percent of Hyalella azteca crawling on the substrate (Biosolids Elutriate Collected on Day 40 from unplanted troughs)

\begin{tabular}{|c|c|c|c|c|c|c|c|c|}
\hline \multicolumn{6}{|c|}{ Surface Run-off } & \multicolumn{3}{|c|}{ Tile Drainage } \\
\hline & $2 \mathrm{hrs}$ & $4 \mathrm{hrs}$ & $6 \mathrm{hrs}$ & $24 \mathrm{hrs}$ & $2 \mathrm{hrs}$ & $4 \mathrm{hrs}$ & $6 \mathrm{hrs}$ & $24 \mathrm{hrs}$ \\
\hline Reference & & & & & & & & \\
\hline Replicate 1 & 60 & 80 & 80 & 60 & 80 & 60 & 80 & 80 \\
\hline Replicate2 & 80 & 80 & 80 & 80 & 80 & 80 & 100 & 80 \\
\hline Replicate3 & 80 & 100 & 100 & 80 & 100 & 80 & 100 & 100 \\
\hline $1 \% \mathrm{BE}$ & & & & & & & & \\
\hline Replicate 1 & 60 & 80 & 80 & 80 & 80 & 80 & 80 & 60 \\
\hline Replicate2 & 80 & 100 & 80 & 80 & 100 & 100 & 80 & 80 \\
\hline Replicate3 & 80 & 100 & 100 & 80 & 100 & 100 & 100 & 80 \\
\hline $10 \% \mathrm{BE}$ & & & & & & & & \\
\hline Replicate1 & 80 & 80 & 60 & 80 & 80 & 80 & 80 & 60 \\
\hline Replicate2 & 80 & 80 & 80 & 40 & 80 & 80 & 80 & 80 \\
\hline Replicate3 & 100 & 100 & 80 & 80 & 100 & 100 & 100 & 80 \\
\hline $100 \% \mathrm{BE}$ & & & & & & & & \\
\hline Replicate1 & 80 & 80 & 60 & 50 & 60 & 80 & 60 & 80 \\
\hline Replicate2 & 80 & 80 & 80 & 40 & 80 & 80 & 80 & 80 \\
\hline Replicate3 & 100 & 100 & 80 & 40 & 80 & 100 & 80 & 80 \\
\hline
\end{tabular}


Percent of Hyalella azteca crawling on the substrate (Biosolids Elutriate Collected on Day 40 from planted troughs)

\begin{tabular}{|c|c|c|c|c|c|c|c|c|}
\hline \multicolumn{6}{|c|}{ Surface Run-off } & \multicolumn{3}{|c|}{ Tile Drainage } \\
\hline & $2 \mathrm{hrs}$ & $4 \mathrm{hrs}$ & $6 \mathrm{hrs}$ & $24 \mathrm{hrs}$ & $2 \mathrm{hrs}$ & $4 \mathrm{hrs}$ & $6 \mathrm{hrs}$ & $24 \mathrm{hrs}$ \\
\hline Reference & & & & & & & & \\
\hline Replicate1 & 80 & 80 & 80 & 80 & 80 & 80 & 80 & 80 \\
\hline Replicate2 & 100 & 80 & 80 & 80 & 80 & 80 & 80 & 80 \\
\hline Replicate3 & 100 & 80 & 100 & 100 & 100 & 80 & 100 & 80 \\
\hline $1 \% \mathrm{BE}$ & & & & & & & & \\
\hline Replicate 1 & 80 & 100 & 80 & 80 & 80 & 80 & 80 & 80 \\
\hline Replicate2 & 80 & 80 & 100 & 80 & 100 & 80 & 100 & 80 \\
\hline Replicate3 & 100 & 100 & 100 & 100 & 100 & 100 & 100 & 100 \\
\hline $10 \% \mathrm{BE}$ & & & & & & & & \\
\hline Replicate1 & 80 & 80 & 80 & 80 & 100 & 80 & 80 & 80 \\
\hline Replicate2 & 100 & 80 & 80 & 80 & 100 & 100 & 80 & 80 \\
\hline Replicate3 & 100 & 100 & 80 & 80 & 100 & 100 & 80 & 100 \\
\hline $100 \% \mathrm{BE}$ & & & & & & & & \\
\hline Replicate1 & 80 & 80 & 80 & 60 & 60 & 80 & 60 & 80 \\
\hline Replicate2 & 80 & 80 & 80 & 80 & 80 & 80 & 80 & 100 \\
\hline Replicate3 & 100 & 80 & 100 & 80 & 80 & 80 & 80 & 100 \\
\hline
\end{tabular}


Percent of Hyalella azteca displaying normal body length (Biosolids Elutriate Collected on Day 1)

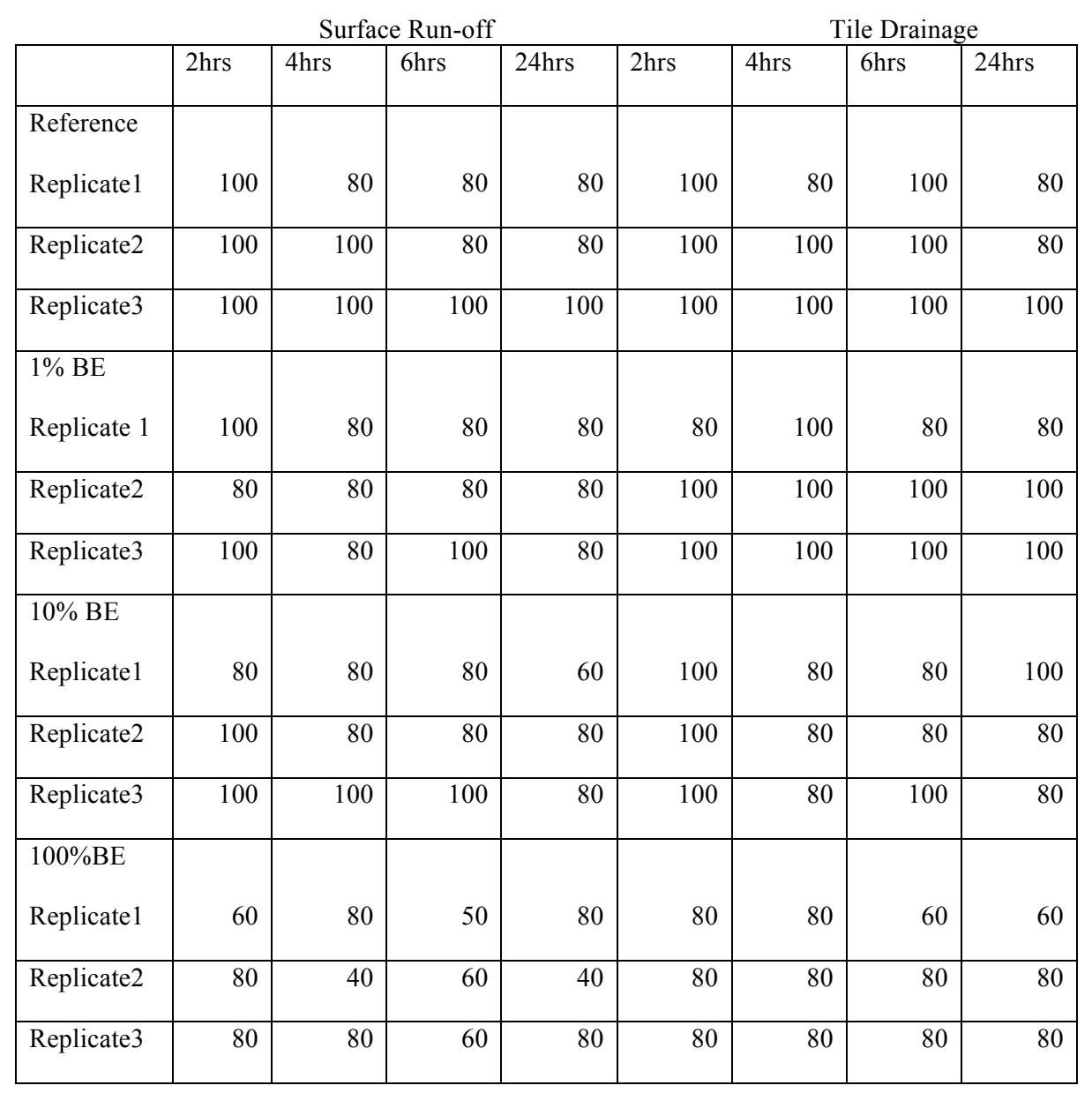


Percent of Hyalella azteca displaying normal body length (Biosolids Elutriate Collected on Day 40 from unplanted troughs)

\begin{tabular}{|c|c|c|c|c|c|c|c|c|}
\hline \multicolumn{6}{|c|}{ Surface Run-off } & \multicolumn{3}{|c|}{ Tile Drainage } \\
\hline & $2 \mathrm{hrs}$ & $4 \mathrm{hrs}$ & $6 \mathrm{hrs}$ & $24 \mathrm{hrs}$ & $2 \mathrm{hrs}$ & $4 \mathrm{hrs}$ & $6 \mathrm{hrs}$ & $24 \mathrm{hrs}$ \\
\hline Reference & & & & & & & & \\
\hline Replicate1 & 80 & 60 & 80 & 60 & 80 & 80 & 80 & 60 \\
\hline Replicate2 & 100 & 80 & 80 & 80 & 100 & 100 & 80 & 80 \\
\hline Replicate3 & 100 & 80 & 80 & 80 & 100 & 100 & 100 & 80 \\
\hline $1 \% \mathrm{BE}$ & & & & & & & & \\
\hline Replicate 1 & 100 & 100 & 80 & 70 & 80 & 60 & 60 & 80 \\
\hline Replicate2 & 100 & 100 & 80 & 70 & 100 & 80 & 80 & 80 \\
\hline Replicate3 & 100 & 100 & 80 & 70 & 100 & 80 & 80 & 80 \\
\hline $10 \% \mathrm{BE}$ & & & & & & & & \\
\hline Replicate1 & 80 & 80 & 60 & 80 & 100 & 60 & 80 & 80 \\
\hline Replicate2 & 100 & 80 & 80 & 40 & 100 & 80 & 80 & 80 \\
\hline Replicate3 & 100 & 100 & 80 & 80 & 100 & 80 & 80 & 80 \\
\hline $100 \% \mathrm{BE}$ & & & & & & & & \\
\hline Replicate1 & 80 & 80 & 60 & 50 & 80 & 60 & 60 & 80 \\
\hline Replicate2 & 80 & 80 & 80 & 40 & 80 & 80 & 80 & 40 \\
\hline Replicate3 & 100 & 80 & 80 & 40 & 80 & 80 & 80 & 80 \\
\hline
\end{tabular}


Percent of Hyalella azteca displaying normal body length (Biosolids Elutriate Collected on Day 40 from planted troughs)

\begin{tabular}{|c|c|c|c|c|c|c|c|c|}
\hline \multicolumn{6}{|c|}{ Surface Run-off } & \multicolumn{3}{|c|}{ Tile Drainage } \\
\hline & $2 \mathrm{hrs}$ & $4 \mathrm{hrs}$ & $6 \mathrm{hrs}$ & $24 \mathrm{hrs}$ & $2 \mathrm{hrs}$ & $4 \mathrm{hrs}$ & $6 \mathrm{hrs}$ & $24 \mathrm{hrs}$ \\
\hline Reference & & & & & & & & \\
\hline Replicate1 & 100 & 80 & 80 & 80 & 100 & 80 & 80 & 60 \\
\hline Replicate2 & 100 & 100 & 80 & 80 & 100 & 80 & 80 & 80 \\
\hline Replicate3 & 100 & 100 & 100 & 100 & 100 & 100 & 80 & 80 \\
\hline $1 \% \mathrm{BE}$ & & & & & & & & \\
\hline Replicate 1 & 80 & 80 & 60 & 80 & 80 & 80 & 80 & 80 \\
\hline Replicate2 & 100 & 100 & 80 & 80 & 100 & 80 & 80 & 80 \\
\hline Replicate3 & 100 & 100 & 80 & 80 & 100 & 100 & 80 & 80 \\
\hline $10 \% \mathrm{BE}$ & & & & & & & & \\
\hline Replicate1 & 80 & 80 & 80 & 60 & 80 & 80 & 80 & 80 \\
\hline Replicate2 & 100 & 80 & 80 & 80 & 80 & 80 & 80 & 40 \\
\hline Replicate3 & 100 & 100 & 100 & 80 & 100 & 80 & 80 & 80 \\
\hline $100 \% \mathrm{BE}$ & & & & & & & & \\
\hline Replicate1 & 100 & 100 & 80 & 80 & 100 & 100 & 80 & 80 \\
\hline Replicate2 & 100 & 100 & 100 & 80 & 100 & 100 & 80 & 80 \\
\hline Replicate3 & 100 & 100 & 100 & 80 & 100 & 100 & 100 & 80 \\
\hline
\end{tabular}


Appendix H. Survivorship and Motility Data for Daphnia magna in Guelph Biosolids Elutriate

Percent of Daphnia magna survived in Biosolids Elutriate collected on Day 1.

\begin{tabular}{|c|c|c|c|c|}
\hline & \multicolumn{2}{|c|}{ Surface Run-off } & \multicolumn{2}{|c|}{ Tile Drainage } \\
\hline & $24 \mathrm{hrs}$ & 7days & $24 \mathrm{hrs}$ & 7days \\
\hline Reference & & & & \\
\hline Replicate 1 & 100 & 100 & 100 & 80 \\
\hline Replicate2 & 100 & 100 & 100 & 100 \\
\hline Replicate3 & 100 & 100 & 100 & 100 \\
\hline 1\% Biosolids Elu & & & & \\
\hline Replicate 1 & 100 & 80 & 100 & 80 \\
\hline Replicate2 & 100 & 100 & 100 & 80 \\
\hline Replicate3 & 100 & 100 & 100 & 100 \\
\hline $10 \%$ Biosolids El & & & & \\
\hline Replicate1 & 100 & 100 & 100 & 80 \\
\hline Replicate2 & 100 & 100 & 100 & 100 \\
\hline Replicate3 & 100 & 100 & 100 & 100 \\
\hline $\begin{array}{c}\text { 100\%Biosoli } \\
\text { Elutriate }\end{array}$ & & & & \\
\hline Replicate1 & 80 & 20 & 80 & 80 \\
\hline Replicate2 & 80 & 60 & 80 & 40 \\
\hline Replicate3 & 80 & 20 & 100 & 80 \\
\hline
\end{tabular}


Percent of Daphnia magna survived in Biosolids Elutriate collected on Day 40 from unplanted troughs.

\begin{tabular}{|c|c|c|c|c|}
\hline & \multicolumn{2}{|c|}{ Surface Run-off } & \multicolumn{2}{|c|}{ Tile Drainage } \\
\hline & $24 \mathrm{hrs}$ & 7days & $24 \mathrm{hrs}$ & 7days \\
\hline Reference & & & & \\
\hline Replicate 1 & 100 & 80 & 100 & 80 \\
\hline Replicate2 & 100 & 80 & 100 & 80 \\
\hline Replicate3 & 100 & 100 & 100 & 80 \\
\hline 1\% Biosolids Elutriate & & & & \\
\hline Replicate 1 & 80 & 80 & 80 & 80 \\
\hline Replicate2 & 80 & 80 & 100 & 80 \\
\hline Replicate3 & 100 & 80 & 100 & 80 \\
\hline $10 \%$ Biosolids Elutriate & & & & \\
\hline Replicate1 & 100 & 80 & 100 & 80 \\
\hline Replicate2 & 100 & 100 & 100 & 80 \\
\hline Replicate3 & 100 & 100 & 100 & 100 \\
\hline $\begin{array}{c}100 \% \text { Biosolids } \\
\text { Elutriate }\end{array}$ & & & & \\
\hline Replicate 1 & 100 & 50 & 80 & \\
\hline Replicate2 & 100 & 40 & 80 & 100 \\
\hline Replicate3 & 100 & 40 & 80 & 100 \\
\hline
\end{tabular}


Percent of Daphnia magna survived in Biosolids Elutriate collected on Day 40 from unplanted troughs.

\begin{tabular}{|c|c|c|c|c|}
\hline \multicolumn{2}{|c|}{ Surface Run-off } & \multicolumn{3}{|c|}{ Tile Drainage } \\
\hline & $24 \mathrm{hrs}$ & 7days & $24 \mathrm{hrs}$ & 7days \\
\hline Reference & & & & \\
\hline Replicate 1 & 100 & 100 & 100 & 100 \\
\hline Replicate2 & 100 & 100 & 100 & 100 \\
\hline Replicate3 & 100 & 100 & 100 & 100 \\
\hline 1\% Biosolids Elu & & & & \\
\hline Replicate 1 & 100 & 100 & 100 & 100 \\
\hline Replicate2 & 100 & 100 & 100 & 100 \\
\hline Replicate3 & 100 & 100 & 100 & 100 \\
\hline $10 \%$ Biosolids El & & & & \\
\hline Replicate 1 & 100 & 80 & 100 & 100 \\
\hline Replicate2 & 100 & 100 & 100 & 100 \\
\hline Replicate3 & 100 & 100 & 100 & 100 \\
\hline $\begin{array}{c}100 \% \text { Biosolic } \\
\text { Elutriate }\end{array}$ & & & & \\
\hline Replicate 1 & 100 & 100 & 80 & 80 \\
\hline Replicate2 & 100 & 100 & 100 & 100 \\
\hline Replicate3 & 100 & 100 & 100 & 100 \\
\hline
\end{tabular}


Percent of motile Daphnia magna in Guelph Biosolids Elutriate collected on Day 1.

Surface Run-off Tile Drainage

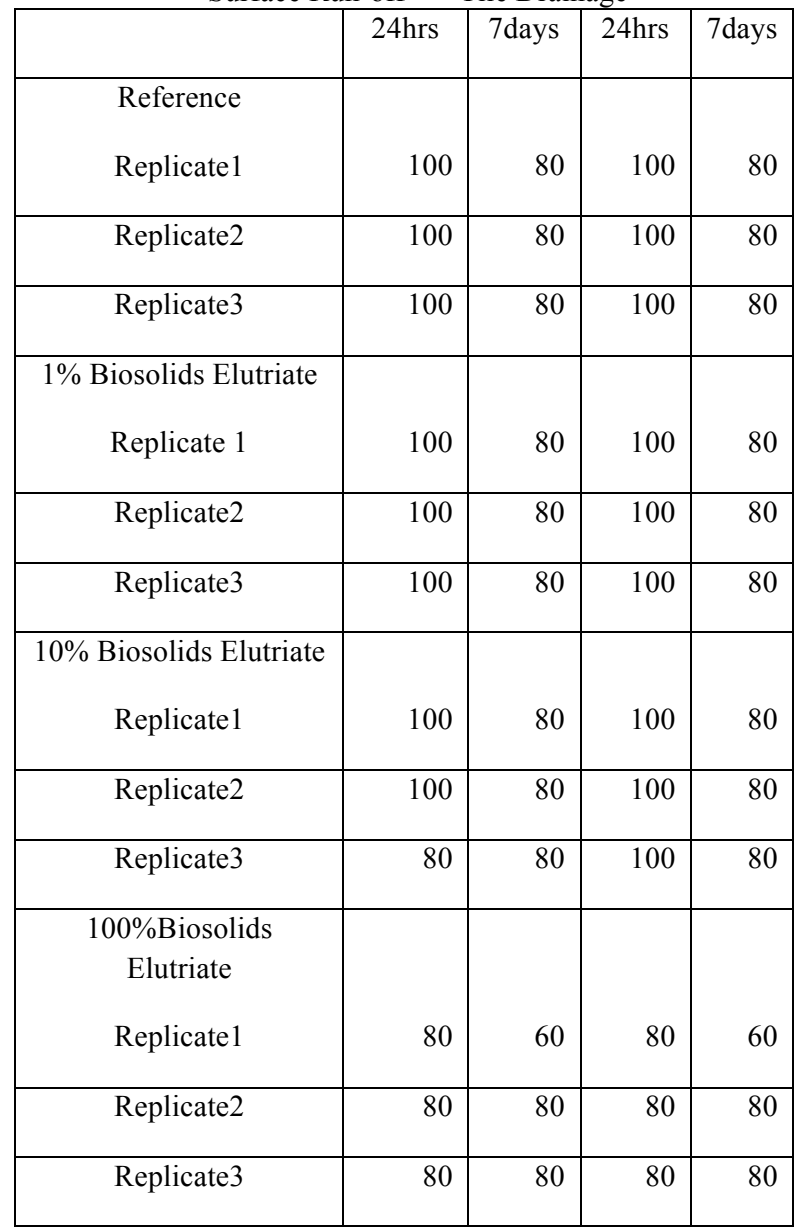


Percent of motile Daphnia magna in Guelph Biosolids Elutriate collected on Day 40 from unplanted troughs.

\begin{tabular}{|c|c|c|c|c|}
\hline \multicolumn{2}{|c|}{ Surface Run-off } & \multicolumn{3}{|c|}{ Tile Drainage } \\
\hline & $24 \mathrm{hrs}$ & 7days & $24 \mathrm{hrs}$ & 7days \\
\hline Reference & & & & \\
\hline Replicate 1 & 100 & 80 & 100 & 80 \\
\hline Replicate2 & 100 & 100 & 100 & 100 \\
\hline Replicate 3 & 100 & 100 & 100 & 100 \\
\hline 1\% Biosolids Elu & & & & \\
\hline Replicate 1 & 100 & 80 & 100 & 100 \\
\hline Replicate2 & 100 & 80 & 100 & 100 \\
\hline Replicate3 & 100 & 80 & 100 & 100 \\
\hline $10 \%$ Biosolids El & & & & \\
\hline Replicate 1 & 100 & 60 & 100 & 80 \\
\hline Replicate2 & 100 & 80 & 100 & 80 \\
\hline Replicate3 & 80 & 80 & 100 & 100 \\
\hline $\begin{array}{c}\text { 100\%Biosolic } \\
\text { Elutriate }\end{array}$ & & & & \\
\hline Replicate 1 & 100 & 80 & 100 & 100 \\
\hline Replicate2 & 100 & 80 & 100 & 100 \\
\hline Replicate3 & 100 & 80 & 80 & 100 \\
\hline
\end{tabular}


Percent of motile Daphnia magna in Guelph Biosolids Elutriate collected on Day 40 from planted troughs.

\begin{tabular}{|c|c|c|c|c|}
\hline \multicolumn{2}{|c|}{ Surface Run-off } & \multicolumn{3}{|c|}{ Tile Drainage } \\
\hline & $24 \mathrm{hrs}$ & 7days & $24 \mathrm{hrs}$ & 7days \\
\hline Reference & & & & \\
\hline Replicate 1 & 100 & 100 & 100 & 100 \\
\hline Replicate2 & 100 & 100 & 100 & 100 \\
\hline Replicate3 & 100 & 100 & 100 & 100 \\
\hline 1\% Biosolids Elu & & & & \\
\hline Replicate 1 & 100 & 100 & 100 & 100 \\
\hline Replicate2 & 100 & 100 & 100 & 100 \\
\hline Replicate3 & 100 & 80 & 100 & 80 \\
\hline $10 \%$ Biosolids El & & & & \\
\hline Replicate 1 & 100 & 100 & 100 & 100 \\
\hline Replicate2 & 100 & 100 & 100 & 100 \\
\hline Replicate3 & 100 & 100 & 100 & 100 \\
\hline $\begin{array}{c}100 \% \text { Biosolic } \\
\text { Elutriate }\end{array}$ & & & & \\
\hline Replicate 1 & 100 & 100 & 100 & 100 \\
\hline Replicate2 & 100 & 100 & 100 & 100 \\
\hline Replicate3 & 100 & 100 & 100 & 100 \\
\hline
\end{tabular}


Appendix I. Survivorship and Motility Data for Daphnia magna in Kitchener biosolids Elutriate

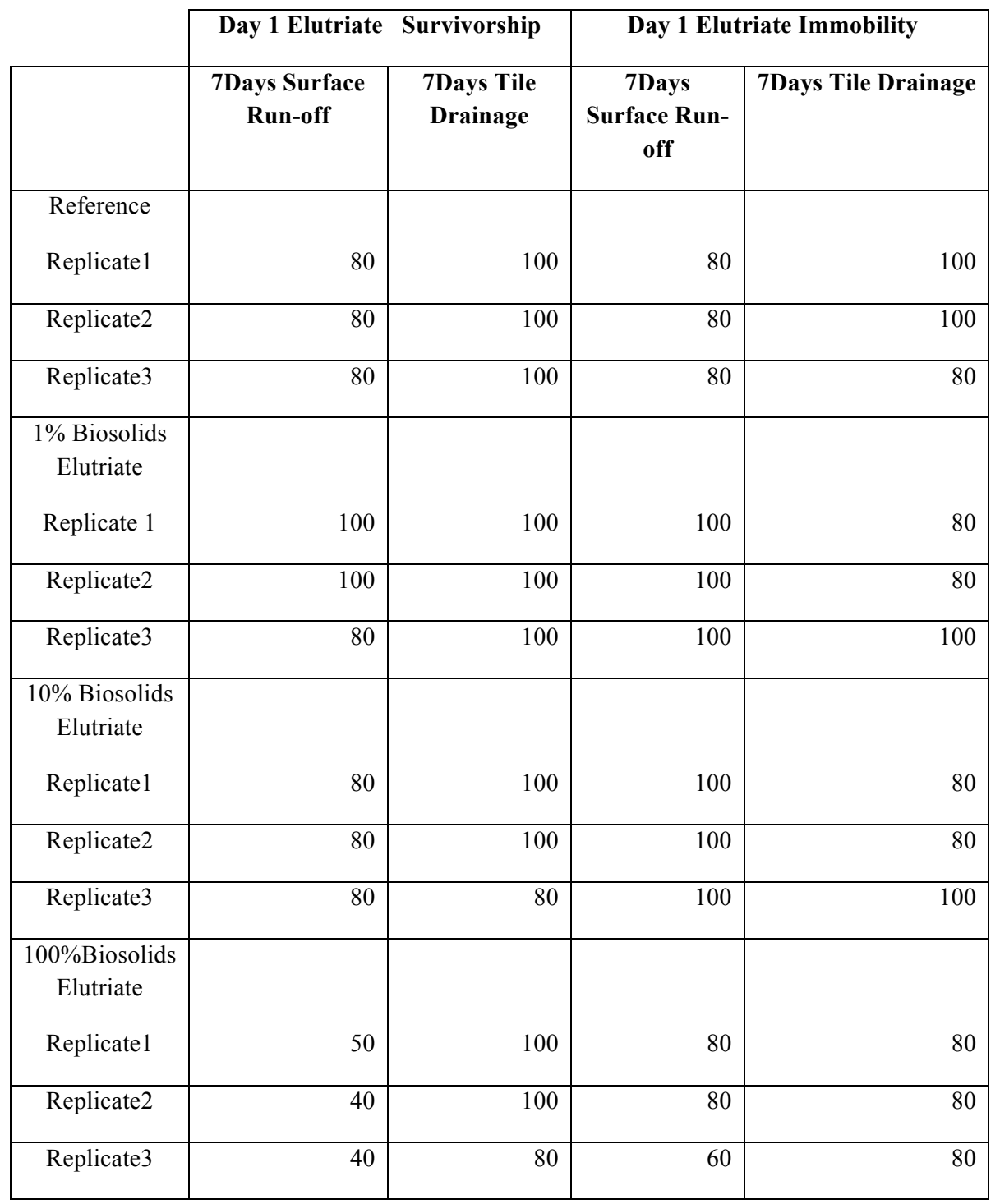


Appendix J. Lemna minor Data - Kitchener Surface Run-off

Weight of 3 Lemna minor plants (mg) in run-off Collected on Day 1

\begin{tabular}{|c|c|c|c|c|}
\hline & Reference & 1\% Surface Runoff & $10 \%$ Surface Runoff & $100 \%$ Surface Runoff \\
\hline Replicate1 & 1.2 & 2.8 & 4.6 & 2.6 \\
\hline Replicate 2 & 1 & 2.3 & 4 & 2.5 \\
\hline Replicate3 & 1.8 & 3.1 & 2.7 & 2.4 \\
\hline
\end{tabular}

Weight of 3 Lemna minor plants (mg) in runoff Collected on Day 40 from unplanted troughs

\begin{tabular}{|c|r|r|r|r|}
\hline & Reference & \multicolumn{1}{|c|}{ 1\% Surface Runoff } & 10\%Surface Runoff & 100\% Surface Runoff \\
\hline Replicate1 & 1.5 & 1.6 & 2.1 & 1.9 \\
\hline Replicate 2 & 1.2 & 1.7 & 1.7 & 1.8 \\
\hline Replicate3 & 1.4 & 1.6 & 1.9 & 2.3 \\
\hline
\end{tabular}

Weight of 3 Lemna minor plants (mg) in runoff Collected on Day 40 from planted troughs

\begin{tabular}{|c|c|c|c|c|}
\hline & Reference & 1\% Surface Runoff & 10\%Surface Runoff & $100 \%$ Surface Runoff \\
\hline Replicate1 & 1.6 & 1.5 & 1.9 & 1.7 \\
\hline Replicate 2 & 1.7 & 1.4 & 1.2 & 1.5 \\
\hline Replicate3 & 1.9 & 1.8 & 1.6 & 1.8 \\
\hline
\end{tabular}


